\title{
EFICIÊNCIA DO SISTEMA DE RESFRIAMENTO ADIABÁTICO EVAPORATIVO EM CONFINAMENTO DO TIPO FREESTALL PARA VACAS EM LACTAÇÃO
}

\author{
SORAIA VANESSA MATARAZZO
}

Tese apresentada à Escola Superior de Agricultura

"Luiz de Queiroz", Universidade de São Paulo, para obtenção de título de Doutor em Agronomia, Área de Concentração: Física do Ambiente Agrícola.

PIRACICABA

Estado de São Paulo - Brasil

Agosto - 2004 


\title{
EFICIÊNCIA DO SISTEMA DE RESFRIAMENTO ADIABÁTICO EVAPORATIVO EM CONFINAMENTO DO TIPO FREESTALL PARA VACAS EM LACTAÇÃO
}

\author{
SORAIA VANESSA MATARAZZO \\ Zootecnista
}

Orientador: Prof. Dr. IRAN JOSÉ OLIVEIRA DA SILVA

Tese apresentada à Escola Superior de Agricultura "Luiz de Queiroz", Universidade de São Paulo, para obtenção de título de Doutor em Agronomia, Área de Concentração: Física do Ambiente Agrícola.

PIRACICABA

Estado de São Paulo - Brasil

Agosto - 2004 


\section{Dados Internacionais de Catalogação na Publicação (CIP) DIVISÃO DE BIBLIOTECA E DOCUMENTAÇÃO - ESALQ/USP}

Matarazzo, Soraia Vanessa

Eficiência do sistema de resfriamento adiabático evaporativo em confinamento do

tipo Freestall para vacas em lactação / Soraia Vanessa Matarazzo. - - Piracicaba, 2004.

143 p. : il.

Tese (doutorado) - - Escola Superior de Agricultura Luiz de Queiroz, 2004.

Bibliografia.

1. Comportamento animal 2. Confinamento animal 3. Conforto térmico das construçõe 4. Fisiologia animal 5. Lactação animal 6. Vacas I. Título

CDD 636.2 
A memória de meu adorado pai Geraldo,

A minha mãe $\mathcal{N}$ eide exemplo de vida e Luta, cujo amor e dedicação elevam-me a cada instante;

A meu irmão Anibal, e minha avó Amélia, pelo amor, e incentivo.

Dedico 


\section{Agradecimentos}

A Deus... Sobretudo pela vida e por me fortalecer nos momentos mais dolorosos ....

À Escola Superior de Agricultura "Luiz de Queiroz" e Curso de PósGraduação em Física do Ambiente Agrícola pela oportunidade;

Ao Professor Dr. Iran José Oliveira da Silva, pela orientação, perseverança e apoio à realização deste trabalho;

À Professora Dra. Daniella Jorge de Moura, incentivo e entusiasmo na execução deste trabalho;

Aos Srs. Jorge e Carlos Gonzales, proprietários da fazenda Campestre,

Aos colegas do Núcleo de Pesquisa em Ambiência e CPG pela convivência durante esses anos de doutorado;

Aos sinceros amigos Mi, Pauletti, Maurício, Jocelito e Adriana, Zoo 91;

Ao Sérgio, por tudo.... 


\section{SUMÁRIO}

Página

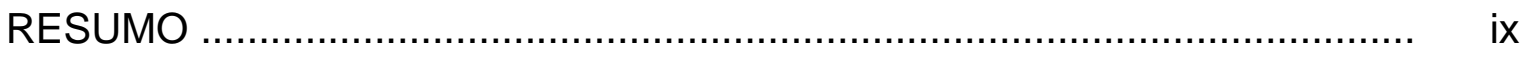

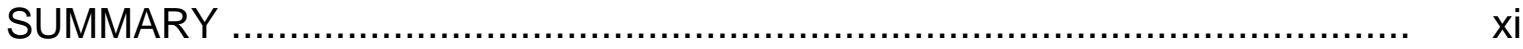

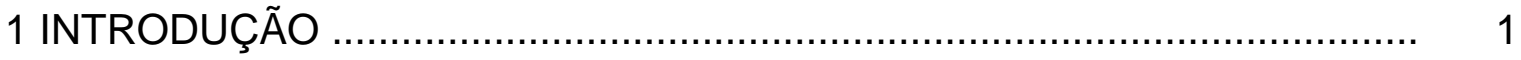

2 REVISÃO DE LITERATURA ……..................................................

2.10 ambiente tropical e a produção de leite................................................

2.2 Zona de termoneutralidade .............................................................. 6

2.3 Manutenção da temperatura corporal e mecanismos de dissipação de

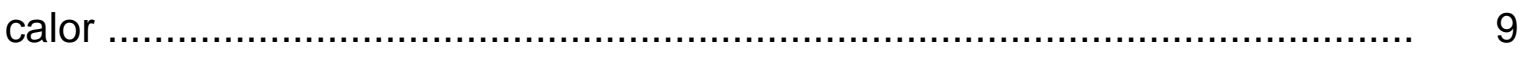

2.4 Climatização das instalações para bovinos de leite ................................ 11

2.5 Índices de conforto térmico para a bovinocultura leiteira ......................... 15

2.6 Respostas fisiológicas .................................................................. 18

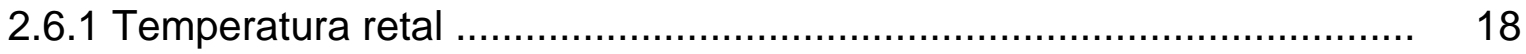

2.6.2 Freqüência respiratória ............................................................. 20

2.6.3 Temperatura da superfície do pelame.............................................. 21

2.7 Consumo de alimentos, produção e composição do leite ......................... 23

2.8 Comportamento e bem-estar animal ................................................. 25

3 EFICIÊNCIA DA INTERMITÊNCIA DO SISTEMA DE RESFRIAMENTO ADIABÁTICO EVAPORATIVO POR ASPERSÃO E SUA INFLUÊNCIA NO CONFORTO TÉRMICO DE VACAS EM LACTAÇÃO ............................... 29

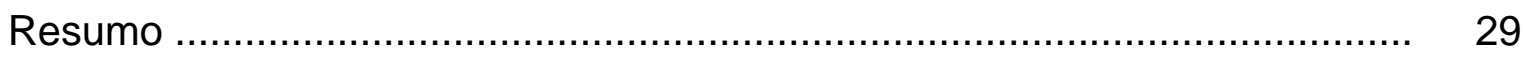

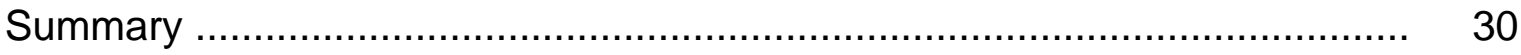

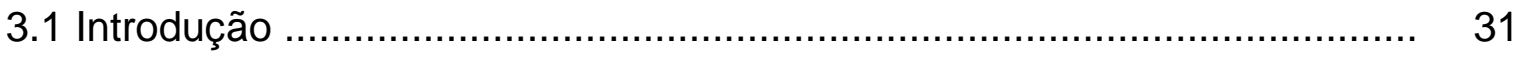




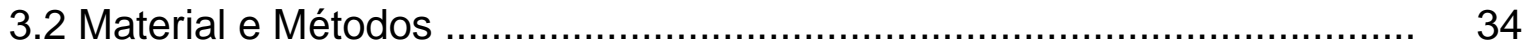

3.2.1 Local e duração do experimento.................................................... 34

3.2.2 Caracterização dos animais e manejo ............................................... 34

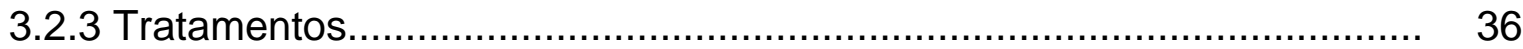

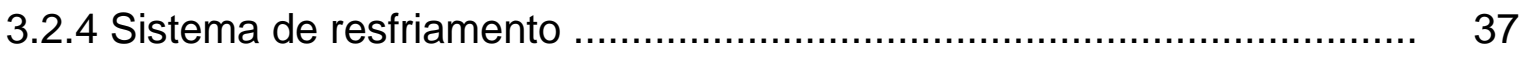

3.2.5 Variáveis meteorológicas .......................................................... 38

3.2.6 Variáveis fisiológicas ................................................................... 40

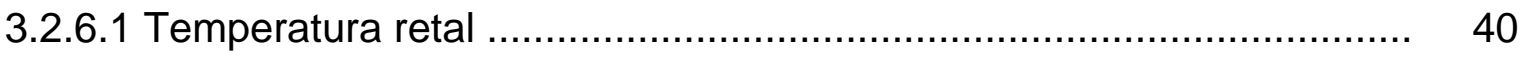

3.2.6.2 Temperatura da superfície do pelame …..................................... 40

3.2.6.3 Freqüência respiratória ............................................................ 40

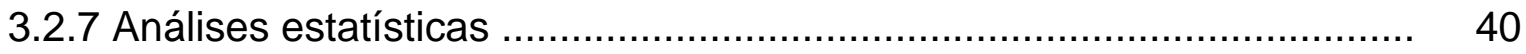

3.3 Resultados e Discussão............................................................... 41

3.3.1 Variáveis meteorológicas ........................................................... 41

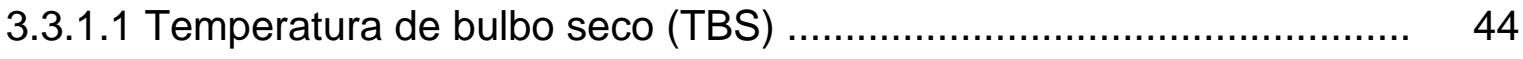

3.3.1.2 Umidade relativa (UR) ............................................................ 47

3.3.1.3 Temperatura de globo negro (TGN) ......................................... 48

3.3.1.4 Índice de temperatura e umidade (THI) ....................................... 50

3.3.1.5 Índice de temperatura de globo negro e umidade (BGHI) ................. 51

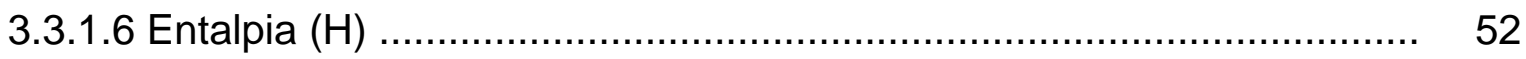

3.3.2 Variáveis fisiológicas ............................................................. 54

3.3.2.1 Temperatura retal (TR) ........................................................ 54

3.3.2.2 Freqüência respiratória (FR) .................................................... 57

3.3.2.3 Temperatura da superfície do pelame (TP) .................................... 59

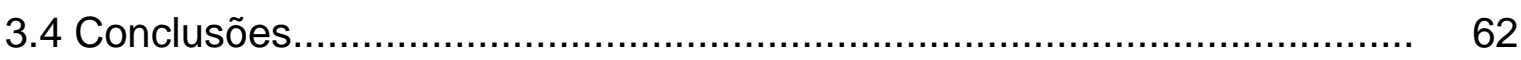

4 EFICIÊNCIA DE SISTEMAS DE CLIMATIZAÇÃO NA ÁREA DE DESCANSO EM INSTALAÇÕES DO TIPO FREESTAL E SUA INFLUÊNCIA NAS RESPOSTAS PRODUTIVAS E FISIOLÓGICAS DE

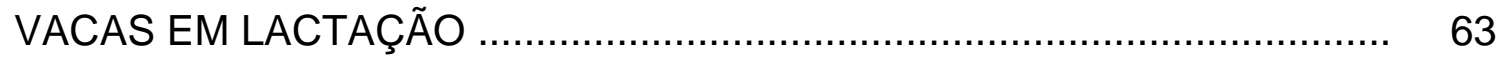

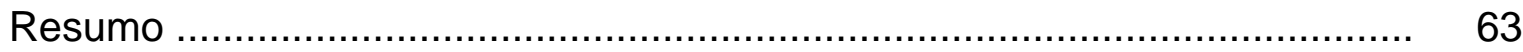

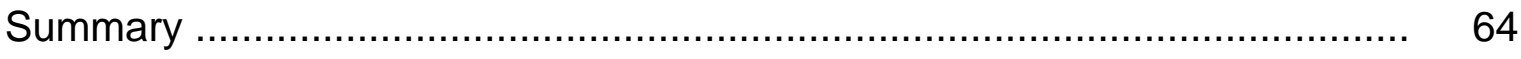


4.1 Introdução

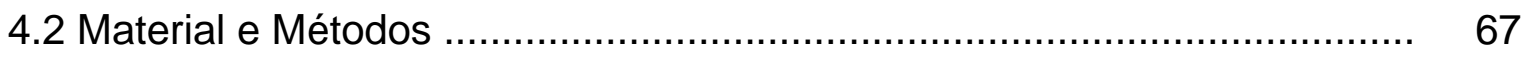

4.2.1 Local e instalações ......................................................................... 67

4.2.2 Caracterização dos animais e manejo .............................................. 69

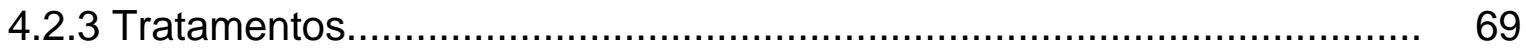

4.2.4 Sistema de resfriamento ........................................................ 70

4.2.5 Variáveis meteorológicas .............................................................. 71

4.2.6 Variáveis fisiológicas .............................................................. 72

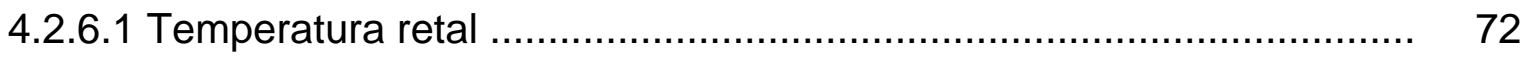

4.2.6.2 Freqüência respiratória ............................................................... 73

4.2.6.3 Temperatura da superfície do pelame …........................................ 73

4.2.7 Análises estatísticas ........................................................................... 73

4.3 Resultados e Discussão ........................................................... 74

4.3.1 Variáveis meteorológicas ........................................................... 74

4.3.1.1 Temperatura de bulbo seco (TBS) …….................................... 76

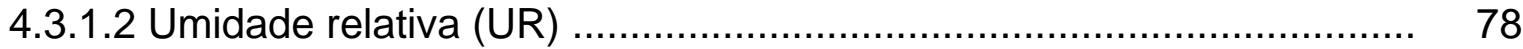

4.3.1.3 Temperatura de globo negro (TGN) …................................... 80

4.3.1.4 Índice de temperatura e umidade (THI) ....................................... 81

4.3.1.5 Índice de temperatura de globo negro e umidade (BGHI) ................. 83

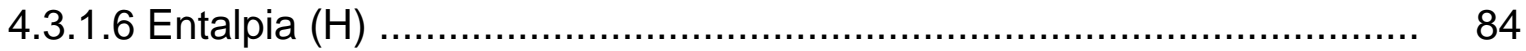

4.3.2 Variáveis fisiológicas ............................................................... 86

4.3.2.1 Temperatura retal (TR) ........................................................ 86

4.3.2.2 Freqüência respiratória (FR) ……............................................ 89

4.3.2.3 Temperatura da superfície do pelame (TP) .................................. 92

4.3.3 Ingestão de matéria seca e produção de leite ...................................... 94

4.3.6 Conclusões …......................................................................... 97

5 ZOOTECNIA DE PRECISÃO: MONITORAMENTO ELETRÔNICO DAS RESPOSTAS COMPORTAMENTAIS DE VACAS EM LACTAÇÃO ALOJADAS EM FREESTALL CLIMATIZADO …................................... 98

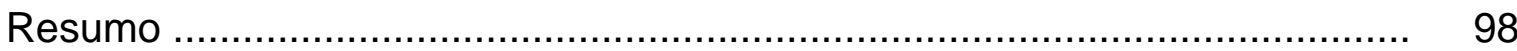




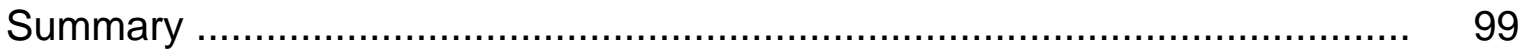

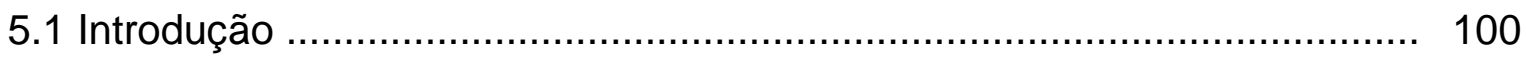

5.2 Material e Métodos .......................................................................... 103

5.2.1 Local, instalações e manejo ....................................................... 103

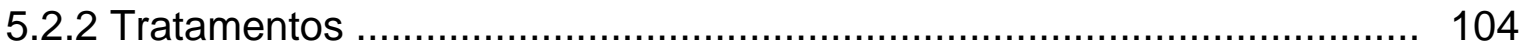

5.2.3 Monitoramento ambiental ...................................................... 105

5.2.4 Monitoramento eletrônico do comportamento animal ........................... 106

5.2.5 Análises estatísticas .................................................................... 108

5.3 Resultados e Discussão ............................................................ 109

5.3.1 Tempo despendido em cada atividade ......................................... 109

5.3.2 Tempo despendido em cada local da instalação ................................. 117

5.3.3 Conclusões ............................................................................ 121

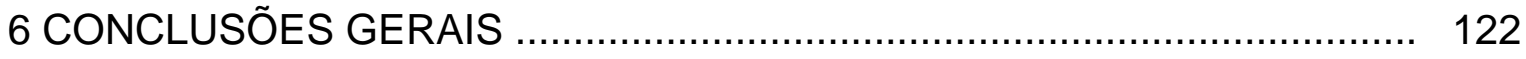

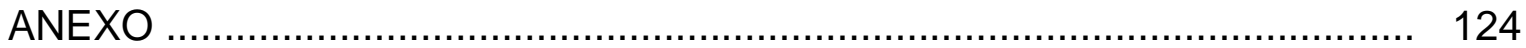

REFERÊNCIAS BIBLIOGRÁFICAS ....................................................... 126 


\title{
EFICIÊNCIA DO SISTEMA DE RESFRIAMENTO ADIABÁTICO EVAPORATIVO EM CONFINAMENTO DO TIPO FREESTALL PARA VACAS EM LACTAÇÃO
}

\author{
Autor: SORAIA VANESSA MATARAZZO \\ Orientador: Prof. Dr. IRAN JOSÉ OLIVEIRA DA SILVA
}

\section{RESUMO}

$\mathrm{O}$ trabalho foi realizado em duas fases. A primeira teve como objetivo avaliar as intermitências do sistema de resfriamento adiabático evaporativo por aspersão na linha de alimentação em freestall usando os índices de conforto térmico e respostas fisiológicas de vacas em lactação. Foram utilizadas 12 vacas, multíparas, produção média de $30 \mathrm{~kg}$ de leite dia $^{-1}$. Os tratamentos adotados foram às intermitências de 12, 14 e 16 min. A temperatura do bulbo seco (TBS), umidade relativa (UR) e temperatura de globo negro (TGN) foram mensuradas ao longo das 24 horas. A freqüência respiratória (FR), temperatura retal (TR) e temperatura da pele (TP) foram medidas diariamente em intervalos determinados. A TBS $\left(31,5^{\circ} \mathrm{C}\right), \operatorname{TGN}\left(32,5^{\circ} \mathrm{C}\right), \mathrm{THI}(79,1)$ e BGH $(80,9)$ foram maiores na intermitência 12 min quando comparados aos demais tratamentos. A UR foi mais elevada no tratamento 14 min (60,3\%) em relação à intermitência 
de $12 \mathrm{~min}(51,0 \%)$. As vacas que receberam o tratamento $12 \mathrm{~min}$ apresentaram maior valor de $\operatorname{TR}\left(39,1^{\circ} \mathrm{C}\right)$ e $\mathrm{FR}(76,0$ mov min-1) quando comparadas ao tratamento $16 \mathrm{~min}$. O intervalo de $16 \mathrm{~min}$ resultou em menor consumo de água, devendo ser empregado para evitar desperdícios do SRAE. O segundo experimento objetivou avaliar a eficiência de sistemas de climatização na área de descanso em freestall e sua influência nas respostas produtivas, fisiológicas e comportamentais de vacas em lactação. O período experimental teve duração de 28 dias consecutivos do mês de novembro de 2003. Foram utilizadas 30 vacas em lactação, multíparas, com produção média de $20 \mathrm{~kg}$ de leite dia $^{-1}$. Os tratamentos adotados foram: ausência de ventilação (V0), ventilação (V) e ventilação + nebulização (VN) posicionados na cama dos animais. A temperatura do bulbo seco (TBS), umidade relativa do ar (UR) e temperatura de globo negro (TGN) foram mensurados ao longo das 24 horas. A freqüência respiratória (FR), temperatura retal (TR) e temperatura do pelame (TP) foram realizadas às $9,11,13,15$ e 17 horas. Para a análise comportamental, instalaram-se quatro vídeo-câmeras por tratamento, em locais estratégicos do freestall para capturar a ingestão, ruminação, ócio e deslocamento dos animais. As variáveis meteorológicas e índices de conforto permaneceram acima da termoneutralidade. Também não foram constatadas alterações na freqüência respiratória e temperatura do pelame. Os animais em V0 e $\mathrm{V}$ apresentaram maior consumo de matéria seca, entretanto, este não refletiu em maior produção de leite. Verificou-se maior tempo despendido com a ingestão de alimentos (106,8 min) e água (21,7 min) nos animais do tratamento $V$ quando comparados com V0 e VN. O tempo de ruminação dos animais em V0 (164,3 min) foi superior aos constatados em V (102,5 min) e VN (129,5 min). Já as vacas do tratamento VN (200,2 min) apresentaram maior tempo em ócio quando comparadas com V0 (164,3 min) e V (117,0 min). Não foram constatas diferenças no tempo que as vacas permaneceram deitadas. Nas condições do presente experimento, a adoção de sistemas de climatização na área de descanso não se mostrou eficiente. 


\title{
EFFICIENCY OF THE ADIABATIC EVAPORATIVE COOLING SYSTEM IN FREESTALL FOR DAIRY COWS
}

\author{
Author: SORAIA VANESSA MATARAZZO \\ Adviser: Prof. Dr. IRAN JOSÉ OLIVEIRA DA SILVA
}

\section{SUMMARY}

This first work aimed to evaluate the effect of sprinkling frequency of adiabatic evaporative cooling system within feed line of a freestall in relation to temperature and humidity index ( $\mathrm{THI})$ and black globe temperature index (BGHI) and physiological responses in dairy cows. Data were registered during 116 days from January to May 2003. Twelve multiparous dairy cows with mean milk production of $30 \mathrm{~kg} \mathrm{day}^{-1}$ were used. Treatments were sprinkling frequencies every 12,14 or 16 minutes in sprinkler system with the same non-intermittent interval (85 seconds). Dry bulb temperature (DBT), air relative humidity $(\mathrm{RH})$ and black globe temperature (BGT) inside and outside of facilities were measured hourly through a period of 24 hours. Respiratory frequency (RF), rectal temperature (RT) and skin temperature (ST) were taken at 13, 14, 15 and $16 \mathrm{~h}$ in all the animals submitted to the treatments. The meteorological variables, DBT $\left(31.5^{\circ} \mathrm{C}\right)$ and BGT $\left(32.5^{\circ} \mathrm{C}\right)$, and the indexes of thermal comfort, THI (79.1) and $\mathrm{BGHI}$ (80.9), were higher with 12 minutes of sprinkling frequency when 
compared to other treatments. The RH was higher (60.3\%) with 14 minutes than with 12 minutes (51.0\%). In relation to physiological parameters, lactating cows with 12 minutes had higher rectal temperature $\left(39.1^{\circ} \mathrm{C}\right)$, respiratory frequency (76.0 mov min-1) when compared to with 16 minutes. To avoid unnecessary wastes should be used the interval of 16 min that resulted in the smallest amount of water consumed by the sprinkling cooling system. The second work aimed to evaluate the efficiency of thermal conditioned in free-stall facilities and its consequences on productive and physiological responses in dairy cows. Experimental period was 28 consecutive days of November 2003. Third dairy multiple cows with mean milk production of $20 \mathrm{~kg}$.day-1. Treatments were: nonfan (NF), fan (F) and fan + misting (FM) in direction to animal bedding. Dry bulb temperature (DBT), air relative humidity $(\mathrm{RH})$ and black globe temperature (BGT) inside and outside of facilities were measured every 15 minutes through a period of 24 hours. Milking was realized at 1, 9 and 17 hours and registering daily production. Animals were fed twice a day (10 and 15 hours) and amounts of offered and rejected feed were daily registered. Physiological data, as respiratory frequency $(\mathrm{RF})$, rectal temperature $(\mathrm{RT})$ and skin temperature (ST), were taken at 9,11,13, 15 and $17 \mathrm{~h}$. The $\mathrm{RH}$ was higher in $\mathrm{V} 0(61.8 \%)$ and VN $(61.8 \%)$ treatments than in $\mathrm{V}(60.3 \%)$. The facilities $(\mathrm{V})$ where it was used had higher BGT $\left(27.4^{\circ} \mathrm{C}\right)$ in relation to $\mathrm{VO}\left(27.1^{\circ} \mathrm{C}\right)$. Also, THI was higher in $\mathrm{V}(75.0)$ than in V0 (74.5) and VN (74.3) treatments. In relation to physiological parameters, lactating cows of $\mathrm{V} 0$ treatment had lower rectal temperature at 11 , 13 and $17 \mathrm{~h}$. Respiratory frequencies were within normal variation, showing that animals of all treatments did not in heat stress condition. Higher feed intakes were observed in animals of $\mathrm{V} 0\left(20.5 \mathrm{~kg} \mathrm{DM}\right.$ day $\left.^{-1}\right)$ and $\mathrm{V}\left(21.3 \mathrm{~kg} \mathrm{DM} . \mathrm{day}^{-1}\right)$ treatments, but it did not increase milk productions. 


\section{INTRODUÇÃO}

O cenário da pecuária leiteira nacional tem passado por grandes transformações, em face da competitividade e da nova realidade econômica mundial. O suprimento adequado de leite, para atender a grande demanda do nosso mercado futuro, irá depender da modernização e intensificação da produção.

A intensificação pode ocorrer de várias maneiras, principalmente em função de fatores relacionados ao mercado consumidor, nível de investimento, disponibilidade de mão-de-obra, emprego racional e preservação dos recursos naturais. Sendo assim, as opções direcionam a dois caminhos: a intensificação da produção de leite por vaca, utilizando o confinamento dos animais; e o outro baseia-se em sistemas de produção de leite a pasto.

Para o confinamento, muitos produtores têm buscado animais de alto potencial genético, os quais possuem metabolismo intenso, com produção de grandes quantidades de calor endógeno, portanto, bastante susceptíveis ao estresse térmico.

O aumento da produtividade dos rebanhos leiteiros nas regiões tropicais tem sido obtido com a introdução de raças especializadas, originárias de climas temperados. Na maioria das vezes, observa-se que essas raças comportam-se diferentemente do seu país de origem, com perdas nas características raciais e produtivas.

Determinar se o animal está em ambiente ótimo ou estressante, é de fundamental importância para a eficiência fisiológica e econômica da exploração. Desta forma, torna-se necessário avaliar o desempenho produtivo, 
fisiológico e comportamental do animal em um dado ambiente. A maioria dos estudos tem-se desenvolvido em condições controladas (câmaras climáticas), as quais não refletem as flutuações normalmente verificadas nas condições naturais.

A freqüente situação de temperatura elevada dentro das instalações deve-se principalmente ao seu dimensionamento inadequado, do que propriamente à adversidade climática. Sendo assim, o microclima interno de uma instalação do tipo freestall pode ser alterado com a adoção de sistemas de condicionamento de ambiente, que, projetados adequadamente, poderão proporcionar um resfriamento eficiente.

Em função da adversidade climática existente entre as regiões, os sistemas e tecnologias devem ser adaptados às condições locais. Um dos grandes problemas da ambiência na produção de leite é que existem vários modelos relacionados aos sistemas de resfriamento, entretanto, sua maioria foi desenvolvida em condições ambientais distintas dos países tropicais.

O sistema de resfriamento adiabático evaporativo (SRAE) pode ser aplicado das mais diversas maneiras, entre elas, a nebulização, microaspersão e aspersão sobre os animais ou telhados. Tal prática tem proporcionado reduções na temperatura interna da instalação, melhorando as condições de conforto.

A necessidade de pesquisas nacionais que resultem em informações sobre intermitência de acionamento dos sistemas de resfriamento, distribuição das linhas de nebulização e/ou aspersão é de suma importância para que possamos adotar tal prática de maneira adequada. O Núcleo de Pesquisa em Ambiência (NUPEA - ESALQ/USP) desenvolve uma linha de pesquisa nessa área, a fim de gerar informações pertinentes às condições brasileiras.

O presente trabalho teve como objetivo geral avaliar a eficiência do sistema de resfriamento adiabático evaporativo (SRAE) em instalações do tipo freestall. Os objetivos específicos foram: 
$\checkmark$ Avaliar as intermitências de acionamento do SRAE por aspersão na linha de alimentação, usando os índices de conforto térmico (BGHI e THI) e as repostas fisiológicas de vacas em lactação;

$\checkmark$ Avaliar a distribuição de linhas de nebulização ou ventilação na área de descanso, e seus reflexos nas repostas produtivas e fisiológicas de vacas em lactação;

$\checkmark$ Avaliar as respostas comportamentais de vacas em lactação submetidas aos sistemas de climatização. 


\section{REVISÃO DE LITERATURA}

\subsection{0 ambiente tropical e a produção de leite}

O Brasil possui cerca de dois terços de seu território situados na faixa tropical do planeta, onde predominam altas temperaturas do ar, em virtude da elevada radiação solar incidente. A temperatura média do ar situa-se acima dos $20^{\circ} \mathrm{C}$, sendo que a temperatura máxima se encontra acima dos $30^{\circ} \mathrm{C}$ em grande parte do ano, atingindo, muitas vezes, valores entre $35^{\circ} \mathrm{C}$ e $38^{\circ} \mathrm{C}$ (Titto,1998).

Os animais vivem em equilíbrio dinâmico com o meio e a ele reagem de forma individual. Sua produção está condicionada às influências do ambiente, o qual não se mantém constante ao longo do tempo. A vulnerabilidade dos animais às condições meteorológicas, uma vez deslocados para um ambiente diferente do original ou frente a mudanças dentro do mesmo ambiente, faz com que recorram a mecanismos de adaptação fisiológica a fim de manter a homeostase (Baccari Junior, 2001).

De acordo com Hanh (1993), o estresse caracteriza a soma dos mecanismos de defesa do organismo em resposta a um estímulo provocado por um agente estressor, externo ou interno, para manter o equilíbrio fisiológico.

O ambiente é composto de estressores que interagem e incluem todas as combinações nas quais o organismo vive. $O$ estresse climático é função da temperatura do ar, umidade relativa, radiação solar, vento, temperatura corporal, intensidade e duração do agente estressor; podendo resultar em decréscimo na produção de leite e distúrbios reprodutivos. 
A resposta dos animais a um evento estressante compreende três componentes principais: o reconhecimento da ameaça à homeostase ou ao bem-estar, a resposta e as conseqüências do estresse. Uma série de fatores, como experiência anterior, genética, idade, sexo ou condições fisiológicas modela a natureza da resposta biológica de um animal a um estressor (Moberg, 1987).

As respostas dos animais aos estressores são ilustradas pela Figura 1. A intensidade e duração do agente estressor atuando sobre o animal irão desencadear alterações fisiológicas, imunológicas e comportamentais à agressão do organismo em sua totalidade. O êxito das respostas de adaptação permite que a função normal continue. Entretanto, quando certos limites são ultrapassados, a função é prejudicada, afetando a sanidade e o desempenho produtivo e reprodutivo (Hahn, 1993).

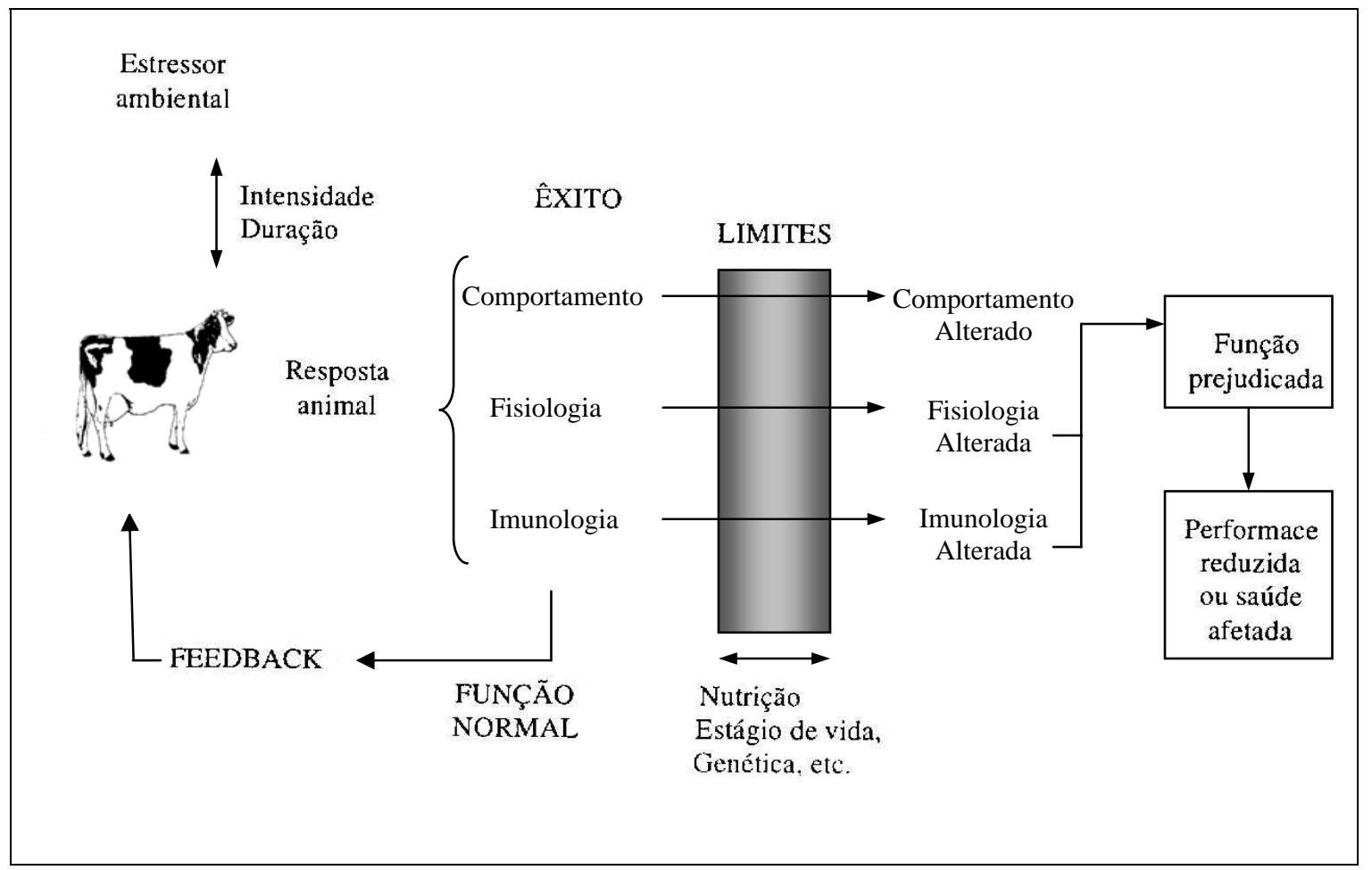

Figura 1 - Respostas dos animais aos estressores ambientais (Hahn, 1993) 
As respostas fisiológicas incluem a vasodilatação periférica e aumentos na taxa de sudorese e freqüência respiratória. No campo imunológico, os glicocorticóides produzem alterações no número de glóbulos brancos e inibem a resposta linfocitária aos desafios imunogênicos. Como reação á resposta comportamental, verifica-se que os bovinos de origem européia, não bem adaptada geneticamente ao calor, procuram sombra nas horas mais quentes do dia, durante o verão, tentando amenizar os efeitos do estresse térmico causado pela radiação solar direta (Baccari Junior, 2001). Também ocorre um aumento no número de visitas ao bebedouro, procura por sombra, e quando há disponibilidade de lagoas, os animais tendem a permanecer em pé na água, de modo a facilitar a perda de calor por condução (Pires et al., 1998b).

\subsection{Zona de termoneutralidade}

Os bovinos são animais homeotérmicos, isto é, são capazes de manter a temperatura corporal independente das variações da temperatura ambiente. As vacas em lactação, dependendo da raça, nível de produção, estádio fisiológico e plano nutricional, apresentam uma faixa de temperatura ambiente na qual se encontram em conforto térmico, isto é, não sofrem estresse por frio ou calor, denominada zona de termoneutralidade (Figura 2).

$\mathrm{Na}$ zona de termoneutralidade, o sistema termorregulador não é acionado, seja para fazer termólise ou termogênese. Assim, o gasto de energia para manutenção é mínimo, resultando em máxima eficiência produtiva. Os limites da zona de termoneutralidade são a temperatura crítica inferior (TCl) e a temperatura crítica superior (TCS). Abaixo da TCl, a vaca entra em estresse pelo frio, e acima da TCS, em estresse pelo calor (Baccari Junior, 1998). 


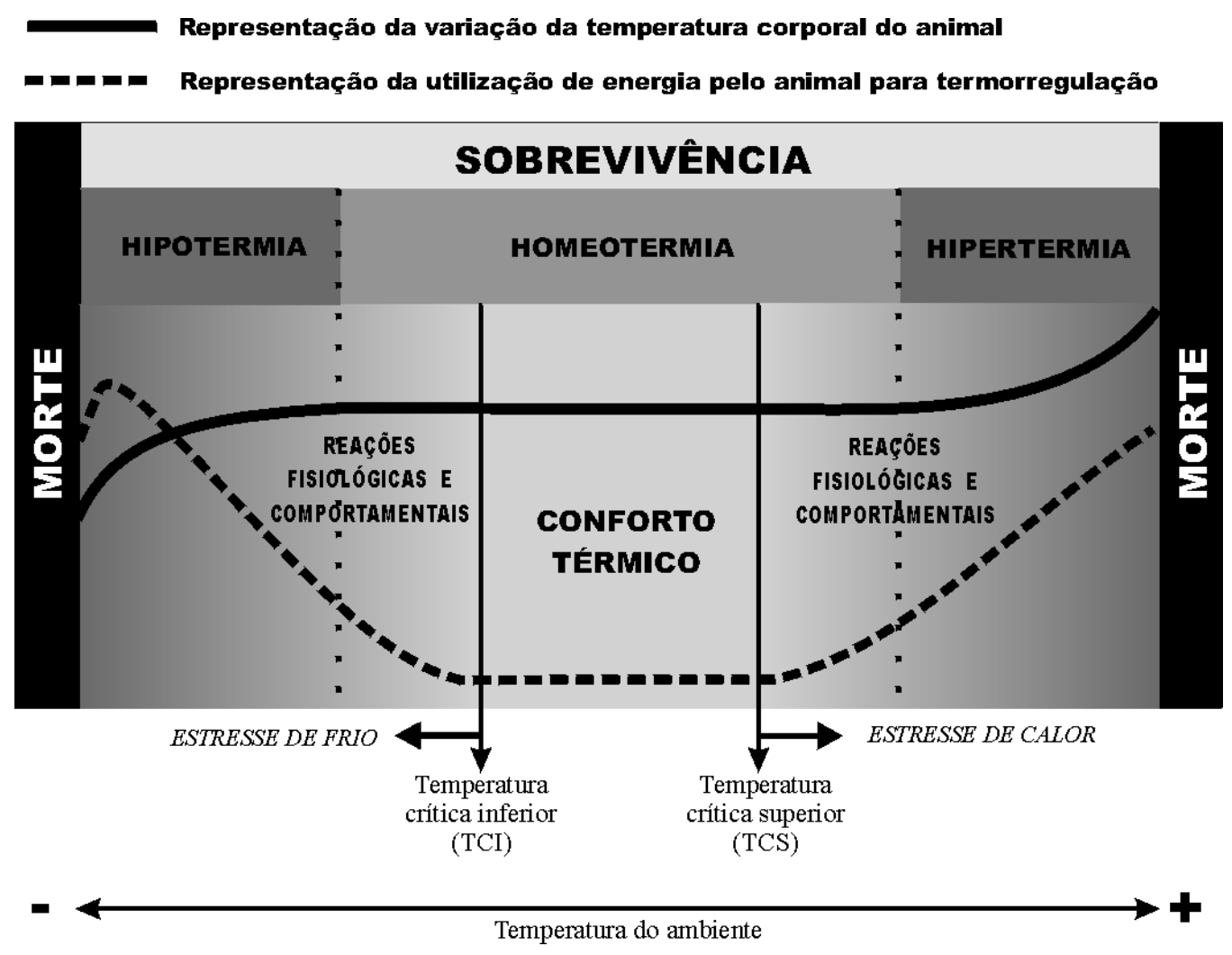

Figura 2 - Zona de Termoneutralidade

Ao ultrapassar a TCS, começam a atuar os primeiros mecanismos de termorregulação, como vasodilatação periférica, sudorese e polipnéia. $\mathrm{Na}$ persistência dessa situação de estresse térmico, os mecanismos de termorregulação intensificam-se, e o animal busca reduzir seu metabolismo por meio da depressão da atividade da tireóide, produzindo uma menor quantidade de tiroxina. Tal evento está associado à diminuição da ingestão de alimentos e mobilização das reservas corporais. Mesmo sob essas condições, o animal é capaz de manter a homeotermia. Entretanto, irá ocorrer um momento em que os mecanismos de defesa se tornam insuficientes, ocorrendo um quadro de hipertermia acentuada que, se persistir durante algumas horas, provoca a morte do animal (Hafez, 1973).

Embora se saiba que a genética das vacas produtoras de leite tem origem em países de clima temperado, há uma eminente adaptação desses 
animais às situações de climas quentes. Entretanto, existe uma grande variação na literatura sobre as temperaturas crítica superior e inferior. Os valores mais altos de temperatura crítica superior indicam maior tolerância ao calor. Uma vaca mantida com alto nível de produção será mais sensível ao calor que uma vaca de baixa produção. Tal fato deve-se à maior taxa metabólica da primeira (Baccari Junior, 2001).

A temperatura crítica superior estaria entre 25 a $26^{\circ} \mathrm{C}$ para vacas em lactação, independente destas terem sido submetidas à aclimatação prévia ou nível de produção (Berman et al., 1985). Essa especificidade generalizada de temperatura crítica superior contradiz as considerações de Yousef e Johnson (1985), mencionaram que a zona de termoneutralidade varia com o estado fisiológico e as condições ambientais.

Fuquay (1997) considerou para o gado europeu valor de temperatura crítica superior entre 25 a $27^{\circ} \mathrm{C}$. De acordo com Nääs (1989), em função da umidade relativa do ar e radiação solar local, a faixa de termoneutralidade poderia ser restringida entre 7 e $21^{\circ} \mathrm{C}$. Huber (1990) considerou como adequadas para o conforto térmico de vacas em lactação temperatura do ar entre 4 e $26^{\circ} \mathrm{C}$.

Quando a temperatura ambiente for superior a $29^{\circ} \mathrm{C}$ e a umidade relativa correspondente a $40 \%$, as produções das vacas Holandesas, Jerseys e PardoSuiças equivalem a 97, 83 e 98\% da produção de leite normal. Quando a umidade relativa é igual a $90 \%$, a produção de leite foi 69,75 e $83 \%$ da produção normal (West, 2003).

Acima da temperatura crítica superior, o aumento da temperatura corporal influencia negativamente o desempenho, reduzindo a produção e alterando a composição do leite (Roenfeldt, 1998).

Com referência a esses valores, pode-se concluir que o Brasil apresenta freqüentemente temperaturas superiores a estas, por várias horas do dia e em grande parte do ano, submetendo, então, as vacas leiteiras ao estresse térmico. 


\subsection{Manutenção da temperatura corporal e mecanismos de dissipação de calor}

Os animais mantêm a homeotermia por meio de trocas de calor com o meio ambiente, utilizando mecanismos fisiológicos, metabólicos e comportamentais. Entre esses mecanismos, destaca-se a vasodilatação periférica, que é responsável pelo redirecionamento do fluxo sangüíneo dos órgãos internos para a superfície corporal, facilitando a dissipação de calor por meios não evaporativos, como a condução, convecção e radiação (Johnson, 1987).

A perda de calor por condução ocorre pelo contato entre as superfícies. São nas lagoas, pisos cimentados, locais com barro que geralmente ocorrem essas transferências. Na perda de calor por convecção, ocorre a circulação de moléculas, com a reposição da camada mais quente de ar por uma mais fria. Tal perda pode ser facilitada pelo uso de ventiladores ou orientação adequada do eixo central da instalação, favorecendo a ventilação natural. Já a perda por radiação ocorre, quando o animal emite radiação para o meio ambiente. Entretanto, esta via é mais importante para a aquisição de calor que propriamente para a perda. A disponibilidade de áreas sombreadas tem demonstrado resultados expressivos no aumento da produção de leite (Cunninghan, 1999).

Para que esses mecanismos atuem de maneira eficiente, é necessário que ocorra um gradiente térmico entre o corpo do animal e o ambiente a sua volta. $\mathrm{Na}$ zona de conforto térmico, para a maioria dos ruminantes, aproximadamente $75 \%$ das perdas de calor ocorrem pela forma não evaporativa (trocas secas), ou seja, por condução, convecção e/ou radiação. Quando a temperatura ambiente ultrapassa a temperatura crítica superior, o gradiente torna-se pequeno para que o resfriamento não evaporativo seja efetivo. Nesse caso, os animais utilizam os mecanismos evaporativos (respiração e sudação) para manter o balanço térmico, tornando-se principal a 
via de dissipação de calor; uma vez que $80 \%$ são perdidos dessa forma (Shearer e Beede, 1990).

É importante salientar que, quando a temperatura ambiente ultrapassa os valores máximos de conforto para o animal, a umidade relativa assume fundamental importância na eliminação de calor. Isso ocorre porque, em condições de umidade elevada, o ar saturado irá inibir a evaporação da água pela pele e sistema respiratório, proporcionando um ambiente ainda mais estressante para o animal (Sota, 1996).

A Figura 3 ilustra os mecanismos de perda de calor utilizados por uma vaca em lactação, quando a temperatura ambiente aumenta. Em temperaturas amenas, a maior parte é perdida pelo resfriamento não evaporativo. À medida que a temperatura ambiente se eleva, a vaca mostra-se cada vez mais dependente do resfriamento evaporativo (Kliber, 1950).

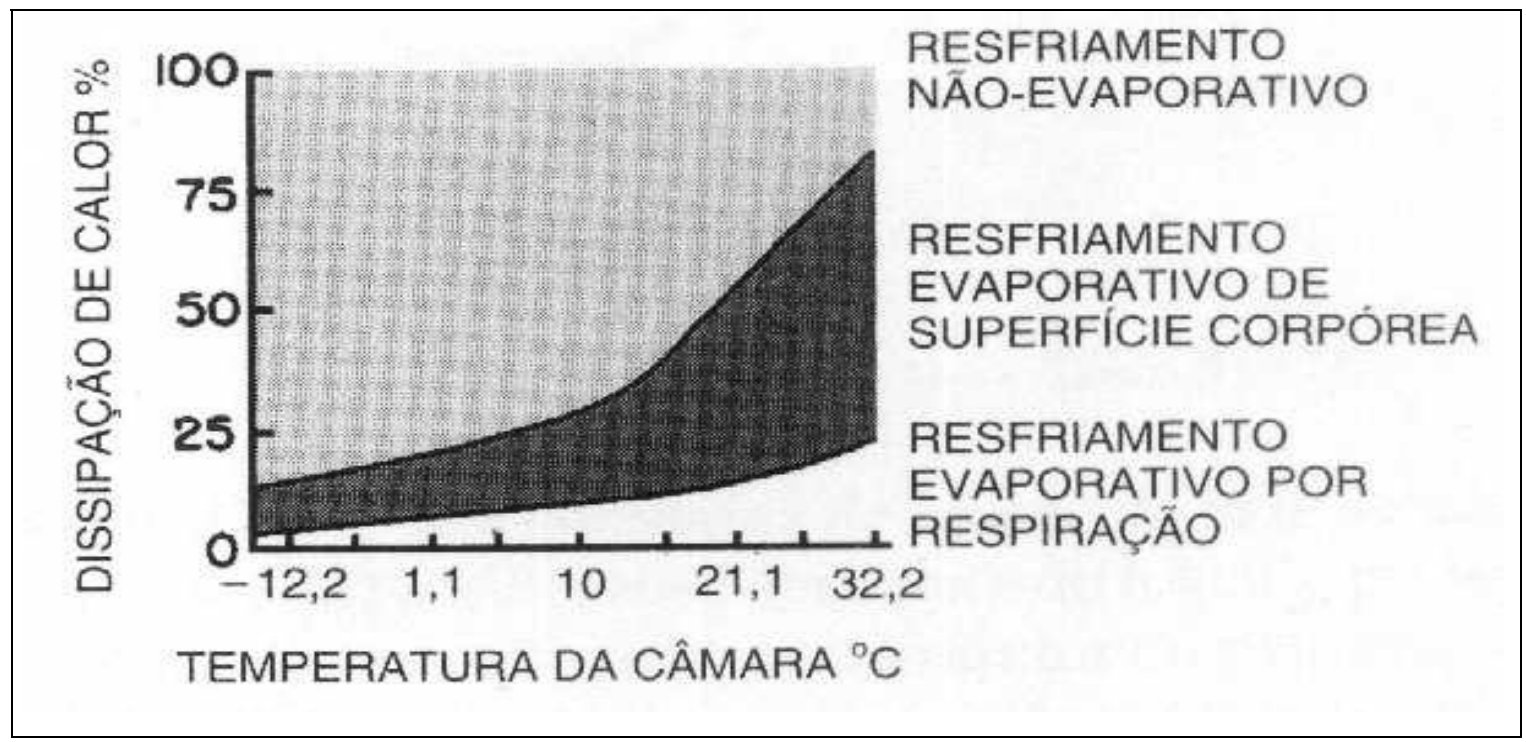

Figura 3 - Perda total de calor por meio dos mecanismos evaporativos e não evaporativos 


\subsection{Climatização das instalações para bovinos de leite}

As instalações têm como objetivo oferecer conforto ao animal, permitindo que ele expresse seu potencial para produção. Devem ser construídas e planejadas com a finalidade principal de reduzir a ação dos elementos climáticos (insolação, temperatura, ventos, chuvas e umidade relativa do ar) que pode ter efeitos indesejáveis aos animais. As variáveis ambientais são controladas com diferentes materiais de construção, dimensionamento dos espaços físicos disponíveis, densidade e sistema de ventilação e resfriamento (Nääs e Souza, 2003).

A primeira condição de conforto térmico dentro de uma instalação é que o balanço térmico seja nulo. Assim, o calor produzido pelo organismo animal mais o calor ganho pelo ambiente será igual ao calor perdido por radiação, convecção, condução e evaporação. Caso contrário, o animal tem que se defender, utilizando mecanismos fisiológicos para manter a termorregulação. A produção de calor, bem como sua dissipação para o meio é um processo interativo, que depende diretamente da fisiologia animal e das condições psicrométricas do ar (Esmay, 1982).

O controle eficiente do ambiente pode empregar sistemas naturais e artificiais. Inúmeros métodos têm sido desenvolvidos para modificar o ambiente no qual o animal está inserido, visando a amenizar o efeito do estresse térmico. A movimentação do ar, o umedecimento da superfície do animal, o resfriamento evaporativo do ar e o uso de sombras para minimizar o efeito da radiação solar, são artifícios empregados para potencializar a dissipação de calor (West, 2003).

O sistema de resfriamento adiabático evaporativo (SRAE) tem se expandido rapidamente em climas quentes, devido à sua simplicidade técnica, praticidade e relação custo: benefício favorável, resultando na sua aceitação por muitos produtores (Lin et al., 1998).

O resfriamento evaporativo é essencialmente um processo de saturação adiabática, em que não há perda nem ganho de calor. Nesse processo, ocorre 
a mudança do ponto de estado psicrométrico do ar, verificando-se elevação da umidade relativa e decréscimo na temperatura, mediante o contato do ar com uma superfície umedecida ou líquida. A pressão de vapor do ar insaturado a ser resfriado é menor que a da água de contato, fazendo com que ocorra a vaporização da água. A energia necessária para esta mudança de estado vem do calor sensível contido no ar e na água, resultando em decréscimo da temperatura de ambos, e, conseqüentemente, do ambiente. Ao passar do estado líquido para o gasoso, a água retira do ambiente aproximadamente 584 kcal para cada kg de água evaporada (Wiersma e Stott, 1983).

Para Whitaker (1979), a eficiência de aplicação do SRAE depende da diferença entre as temperaturas de bulbo seco e úmido (depressão psicrométrica), a qual é característica para cada região. O uso do SRAE permitiu uma queda de 4 a $7^{\circ} \mathrm{C}$ na temperatura em determinada região dos Estados Unidos, o que correspondeu a uma depressão psicrométrica, ao meio dia, de 7 a $9^{\circ} \mathrm{C}$. Acredita-se que a eficiência do sistema seja maior em climas quentes e secos, devendo ser tomados os devidos cuidados com diferentes manejos, principalmente em regiões úmidas.

De maneira geral, o SRAE é empregado na climatização de instalação para animais, apresentando resultados satisfatórios na redução da temperatura interna da instalação, e assim, melhorando as condições de conforto. Pode ser obtido por vários processos, entre eles destacam-se: a nebulização, microaspersão e aspersão sobre os animais ou telhados (Silva, 1999).

A diferença entre a nebulização e a aspersão consiste no diâmetro da gota e na pressão na qual esses sistemas operam. A nebulização permite a formação de gotículas extremamente pequenas, que aumentam a superfície de contato da gota d'água exposta ao ar, assegurando uma evaporação mais rápida. Esses sistemas operam com uma pressão de 1100 a 1380 kPa (Turner, 1998). Um nebulizador bem calibrado com água limpa é capaz de dividir uma gota d'água em aproximadamente 611 gotículas com diâmetro de $0,5 \mathrm{~mm}$ e área total 850 vezes maior (Marques, 1992). 
Quando os animais são borrifados com gotículas de água (formando uma névoa), torna-se desejável que essa névoa permaneça no microambiente que circunda o animal, para que seja removida pelos ventiladores, resfriando o ambiente. Desta forma, a nebulização associada à movimentação do ar proporcionada por ventiladores, acelera a evaporação (Armstrong, 1994).

Os trabalhos realizados por Frazzi et al. (1998) apontaram redução de 2 a $3^{\circ} \mathrm{C}$ na temperatura interna da instalação e aumento da umidade relativa entre 10 e 15\%, com o uso de sistema de nebulização de alta pressão.

Nas condições tropicais, Pinheiro et al. (2001) avaliaram os efeitos do sistema de resfriamento evaporativo por nebulização associada à ventilação, sobre a produção de leite de vacas Jersey e verificaram que as vacas mantidas no ambiente climatizado apresentaram produção média diária maior que as vacas no tratamento controle.

Poucos trabalhos descrevendo os efeitos do resfriamento evaporativo têm sido conduzidos em regiões de umidade relativa elevada. Nas condições em que a temperatura e umidade do ar forem elevadas, poderá ocorrer limitação na aplicação desse sistema, uma vez que o ar saturado irá inibir a evaporação da água pela pele e sistema respiratório, proporcionando um ambiente ainda mais estressante para o animal. Quando a umidade relativa é superior a $70 \%$, o potencial de redução no THI é inferior a 10\% (Brouk et al., 2001b).

Em períodos de temperaturas elevadas e com ocorrência de chuvas, situações características do verão nas condições tropicais, os sistemas de nebulização poderiam aumentar excessivamente a umidade relativa dentro da instalação. Essa umidade deve ser removida por meio de trocas de ar na instalação. A ventilação destes ambientes pode promover melhorias nas condições termo-higrométricas, podendo representar um fator de conforto térmico de verão, ao incrementar as trocas de calor por convecção e evaporação (Silva, 1999). 
A dissipação de calor por meios não evaporativos pode ser facilitada com a aplicação de água na superfície corporal do animal. A água evapora e remove o calor, favorecendo as trocas entre a pele e o ambiente. Sendo assim, quando a temperatura ambiente for superior à temperatura crítica, a adoção de um sistema de aspersão mostra-se como uma estratégia, a fim de aumentar a quantidade de calor perdido por meio da pele (Davis, 2001).

A aspersão não tem por finalidade resfriar o ar, pois emprega gotas com tamanho maior, de modo a promover o umedecimento dos pêlos das vacas. $O$ animal se resfria com a evaporação da água, através da pele e pêlos, permitindo a troca de calor mais eficiente, quando comparada apenas com a sudação. Quando associada à ventilação natural ou forçada, aumenta a eficiência do resfriamento, por acelerar o processo de evaporação (Bucklin e Bray, 1998).

O efeito da aspersão em vacas Holandesas, durante o verão, no estado de Columbia (EUA), foi evidente mesmo em verão moderado, em que o THI foi ligeiramente superior justamente no ponto em que a produção de leite começa a decrescer, resultando em acréscimo diário de $0,7 \mathrm{~kg}$ de leite por vaca. (Igono et al. 1997).

A eficiência do SRAE por aspersão ou nebulização associada à ventilação forçada na linha de alimentação, foi avaliada em condições de clima tropical. Verificou-se que a nebulização proporcionou menores valores de temperatura de bulbo seco e maiores valores de umidade relativa devido à maior quantidade de vapor d'água produzida pelo sistema (Perissinotto, 2003).

O efeito das condições climáticas sobre o desempenho das vacas leiteiras é marcante. Por esta razão, o conhecimento das relações funcionais existentes entre $o$ animal e o meio ambiente permite adotar procedimentos que elevam a eficiência da exploração leiteira (Damasceno et al., 1999). 


\section{5 Índices de conforto térmico para a bovinocultura leiteira}

Os índices de conforto térmico foram desenvolvidos para caracterizar e quantificar as zonas de conforto adequadas às diferentes espécies animais, apresentando em uma única variável, tanto os fatores meteorológicos (temperatura e umidade relativa do ar, velocidade do vento e radiação solar) como o estresse que tal ambiente possa estar causando no momento (Clark, 1981).

Conforme a maneira como o índice foi desenvolvido, Nääs (1998) propôs a seguinte classificação:

- Índices biofísicos: baseiam-se nas trocas de calor entre o corpo e o ambiente, correlacionando os elementos de conforto com as trocas de calor que os originam;

- Índices fisiológicos: baseiam-se nas relações fisiológicas originadas por condições conhecidas de temperatura ambiente, temperatura radiante média, umidade relativa e velocidade do ar;

- Índices subjetivos: baseiam-se nas sensações subjetivas de conforto experimentadas em que os elementos de conforto variam.

\subsection{1 Índices de temperatura e umidade (THI)}

O índice de temperatura e umidade (THI) foi desenvolvido por Thom (1959) como um índice de conforto para humanos. Posteriormente, foi utilizado para descrever o conforto térmico para animais, desde que Johnson et al. (1962) observaram quedas significativas na produção de vacas leiteiras, associadas ao aumento no THI.

Esse índice pode ser calculado a partir da temperatura de bulbo seco e da umidade relativa do ar, conforme descrito por Johnson (1980). Assim:

$\mathrm{THI}=\mathrm{Ts}+0,36 \mathrm{Tpo}+41,2$ 
em que: Ts = temperatura do termômetro de bulbo seco, ${ }^{\circ} \mathrm{C}$;

Tpo $=$ temperatura do ponto de orvalho, ${ }^{\circ} \mathrm{C}$.

Existem vários relatos sobre os limites do THI. Dessa forma, o trabalho clássico de Johnson et al. (1963) relatou que a produção de leite e a ingestão de matéria seca apresentaram decréscimo significativo quando o $\mathrm{THI}$ mostrou valor máximo de 77. Um THI igual ou menor a 70 expressa uma condição normal; um valor entre 71 e 78 é crítico; entre 79 e 83 a situação é de perigo e acima de 83, uma situação de emergência está presente (Hahn, 1985).

Trabalhos realizados posteriormente determinaram que os valores críticos para o mínimo, médio e máximo THI seriam, respectivamente, 64, 72 e 76 (Igono et al. 1992). O estresse severo pode levar os animais a óbito, quando o THI for superior a 84 e não ocorrer recuperação durante o período noturno, ou seja, se o THI não for inferior a 74 (Hahn e Mader, 1997).

A maioria dos trabalhos realizados anteriormente adotava as condições ambientais verificadas no dia de ocorrência do estresse para determinar os efeitos sobre a produção de leite (Aguiar e Targa, 1996; Matarazzo et al., 2003a). Todavia, pode ser que ocorra um atraso entre a ocorrência dos eventos ambientais e as respostas em produção de leite. West (2003) verificou a influência do ambiente térmico na produção de leite nos dois dias que precederam a ocorrência do estresse, observando declínio de 0,88 kg por unidade de aumento no THI acima de 72.

O decréscimo na produção de leite por unidade de aumento nas variáveis ambientais foi significativamente menor, quando avaliadas as medidas no mesmo dia de ocorrência do estresse, comparado com as medidas meteorológicas dos dois dias que precederam o estresse térmico. Sendo assim, o impacto das variáveis ambientais sobre a produção de leite é atrasado, e pode ser relatado por alteração na ingestão de alimentos, demora na utilização dos nutrientes ingeridos ou mudanças no status endócrino da vaca (West, 
2003). Nesta condição de avaliação, Ingraham et al (1979) encontrou redução na produção de leite de $0,32 \mathrm{~kg}$ por unidade de aumento no $\mathrm{THI}$.

Para vacas em lactação em sistema intensivo de produção, os efeitos do estresse térmico a que são submetidas durante o dia, podem ser aliviados quando a temperatura noturna cai, conferindo certa tolerância em curto prazo ao estresse térmico (Akari et al., 1987). Esse fenômeno pode ser explicado pelo padrão circadiano, caracterizado por temperatura corporal elevada entre 17 e 19 horas e mínima entre 4 e 6 horas (Bitman et al., 1984).

\subsection{2 Índices de globo negro e umidade (BGHI)}

O índice de globo negro e umidade (BGHI) foi desenvolvido por Buffington et al. (1981) como um índice de conforto térmico para vacas leiteiras expostas à radiação solar direta e indireta.

O BGHI é calculado substituindo-se em uma das fórmulas do THI, o termo referente à temperatura do termômetro de bulbo seco pela temperatura do globo negro. O termômetro de globo é uma maneira de indicar os efeitos combinados da radiação, convecção e sua influência no organismo vivo. Assim:

$\mathrm{BGHI}=\mathrm{Tg}+0,36 \mathrm{Tpo}+41,5$

em que: $\mathrm{Tg}=$ temperatura do termômetro de globo negro,, $\mathrm{C}$;

$\mathrm{Tpo}=$ temperatura do ponto de orvalho, $\stackrel{\circ}{ } \mathrm{C}$.

De acordo com o National Weather Service (EUA), citado por Baêta (1997), os valores de BGHI até 74 definem condição de conforto para os bovinos, entre 75 e 78 a situação é de alerta, 79 a 84 caracterizam perigo e acima deste, depara-se com situação de emergência.

A produção de leite apresentou correlação mais alta com o BGHI do que com o THI sob radiação solar direta. À sombra, os índices estiveram correlacionados à produção, na mesma magnitude (Baccari Junior, 1998). 
Roma Júnior et al. (2001) avaliaram o efeito do resfriamento por nebulização de alta pressão sobre o ambiente físico do freestall e verificaram que as temperaturas do ar e do termômetro de globo negro reduziram em 1,5 e $1,0^{\circ} \mathrm{C}$, respectivamente, com o emprego da nebulização.

O emprego do SRAE tem resultado em menores valores de BGHI. Trabalho realizado por Martello (2002) apontou valores de 77, 74,7 e 77,8 unidades, respectivamente, para o tratamento sem climatização, nebulização e malha de sombreamento.

\subsection{Respostas fisiológicas}

\subsubsection{Temperatura retal}

A manutenção da temperatura corporal é determinada pelo equilíbrio entre a perda e o ganho de calor. O calor necessário para manter a temperatura corporal deriva do metabolismo energético (oxidação de nutrientes dos alimentos ingeridos) e da absorção da radiação solar direta ou indireta (Baccari Junior, 2001).

A temperatura corporal é um evento biológico de recorrência periódica, obedecendo a um ritmo circadiano, ou seja, ritmo que se repete a cada 24 horas. A flutuação diária é geneticamente determinada. Seu objetivo é preparar o organismo antecipadamente para as mudanças previsíveis da alternância do dia e da noite (Cipola-Neto et al., 1988).

Nas condições de termoneutralidade, a temperatura retal de bovinos holandeses apresentou correlação mais alta $(0,96)$ com a hora do dia do que com a temperatura do ar $(0,71)$, no período das 8 às 18 horas. A partir das 15 horas, a temperatura do ar começou a cair, enquanto a temperatura retal continuou a aumentar, mostrando que, durante o dia, esta se eleva em função do metabolismo animal do que propriamente da temperatura ambiente (Baccari Junior et al., 1979) 
A referência fisiológica para essa variável está entre 38 e $39,5^{\circ} \mathrm{C}$ sob condições termoneutras (Du Preez, 2000). A medida da temperatura retal é usada freqüentemente como índice de adaptabilidade fisiológica aos ambientes quentes, pois seu aumento mostra que os mecanismos de liberação de calor tornaram-se insuficientes para manter a homeotermia (Mota, 1997).

Baseado nas respostas termorregulátorias, principalmente na temperatura corporal, Bianca (1961) classificou o estresse térmico da seguinte maneira:

- Estresse brando: os mecanismos termorregulatórios são eficientes em manter a temperatura corporal na faixa de normalidade;

- Estresse moderado: os mecanismos termorregulatórios são intensificados, e a temperatura corporal pode estabilizar-se, porém em nível mais elevado;

- Estresse severo: as reservas funcionais dos mecanismos termorregulatórios vão se tornando exaustos, e a temperatura corporal aumenta continuamente;

- Estresse excessivo: os mecanismos termorregulatórios tornam-se insuficientes, ocorrendo então uma hipertermia acentuada e o animal sucumbe em curto espaço de tempo.

Embora a temperatura retal aumente somente quando o THI se mostra superior a 80, a taxa respiratória apresenta-se alterada com THI igual a 73. Tal fato poderia indicar que o aumento verificado na freqüência respiratória poderia preveniria a elevação da temperatura retal até que o THI alcançasse o valor de 80 (Lemerle e Gooddard, 1986).

Quando se utilizou o SRAE associado à ventilação as vacas não apresentaram aumentos na temperatura retal, e foram registradas diminuições na taxa respiratória (Frazzi et al. 1997).

Turner et al. (1992) encontraram a temperatura retal média $0,58^{\circ} \mathrm{C}$ inferior, movimentos respiratórios $21,3 \%$ inferiores e a produção de leite $15,8 \%$ maior para os animais mantidos no tratamento com nebulização em relação aos animais do grupo controle. 
As vacas de alta produção, em início de lactação, são mais sensíveis ao estresse térmico, e a produção de leite diminui significativamente, quando a temperatura retal excede $39^{\circ} \mathrm{C}$ por mais de 16 horas (Igono et al., 1992).

\subsubsection{Freqüência respiratória}

Para se defender do estresse térmico, os bovinos recorrem a mecanismos adaptativos fisiológicos de perda de calor corporal para evitar a hipertermia. Desta forma, aumentam a freqüência respiratória, apresentando taquipinéia, como complemento na perda de calor por sudação, constituindo,ambos, meios importantes de perda de calor por evaporação (Baccari Junior, 2001).

Em condições de termoneutralidade, a freqüência respiratória normal da vaca em lactação varia de 18 a 28 movimentos por minuto e começa a elevarse significativamente a partir da temperatura crítica superior a $26^{\circ} \mathrm{C}$ (Anderson, 1988). Sob temperatura de $31^{\circ} \mathrm{C}$ e THI igual a 79 , vacas Holandesas apresentaram freqüência respiratória de 68 movimentos por minuto, com uma amplitude de variação de 44 a 108 (Baccari Junior et al., 1995).

Em condições subtropicais, os trabalhos realizados com vacas de alta produção relataram freqüência respiratória entre 50 a 60 movimentos por minutos quando a temperatura ambiente foi superior a $25^{\circ} \mathrm{C}$ (Berman et al., 1985).

De acordo com Hahn e Mader (1997), valores de freqüência respiratória de 60 movimentos por minutos indicam animais com ausência de estresse térmico ou este é mínimo, mas, quando ultrapassam 120 movimentos por minuto, refletem carga excessiva de calor e, acima de 160 movimentos por minuto, medidas de emergência devem ser tomadas para reduzir a carga de calor. A freqüência respiratória é mais elevada à tarde que de manhã, ou sob radiação solar direta que à sombra. 
O primeiro sinal visível de resposta ao estresse térmico é a taquipinéia, embora este seja o terceiro mecanismo na seqüência de adaptação fisiológica, pois a vasodilatação periférica e o aumento da sudorese ocorrem antes (Cunninghan, 1999).

O aumento da freqüência respiratória, quando considerada por curto período, caracteriza-se como um mecanismo eficiente de perda de calor. Entretanto, quando este mecanismo passa a ser exigido durante períodos prolongados, pode acarretar problemas aos animais, tais como: interferir na ingestão de alimentos e ruminação, proporcionar calor endógeno adicional em função da atividade muscular (ofegação), desviar energia de outros processos metabólicos e, ainda, redução da capacidade combinante do $\mathrm{CO}_{2}$ com conseqüente diminuição na concentração de ácido carbônico no sangue, resultando em alcalose respiratória (Benjamin, 1981).

As modificações ambientais proporcionadas pelo resfriamento evaporativo no freestall, em condições de estresse térmico, têm demonstrado efeitos positivos nas respostas fisiológicas das vacas em lactação (Turner, 1998; Nienaber et al., 1999; West, 2003).

O resfriamento evaporativo por aspersão conjugado à ventilação forçada, apontou benefícios quanto à freqüência respiratória. As vacas em lactação mantidas neste tratamento responderam mais rapidamente à queda dessa variável, sendo esta queda reduzida em $50 \%$, quando comparada à freqüência respiratória inicial (Brouk et al., 2003a).

\subsubsection{Temperatura da superfície do pelame}

As diferenças verificadas na atividade metabólica dos tecidos fazem com que a temperatura não seja homogênea no corpo todo e apresente variações de acordo com a região anatômica. A superfície corporal apresenta temperatura mais variável e mais sujeita às influências do ambiente externo (Silva, 2000). 
A pele protege o organismo do frio e do calor, e sua temperatura depende, principalmente, das condições de temperatura ambiente, umidade e características fisiológicas como vascularização e evaporação do suor. Desta forma, contribui para a manutenção da temperatura corporal mediante trocas de calor com o ambiente (Baccari Junior, 2001).

Os animais trocam calor por condução, convecção, radiação, evaporação da água e por meio do ar expirado. A troca de calor mediante a pele depende do gradiente de temperatura entre esta e o ar. A perda de calor por meios não evaporativos (trocas secas) diminui à medida que a temperatura crítica superior se eleva, fazendo com que as vacas se tornem dependentes da vasodilatação periférica e da evaporação da água para aumentar a dissipação de calor e prevenir o aumento da temperatura corporal. A taxa máxima de evaporação de água nas vacas em lactação corresponde a 1,5 kg por hora, que equivale a 4,3 kJ por dia (Berman et al., 1985).

A temperatura da pele de vacas Holandesas em lactação foi medida em dois ambientes térmicos. A condição quente foi considerada, quando a temperatura do ar estivesse entre 27 e $28^{\circ} \mathrm{C}$, e a condição fria foi considerada, quando a temperatura alcançasse 23 a $24^{\circ} \mathrm{C}$. Os resultados encontrados foram, respectivamente, 37,59 e $36,75^{\circ} \mathrm{C}$ (Cappa et al., 1989).

Os efeitos do sistema de resfriamento adiabático por aspersão associado à ausência ou presença de fluxo de ar (ventilação forçada) e seus reflexos sobre a temperatura da pele foram avaliados por Brouk et al. (2001). Os resultados apontaram que os tratamentos associados à ventilação foram responsáveis por menores temperaturas de pele.

É importante ressaltar que os efeitos evaporativos e convectivos na perda de calor não são facilmente separáveis. Assim, a velocidade do ar é um fator importante que influencia o processo de transferência evaporativa (Kadzere et al., 2002). 


\subsection{Consumo de alimentos, produção e composição do leite}

A principal razão para o decréscimo na produção de leite em climas quentes é a redução no consumo de alimentos, sendo esta uma tentativa do animal de minimizar o desbalanço térmico e manter a homeotermia (Yousef e Johnson, 1985).

A ingestão de alimentos das vacas em lactação começa a diminuir quando a temperatura ambiente está entre 25 e $26^{\circ} \mathrm{C}$, e esta queda é mais acentuada quando a temperatura é superior a $30^{\circ} \mathrm{C}$. A $40^{\circ} \mathrm{C}$, a ingestão da dieta declina em 40\% (NRC, 2001).

O estresse térmico em vacas de alta produção resulta em redução na ingestão de volumoso e tempo de ruminação. A diminuição na ingestão de volumoso contribui para o decréscimo na produção de ácidos graxos voláteis e pode proporcionar alterações na taxa acetato: propionato. Ocorrel ainda, diminuição no valor de pH ruminal (Collier et al., 1982). A redução na ingestão de alimentos sob condições de estresse resulta da elevação da temperatura corporal e pode estar relacionada ao enchimento do trato gastrintestinal (Silanikove, 1992).

O decréscimo no consumo de alimentos resultou em aumento das exigências em manutenção. As vacas leiteiras mantidas a $42^{\circ} \mathrm{C}$ por um período de seis horas apresentaram exigências nutricionais para manutenção $30 \%$ maior quando comparadas aos animais em condições termoneutras, havendo, desta forma, a necessidade de aumentar a densidade energética da ração (Head, 1995). Por outro lado, os ruminantes adaptados às condições quentes são capazes de manter sua ingestão próxima à exigência em manutenção ou em períodos de crescimento moderado (Brosh et al., 1988).

A fim de facilitar as trocas de calor e manter a temperatura corporal dentro dos padrões de normalidade, a ocorrência da vasodilatação periférica e do redirecionamento do fluxo sanguíneo dos órgãos internos para os tecidos periféricos irá proporcionar menor fluxo de sangue à veia porta (fígado) e a 
glândula mamária, conseqüentemente, menor quantidade de nutrientes e energia estarão disponíveis para a produção de leite (Shearer e Beede, 1990). Menores produções de leite e gordura foram verificadas em condição de temperatura ambiente elevada. Tais fatos foram atribuídos aos efeitos negativos do estresse térmico sobre a função secretória do úbere (Silanikove, 1992).

Quantificar os efeitos diretos do ambiente térmico sobre a produção de leite não é tarefa fácil, uma vez que esta é amplamente afetada por outros fatores, como por exemplo, o manejo nutricional (Fuquay, 1987).

O ponto na curva de lactação em que a vaca vivencia o estresse térmico é de suma importância na produção de leite total. As vacas são menos capazes de se recuperar do estresse térmico durante o início de lactação. Neste período, as vacas encontram-se em balanço energético negativo, mobilizando reservas corporais (Sharma et al. 1983).

O estresse brando deprimiu a produção diária de vacas Holandesas com produção média de $17 \mathrm{~kg}$ entre 3,6 a 4,5\% nas fases subseqüentes ao estresse, mas, após alguns dias de termoneutralidade, as vacas recuperaram total ou parcialmente a produção. Assim, as vacas puderam revelar uma capacidade de recuperação total ou parcial da produção sob estresse brando, contanto que tivessem permanecido anteriormente alguns dias sob condições de termoneutralidade (Aguiar et al., 1996).

As alterações verificadas na composição do leite compreendem decréscimos nos teores de gordura, lactose, proteína, ácido cítrico, cálcio e potássio (Head, 1989). Rodriguez et al. (1985) verificaram que com a elevação da temperatura de 6 para $36^{\circ} \mathrm{C}$, os teores de gordura e proteína diminuíram $0,54 \%$ e $0,44 \%$, respectivamente, para os animais mantidos a altas temperaturas. 


\subsection{Comportamento e bem-estar animal}

A resposta de um ser vivo ao ambiente no qual está inserido é geralmente adaptativa, ou seja, as possibilidades de sobrevivência da espécie são aumentadas se o animal consegue regular sua resposta de modo apropriado às mudanças das condições ambientais. Geralmente, essas reações são movimentos da totalidade ou parte de seu corpo ou mesmo da inatividade, a qual se mostra uma reação significativa, e diretamente relacionada à mudança no ambiente (Bowler, 1993).

Os homeotérmicos reagem às alterações do ambiente térmico, não só funcionalmente e estruturalmente, mas também por meio de respostas comportamentais Stoot (1981). As modificações comportamentais que ocorrem sob situações de estresse térmico visam a reduzir a produção ou promover a dissipação de calor (Pires et al., 1998b).

Os animais se comportam conforme determinados padrões. São definidos como um segmento organizado de atitudes que possui uma função especial. Determinada situação ambiental, normalmente, estimula mais que uma resposta comportamental, mas o animal aprende a empregar aquela que mais se mostra eficiente (Curtis, 1981).

Embora existam poucas referências sobre a extensão das mudanças comportamentais em condições de estresse térmico, fica claro que as alterações dos padrões usuais de ingestão de água e alimentos, postura e movimentação são importantes mecanismos adaptativos para reduzir o efeito do calor (Pires et al., 2000).

O objetivo primário de todos os animais é de se alimentarem, assim, os conceitos básicos de alimentação, associados ao conhecimento do comportamento animal, devem ser utilizados para melhorar seu bem-estar e produtividade. O consumo de alimentos é determinado pelo número de refeições diárias, pela duração de cada refeição e taxa de ingestão (Grant e Albrigth, 1995). Esses fatores dependem dos mecanismos orais, das 
características físicas e químicas dos alimentos, quantidade de nutrientes, disponibilidade de água, temperatura ambiente, predadores e competição com outros membros do grupo (Muller et al., 1994). Desta forma, não é explicado apenas pelos fatores fisiológicos, uma vez que tal comportamento é fortemente influenciado pelas inter-relações ambientais e sociais (Fraser e Broom, 1990).

O comportamento alimentar é afetado pelo clima e, em geral, o consumo de alimento diminui quando a temperatura ambiente ultrapassa $26^{\circ} \mathrm{C}$. Vale ressaltar, que, em condições de pastejo, esse efeito é ainda mais pronunciado (Beede e Collier, 1986). Vacas estabuladas apresentam de 10 a 12 períodos de alimentação, em média, 68\% deles correndo entre 6 e 18 horas. Próximo ao meio-dia, a maioria das atividades de alimentação é interrompida, e após 21 horas, menos de $10 \%$ dos animais são observados se alimentando (Vasilatos e Wangsness, 1980).

As vacas estabuladas passam em torno de 5 horas comendo, mas caso a proporção de concentrado na dieta seja aumentado, esse tempo pode ser reduzido. Embora o confinamento seja um ambiente diferente do natural, o ritmo diurno do padrão alimentar é semelhante àquele do pastejo, mas o tempo total de alimentação é sensivelmente inferior (Fraser e Broom, 1990)

De maneira geral, os animais tendem a reduzir a ingestão de volumoso, quando este é oferecido separadamente, sendo ainda observado um maior consumo nos períodos noturnos. Quando submetidos a pastejo, procuram evitar as horas mais quentes do dia. Também ocorre um aumento no número de visitas ao bebedouro, procura por sombra e, quando há disponibilidade de lagoas, os animais tendem a permanecer em pé na água, de modo a facilitar a perda de calor por condução (Pires et al., 2000).

A ruminação é uma atividade que permite a regurgitação, mastigação e a passagem do alimento previamente ingerido para o interior do rúmen. Durante a ruminação, deitadas ou em pé, as vacas ficam quietas e relaxadas com sua cabeça baixa e as pálpebras semicerradas. Geralmente, os bovinos preferem ruminar deitados, embora em condições ambientais desfavoráveis (ventos, 
chuvas) possam permanecer em pé ou caminhar lentamente. Quando deitados, utilizam a lateralidade esquerda como uma estratégia para otimizar o posicionamento do rúmen, e obter, assim, uma ruminação mais eficiente. $\mathrm{O}$ tempo total de ruminação pode variar de 4 a 9 horas, sendo dividido em períodos com duração de poucos minutos a uma hora ou mais (Albrigth, 1993).

O período que os animais não estão comendo, ruminando ou ingerindo água é definido como ócio. Os valores médios gastos nesta atividade estão entre 5h48min a $12 \mathrm{~h} 48 \mathrm{~min}$ por dia (Costa, 1995). Trabalho realizado com animais confinados em freestall apontou que $47,2 \%$ do tempo foi dedicado ao ócio, sendo que esse padrão não diferiu entre as estações.

Os animais podem ajustar-se ao ambiente térmico por meio de modificações posturais. Nas épocas quentes, tendem a deitar-se com os membros estirados para aumentar a superfície de contato com o piso frio. Também orientam seus corpos em relação ao sol para aumentar ou diminuir a área de exposição da superfície corporal. Assumem ainda, uma postura de relaxamento e minimizam as atividades físicas (Pires et al., 1998b).

Dentre os padrões fixos de comportamento, o de deitar é considerado de grande importância para as vacas leiteiras. A privação do descanso pode induzir à frustração que se manifesta por comportamentos estereotipados. Outras conseqüências incluem lesões traumáticas e outros danos físicos, resultando em problemas sanitários e baixo desempenho produtivo. O tempo de permanência na posição deitada, em um período de 24 horas, é, geralmente, em torno de 8 a 14 horas (Krohn e Munksgaard, 1993).

O sistema de produção freestall tem sido planejado para maximizar a densidade de animais e a eficiência de manejo, mas nem sempre proporciona condições de conforto para as vacas em lactação (Overton et al., 2002).

Uma instalação dimensionada de modo inadequado, e ainda associada às condições de temperatura elevada nas regiões tropicais, faz com que os animais apresentem modificações nas respostas comportamentais e, muitas vezes, decréscimos no desempenho produtivo. 
Em experimento conduzido por Frazzi et al. (1998) na Itália, em que os animais permaneciam sob ambiente climatizado durante os meses mais quentes do ano (julho a setembro), foram verificadas alterações comportamentais nos animais mantidos nesse tratamento. As vacas em lactação permaneceram por longos períodos descansando nas camas do freestall ou nas áreas adjacentes aos cochos de alimentação, semelhante ao que ocorre quando as temperaturas são mais amenas. Também permaneceram no interior do freestall nas horas mais quentes do dia, sempre para obter abrigo dos raios solares. Durante a noite, saíam à procura de um ambiente mais agradável. Sob estresse térmico, os animais permaneceram por muito mais tempo em pé que deitados.

A ventilação forçada, associada à nebulização em galpão do tipo freestall, teve seus reflexos avaliados no comportamento animal. Os animais do tratamento com nebulização apresentaram maior tempo despendido em pé, na área de alimentação. Esta se mostrou uma situação indicativa de estresse térmico, uma vez que as vacas tendem a ficar com maior área de superfície corporal exposta, a fim de facilitar as trocas de calor. Verificou-se que há a possibilidade de aliviar esses efeitos indesejáveis estendendo o sistema de resfriamento evaporativo nas demais instalações, como por exemplo, na sala de ordenha e área de descanso, evitando assim, que ocorra aglomeração na área de alimentação. Efeitos benéficos adicionais poderiam ser obtidos com 0 aumento do grau de umedecimento da superfície corporal dos animais (Calegari et al., 2003).

Em verdade, mediante diversas formas de comportamento, as vacas buscam seu bem-estar. Desta forma, cabe ao homem auxiliar os animais, provendo-lhes um ambiente de bem-estar, que seja ao mesmo tempo confortável e produtivo (Baccari Junior, 2001). 


\section{EFICIÊNCIA DA INTERMITÊNCIA DO SISTEMA DE RESFRIAMENTO ADIABÁTICO EVAPORATIVO POR ASPERSÃO EM FREESTALL E SUA INFLUÊNCIA NO CONFORTO TÉRMICO DE VACAS EM LACTAÇÃO}

\section{Resumo}

O trabalho teve como objetivo avaliar as intermitências de acionamento do sistema de resfriamento adiabático evaporativo (SRAE) por aspersão na linha de alimentação, em instalação do tipo freestall. Para a avaliação, utilizaram-se o índice de temperatura e umidade (THI) e o índice de globo negro e umidade $(B G H I)$ bem como as respostas fisiológicas de vacas em lactação. $O$ período de coleta dos dados teve duração de 116 dias durante os meses de janeiro a maio de 2003. Foram utilizadas 12 vacas lactantes, multíparas, com produção média de $30 \mathrm{~kg}$ de leite $\mathrm{dia}^{-1}$. Os tratamentos adotados foram as intermitências de acionamento de 12, 14 e 16 min e intervalo que o sistema permaneceu ligado foi igual em todos os tratamentos (1 min $25 \mathrm{seg}$ ). Os dados referentes à temperatura do bulbo seco (TBS), umidade relativa do ar (UR) e temperatura de globo negro (TGN) no interior da instalação e no ambiente externo foram mensurados em intervalo horário ao longo das 24 horas. A freqüência respiratória $(F R)$, temperatura retal $(T R)$ e temperatura da pele (TP) foram medidas diariamente, às 13,14, $15 \mathrm{e} 16 \mathrm{~h}$ em todos os animais submetidos aos tratamentos. As variáveis meteorológicas TBS $\left(31,5^{\circ} \mathrm{C}\right)$, TGN $\left(32,5^{\circ} \mathrm{C}\right)$ e os índices de conforto térmico THI $(79,1)$ e $\mathrm{BGHI}(80,9)$ foram maiores na intermitência de 12 min quando comparados aos demais tratamentos. A UR mostrou-se mais elevada no tratamento $14 \mathrm{~min}(60,3 \%) \mathrm{em}$ 
relação à intermitência de 12 min (51,0\%). Para as variáveis fisiológicas, verificou-se que as vacas em lactação que receberam o tratamento $12 \mathrm{~min}$ apresentaram maior valor de $\operatorname{TR}\left(39,1^{\circ} \mathrm{C}\right)$ e $\mathrm{FR}\left(76,0 \mathrm{mov} \mathrm{min}^{-1}\right)$ quando comparado ao tratamento $16 \mathrm{~min}$. O intervalo de $16 \mathrm{~min}$ resultou em menor consumo de água, devendo ser empregado a fim de evitar desperdícios desnecessários pelo sistema de climatização.

\section{SPRINKLING FREQUENCY OF ADIABATIC EVAPORATIVE COOLING SYSTEM IN FREESTALL AND ITS EFFECTS ON THERMAL COMFORT IN DAIRY COW}

\section{Summary}

This work aimed to evaluate the effect of sprinkling frequency of adiabatic evaporative cooling system within feed line of a freestall in relation to temperature and humidity index ( $\mathrm{THI}$ ) and black globe temperature index (BGHI) and physiological responses in dairy cows. Data were registered during 116 days from January to May 2003. Twelve multiparous dairy cows with mean milk production of $30 \mathrm{~kg} \mathrm{day}^{-1}$ were used. Treatments were sprinkling frequencies every 12,14 or 16 minutes in sprinkler system with the same non-intermittent interval (85 seconds). Dry bulb temperature (DBT), air relative humidity $(\mathrm{RH})$ and black globe temperature (BGT) inside and outside of facilities were measured hourly through a period of 24 hours. Respiratory frequency (RF), rectal temperature (RT) and skin temperature (ST) were taken at 13, 14, 15 and $16 \mathrm{~h}$ in all the animals submitted to the treatments. The meteorological variables, DBT $\left(31.5^{\circ} \mathrm{C}\right)$ and BGT $\left(32.5^{\circ} \mathrm{C}\right)$, and the indexes of thermal comfort, THI (79.1) and $\mathrm{BGHI}$ (80.9), were higher with 12 minutes of sprinkling frequency when compared to other treatments. The $\mathrm{RH}$ was higher (60.3\%) with 14 minutes than with 12 minutes $(51.0 \%)$. In relation to physiological parameters, lactating cows with 12 minutes had higher rectal temperature $\left(39.1^{\circ} \mathrm{C}\right)$, respiratory frequency 
(76.0 mov $\mathrm{min}^{-1}$ ) when compared to with 16 minutes. To avoid unnecessary wastes should be used the interval of 16 min that resulted in the smallest amount of water consumed by the sprinkling cooling system.

\subsection{Introdução}

A produção de leite em ambiente tropical pode ser potencializada com a adoção de tecnologias que possibilitem o manejo estratégico do rebanho. Disponibilizar aos animais água limpa e abundante, sombra e ventilação adequada, devem ser práticas comuns para aliviar os efeitos do estresse térmico.

Em condições de confinamento, as vacas em lactação permanecem a maior parte do tempo no freestall, deixando a instalação somente nos horários da ordenha. Neste caso, é de fundamental importância proporcionar um ambiente confortável aos animais, já que a ausência de um sistema de resfriamento efetivo pode acarretar prejuízos ao desempenho animal (Brouk et al. 2001a).

O controle eficiente do ambiente pode empregar sistemas naturais e artificiais. Inúmeros métodos têm sido desenvolvidos para modificar o ambiente no qual o animal está inserido, visando a minimizar o efeito do estresse térmico. A movimentação do ar, o umedecimento da superfície do animal, o resfriamento evaporativo do ar e o uso de sombras para minimizar o efeito da radiação solar, são artifícios empregados para potencializar a dissipação de calor (Igono et al., 1985; Turner et al.,1992; West, 2003).

O sistema de resfriamento adiabático evaporativo (SRAE) tem se expandido rapidamente em climas quentes, devido à sua simplicidade técnica, praticidade e relação custo: benefício favorável, resultando na sua aceitação por muitos produtores (Strickland et al., 1988; Lin et al., 1998).

O resfriamento evaporativo utiliza a evaporação da água para reduzir a temperatura do ar, embora proporcione aumento na umidade relativa. O grau de 
resfriamento é influenciado pela temperatura e umidade. Sendo assim, a temperatura do ar elevada, associada à baixa umidade relativa, possibilitará grande redução na temperatura ambiente. Por outro lado, nas condições em que a temperatura e umidade do ar forem elevadas, poderá ocorrer limitação na aplicação desse sistema, uma vez que o ar saturado irá inibir a evaporação da água pela pele e respiração, proporcionando um ambiente ainda mais estressante para o animal. Quando a umidade relativa é superior a $70 \%$, o potencial de redução no THI é inferior a 10\% (Brouk et al., 2001b).

Poucos trabalhos descrevendo os efeitos do resfriamento evaporativo têm sido conduzidos em regiões de umidade relativa elevada. Os sistemas de resfriamento em que os aspersores funcionam de maneira intermitente, ou seja, são acionados durante determinado intervalo e então desligados enquanto os ventiladores movimentam grandes volumes de ar ao redor dos animais, tem se mostrado bastante eficiente (Turner et al. 2001).

Diferentes intervalos de acionamento para a aspersão foram avaliados por Hillman et al. (2001). Os tratamentos foram: sem molhar, molhando a cada 20 e $40 \mathrm{~min}$. A água era aplicada durante 1,5 min até que o excesso escorresse pelo flanco da vaca, e as intermitências eram associadas a diferentes fluxos de ar: desligado, 0,$1 ; 0,9 \mathrm{~m} \mathrm{~s}^{-1}$ e $2,2 \mathrm{~m} \mathrm{~s}^{-1}$. A temperatura da pele caiu rapidamente, quando a intermitência foi 20 min e fluxo de ar igual a $2,2 \mathrm{~m} \mathrm{~s}^{-1}$.

$A$ aspersão de água sobre o animal resfria imediatamente a superfície do corpo em até $4^{\circ} \mathrm{C}$ e reduz a taxa respiratória a 18 movimentos por min. A perda de calor por evaporação é favorecida, quando a pele está molhada, representando $82 \%$ da perda total. Estimou-se em $0,9 \mathrm{~L}$ o volume de água exigido para saturar o pêlo do dorso de uma vaca Holandesa de $600 \mathrm{~kg}$. Os bicos devem ter uma taxa de 0,45 a $1,9 \mathrm{~L} \min ^{-1}$ e o tempo de aspersão de água deve ser de 0,5 a 2 min (Chastain e Turner, 1994).

Quando a aspersão é associada à ventilação, ocorre inicialmente o umedecimento do pêlo do animal, seguido da remoção da camada de ar da 
superfície da pele. Dessa forma, as taxas de evaporação são favorecidas, menores temperaturas de pele e corporal são verificadas (Stowell et al., 2003). Por outro lado, estudos realizados por Miltlöhner et al. (2000), os quais avaliaram o efeito da aspersão direta sobre os animais, adotando um fluxo de $5,7 \mathrm{~L} \mathrm{~min}^{-1}$ a cada intervalo de $30 \mathrm{~min}$, não verificaram respostas positivas com o resfriamento evaporativo para as variáveis fisiológicas.

Cabe ressaltar que o SRAE por aspersão utiliza grandes volumes de água. Portanto, deveria ser empregado o intervalo com a menor taxa de aplicação de água, a fim de se evitar desperdícios desnecessários e ainda preservar esse recurso natural. No resfriamento usado por Strickland et al. (1988), foram empregados $454,2 \mathrm{~L}$ por vaca por dia, totalizando $54504 \mathrm{~L}$ por vaca para o período de 120 dias na estação de verão.

A eficiência do SRAE por aspersão ou nebulização, associada à ventilação forçada na linha de alimentação, foi avaliada nas condições brasileiras (região Sudeste) por Perissinotto (2003). De acordo com os resultados obtidos, o consumo de água mensal pelo sistema de aspersão foi cerca de 11 vezes maior em relação ao sistema de nebulização, sendo que foram consumidos aproximadamente $276 \mathrm{~L}_{\text {animal }}{ }^{-1} \mathrm{dia}^{-1}$, utilizando-se 0 sistema de aspersão e cerca de $24 \mathrm{~L}_{\text {animal }}{ }^{-1} \mathrm{dia}^{-1}$ com o sistema de nebulização.

Desta forma, o trabalho teve como objetivo avaliar as intermitências de acionamento do sistema de resfriamento adiabático evaporativo (SRAE) por aspersão na linha de alimentação, em instalação do tipo freestall, usando os índices de conforto térmico ( $\mathrm{THI}$ e $\mathrm{BGHI}$ ) e as repostas fisiológicas de vacas em lactação. 


\subsection{Material e Métodos}

\subsubsection{Local e duração do experimento}

O trabalho foi conduzido com rebanho comercial de gado Holandês, localizado no município de São Pedro, SP, a altitude de $580 \mathrm{~m}$, coordenadas

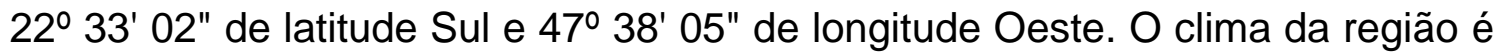
do tipo Cwa da classificação Köppen, ou seja, quente e úmido com estação chuvosa no verão e seco no inverno. A temperatura média anual é de $22^{\circ} \mathrm{C}$, a pluviosidade média anual está próxima de $1200 \mathrm{~mm}$ e os ventos são predominantes do sudeste.

O período experimental teve a duração de 116 dias nos meses de janeiro a maio de 2003, nos quais foram registrados dados de temperatura do bulbo seco (TBS), umidade relativa do ar (UR) e temperatura de globo negro (TGN). Porém, em função da variação climática, principalmente da precipitação ocorrida durante o período experimental, a avaliação dos dados foi realizada considerando-se os dias críticos, adotando-se o conceito da entalpia.

\subsubsection{Caracterização dos animais e manejo}

Foram utilizadas 12 vacas Holandesas, multíparas, em lactação, com peso médio de $600 \mathrm{~kg}$ e produção média de $30 \mathrm{~kg}$ de leite por dia. Os animais foram mantidos em abrigo do tipo freestall, nos quais receberam os tratamentos.

A instalação apresentava as seguintes características construtivas: 120 $\mathrm{m}$ de comprimento e $28 \mathrm{~m}$ de largura, laterais abertas, orientação leste-oeste, corredor central de 3,0 m, pé-direito central de $9 \mathrm{~m}$, telhado de duas águas com cobertura de telha de barro e sistema de lanternim vazado. O piso era de concreto e apresentava ranhuras de $0,5 \mathrm{~cm}$ espaçadas $7 \mathrm{~cm}$ entre si (Figura 4). 

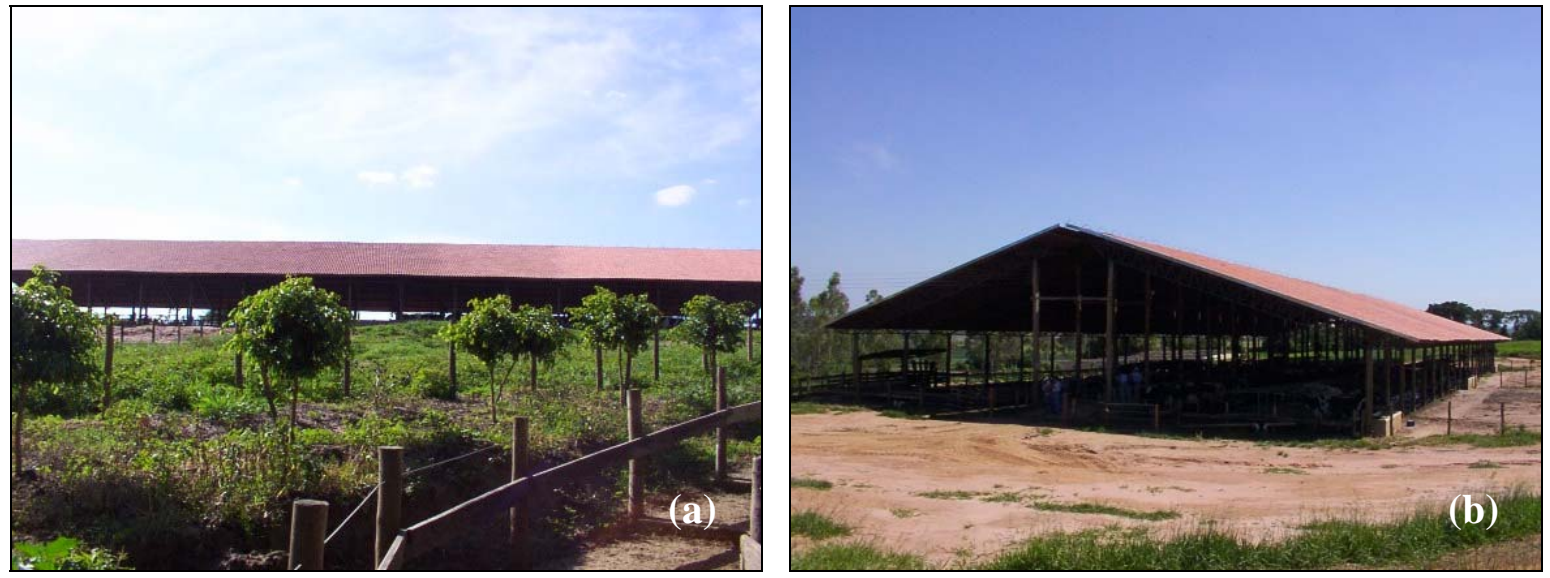

Figura 4 - Vista longitudinal (a) e transversal (b) do freestall

A linha de alimentação tinha a extensão de todo galpão. Os bebedouros eram de alvenaria, localizados estrategicamente nas laterais do galpão, com dimensões de 2,8 $\mathrm{m}$ de comprimento, $0,8 \mathrm{~m}$ de largura e capacidade de $0,8 \mathrm{~m}^{3}$ (Figura 5).
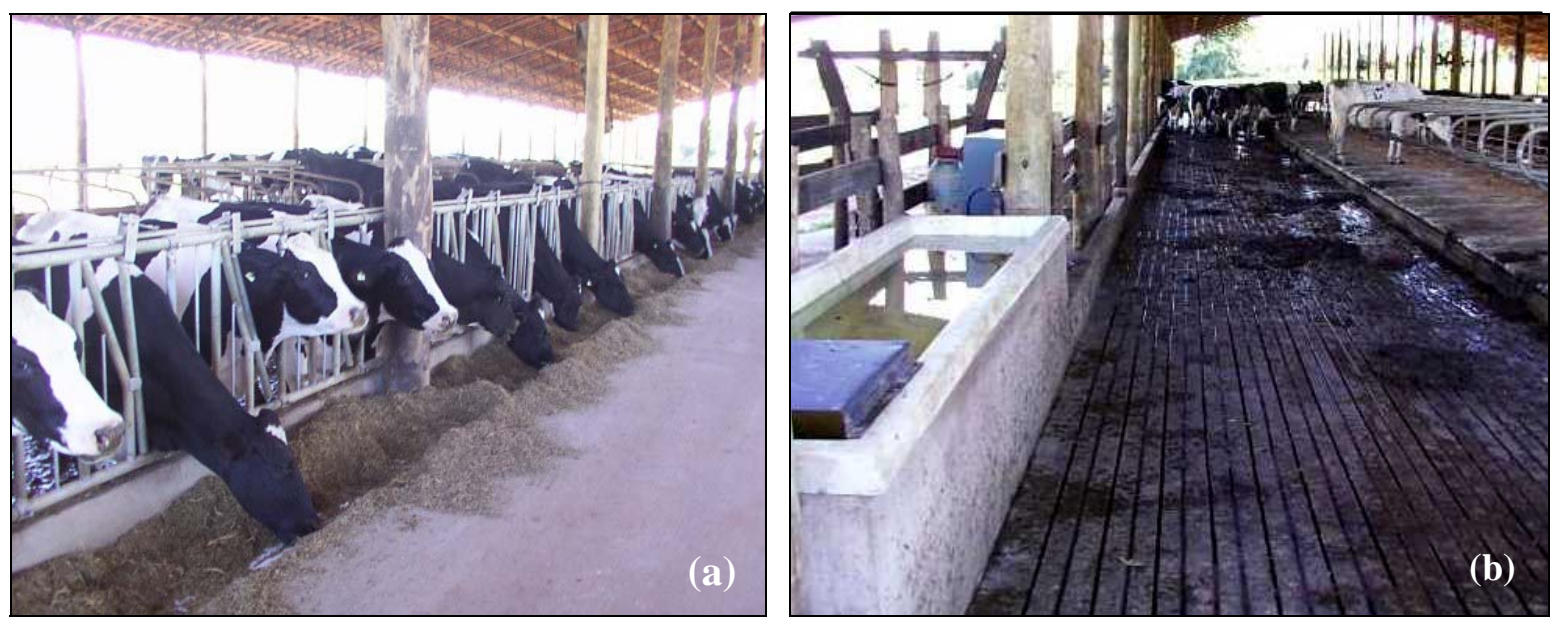

Figura 5 - Vista da linha de alimentação (a) e do bebedouro localizado na lateral do freestall (b)

O manejo dos animais durante a fase experimental consistiu em dois horários de alimentação ( 7 e 15 h), a qual foi fornecida na forma de dieta 
completa composta de silagem de Tifton, polpa cítrica, silagem de milho, milho úmido, silagem de alfafa pré-secada, caroço de algodão e concentrado. A dieta foi formulada de maneira a atender as exigências nutricionais para a manutenção e produção de leite, de acordo com o NRC (2001). Os animais foram ordenhados e suas produções registradas, diariamente, três vezes ao dia (2, 10 e $18 \mathrm{~h})$.

\subsubsection{Tratamentos}

O freestall foi dividido em quatro seções com 72 baias cada, utilizadas para cada período do experimento, duas seções $(\underline{C}, \underline{D})$, onde foram alocados seis animais em cada uma delas. A Figura 6 ilustra as seções do freestall em que os animais foram distribuídos e a vista frontal com detalhe dos equipamentos que compunham o SRAE.

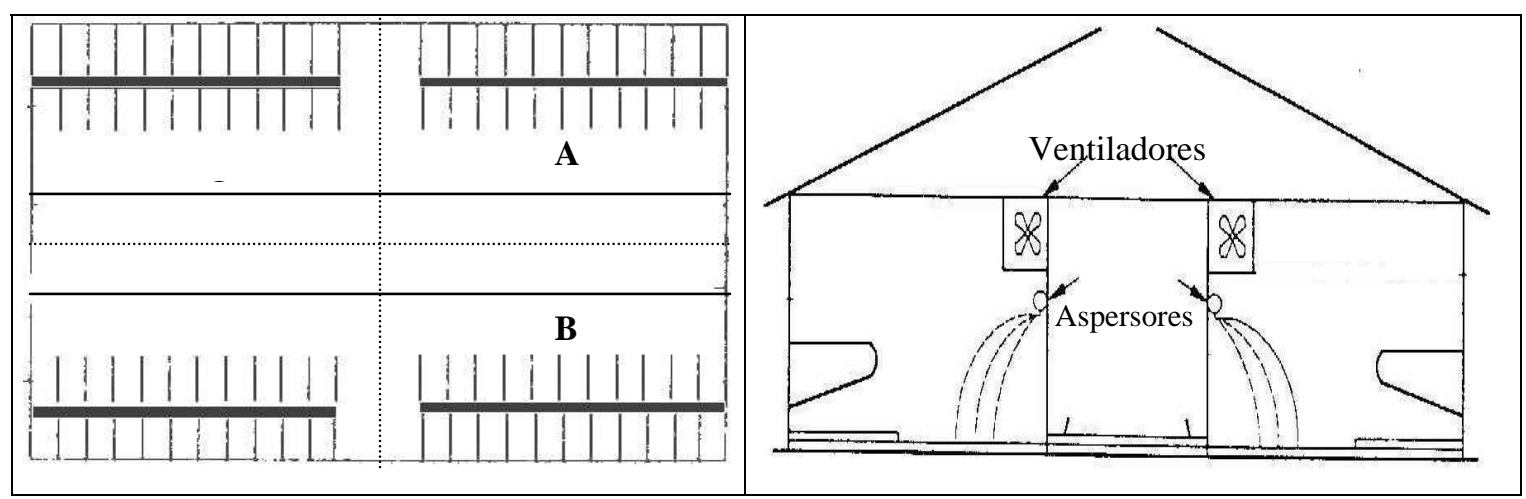

Figura 6 - Representação esquemática das seções utilizadas no experimento

Os tratamentos foram aplicados de maneira aleatória em três períodos, de modo que cada tratamento foi avaliado para o período em questão:

> Período 1: aplicação do tratamento com intermitência de 12 min;

> Período 2: aplicação do tratamento com intermitência de $16 \mathrm{~min}$;

> Período 3: aplicação do tratamento com intermitência de 14 min. 
A intermitência é o ciclo completo entre o acionamento do SRAE, período de pausa e novo acionamento. Na pesquisa, este ciclo variou entre 12, 14 e 16 min. O período em que o sistema permaneceu ligado foi igual em todos os tratamentos, em que os bicos aspersores ficaram ligados 1 min25seg seguidos de um período de pausa de $10 \mathrm{~min} 35 \mathrm{seg}$, totalizando um ciclo de $12 \mathrm{~min}$, e, assim sucessivamente de acordo com a Tabela 1.

Tabela 1. Descrição dos intervalos de intermitência

\begin{tabular}{lcc}
\hline Intermitência & Acionamento & Pausa \\
\hline 12 min & $1 \mathrm{~min} 25 \mathrm{seg}$ & $10 \mathrm{~min} 35 \mathrm{seg}$ \\
$14 \mathrm{~min}$ & $1 \mathrm{~min} 25 \mathrm{seg}$ & $12 \mathrm{~min} 35 \mathrm{seg}$ \\
16 min & $1 \mathrm{~min} 25 \mathrm{seg}$ & $14 \mathrm{~min} 35 \mathrm{seg}$ \\
\hline
\end{tabular}

\subsubsection{Sistema de resfriamento}

O sistema de aspersão foi montado 2,5 m acima da linha de alimentação e constituído por tubo PVC, com espaçamento entre bicos de $1 \mathrm{~m}$. A vazão de água na linha de aspersão foi de $30 \mathrm{~L} \mathrm{hora}^{-1} \mathrm{em}$ todos os tratamentos (Figuras 7 e 8). Foram utilizados ventiladores com diâmetro de 0,9 m, espaçados a cada 11 $\mathrm{m}$, equipados com motor de $1 / 4 \mathrm{CV}$, vazão de $300 \mathrm{~m}^{3}$ hora $^{-1}$, $495 \mathrm{RPM}$, com capacidade de produzir movimentação de ar de até $2,5 \mathrm{~m} \mathrm{~s}^{-1}$ na altura do dorso do animal. 

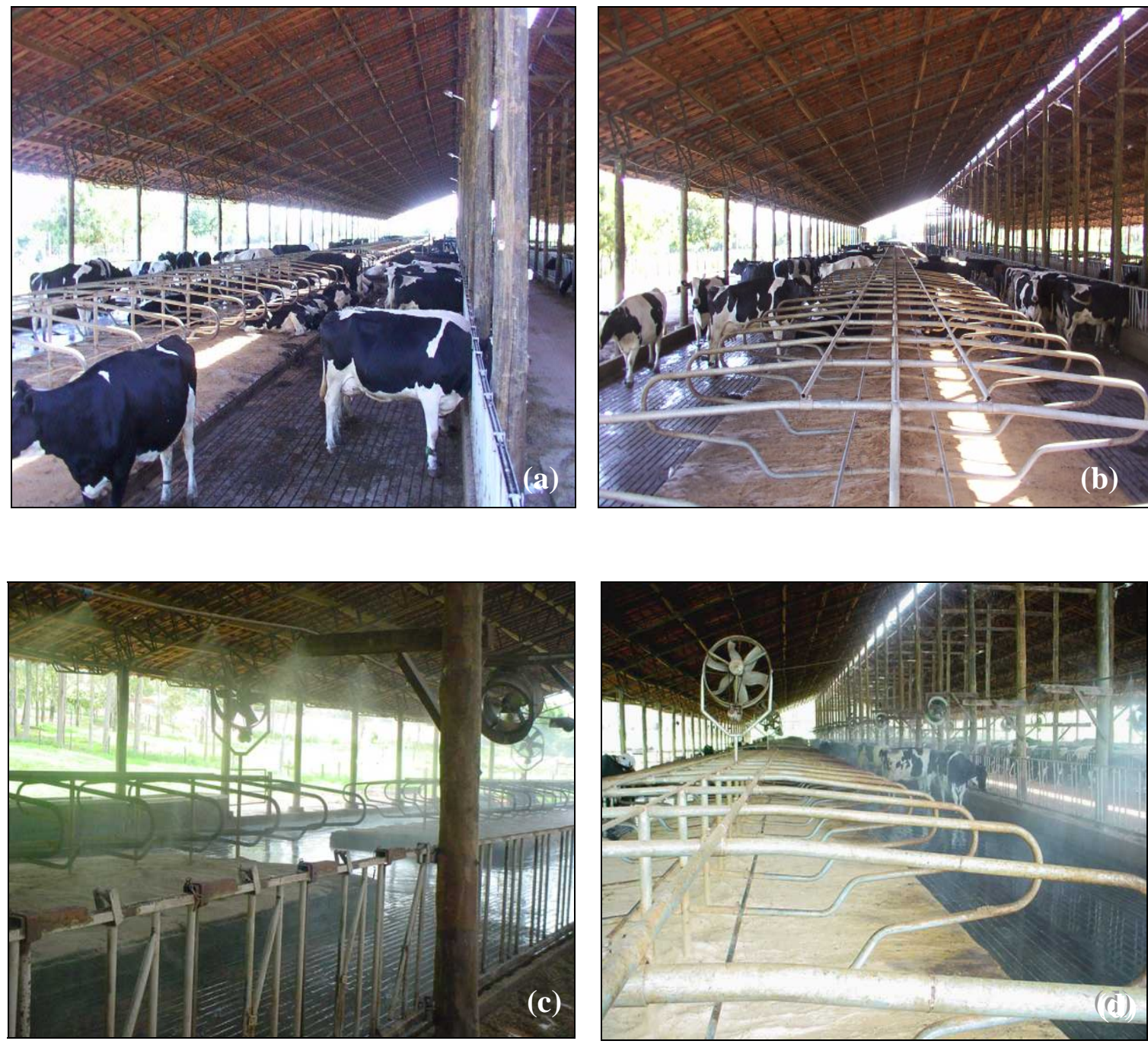

Figura 7 - Vista do freestall antes (a, b) e após (c, d) a implantação do sistema de resfriamento

\subsubsection{Variáveis meteorológicas}

As variáveis registradas no interior do freestall e no ambiente externo foram à temperatura do bulbo seco (TBS), umidade relativa do ar (UR\%) e temperatura do globo negro (TGN). As leituras foram realizadas a cada $15 \mathrm{~min}$ ao longo das 24 horas por sensores acoplados a um sistema eletrônico de aquisição de dados $\left(\mathrm{HOBO}{ }^{\circledR} \mathrm{H} 8\right)$. A estação automática foi fixada a altura de 2,5 $\mathrm{m}$ do piso, a fim de protegê-la dos animais (Figura 8). 

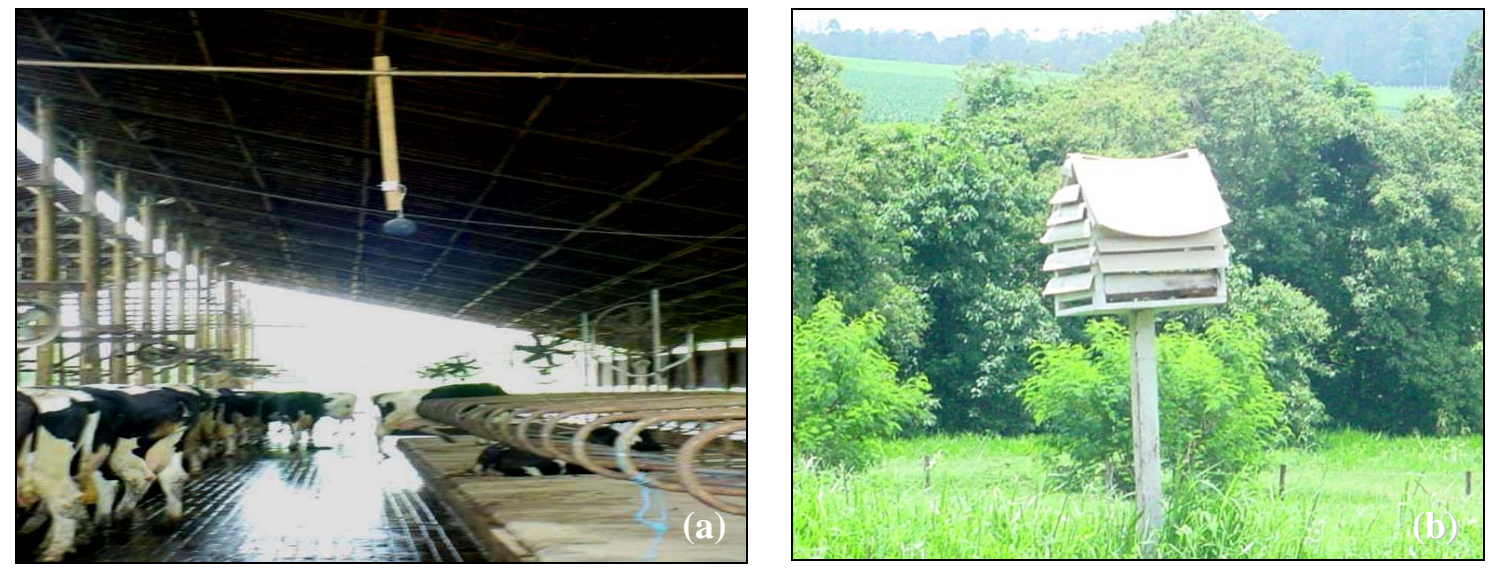

Figura 8 - Vista dos sistemas eletrônicos de aquisição de dados meteorológicos instalados no ambiente interno (a) e externo ao freestall (b)

Para a avaliação do conforto térmico de vacas leiteiras, foi realizada a seleção dos dias críticos, baseados no conceito de entalpia, a qual representa a quantidade total de calor presente em uma massa de ar seco, sendo expressa em $\mathrm{kJ} \mathrm{kg} \mathrm{ar} \mathrm{seco-1.} \mathrm{De} \mathrm{acordo} \mathrm{com} \mathrm{a} \mathrm{zona} \mathrm{de} \mathrm{termoneutralidade} \mathrm{proposta} \mathrm{por}$ Johnson e Vanjonack (1976), a entalpia crítica ocorre quando a TBS é igual ou superior a $24^{\circ} \mathrm{C}$ e a UR igual a $76 \%$.

Para as condições do presente trabalho, este valor foi estimado em 63,0 $\mathrm{kJ} \mathrm{kg}$ ar $\operatorname{seco}^{-1}$, o qual foi calculado por meio do programa computacional PsyCalc $98^{\circledR}$, considerando a pressão barométrica local igual a $708 \mathrm{~mm} \mathrm{Hg}$.

A partir dos valores encontrados para as variáveis meteorológicas TBS, UR e TGN foi calculado o índice de temperatura e umidade (THI), proposto por Thom (1959) e o índice de globo negro e umidade (BGHI) de acordo com Buffington et al. (1981). Todas as avaliações foram realizadas no período crítico do dia, no horário das 13 às 16 horas. 


\subsubsection{Variáveis Fisiológicas}

\subsubsection{Temperatura Retal}

A medida da temperatura retal (TR) foi realizada durante cinco dias às $13,14,15$ e $16 \mathrm{~h}$ nos 12 animais submetidos ao tratamento. A TR foi tomada com termômetro clínico digital, inserido no reto do animal.

\subsubsection{Temperatura da superfície do pelame}

A medida da temperatura do pelame (TP) foi tomada na região dorsolombar do animal, na malha negra durante cinco dias às $13,14,15$ e $16 \mathrm{~h}$ nos 12 animais submetidos ao tratamento. A leitura foi realizada com termômetro de infravermelho empregando-se o valor de emissividade igual a 0,9 $(\varepsilon=0,9)$ para as medidas no pelame negro, conforme Baêta e Souza (1985). Tal procedimento foi adotado, uma vez que a coloração das vacas era predominantemente negra.

\subsubsection{Freqüência Respiratória}

A freqüência respiratória $(F R)$ foi realizada durante cinco dias às 13,14 , 15 e $16 \mathrm{~h}$ nos 12 animais submetidos ao tratamento, mediante a contagem dos movimentos na região do flanco, durante 15 segundos.

\subsubsection{Análise estatística}

Para a análise das variáveis ambientais (TBS, UR, THI, BGHI, TGN e Entalpia) adotou-se um delineamento experimental em blocos casualizados, com os dias sendo usados como repetições. O modelo de análise incluiu como causas de variação os tratamentos (12 min, 14 min e 16 min), os horários (13, 
14, 15 e 16 horas) e a interação entre os tratamentos e os horários. Além desses fatores incorporou-se ao modelo a covariável TBS, UR THI BGHI ou TGN visando padronizar as respostas médias, já que os períodos de observação dos tratamentos não foram simultâneos.

Para as variáveis fisiológicas (TR, FR e TP) adotou-se um delineamento experimental inteiramente casualizado com os animais sendo usados como repetições. O modelo incluiu como causas de variação, os tratamentos (12 min, 14 min e 16 min), os horários (13, 14, 15 e 16 horas) e a interação entre os tratamentos e os horários.

Quando a interação foi significativa, ela foi desdobrada com o intuito de comparar os efeitos dos tratamentos em cada horário, utilizando o teste $t$ de Student, e comparar os efeitos dos horários de avaliação em cada tratamento, utilizando a análise de regressão (contrastes ortogonais).

As análises foram realizadas com o procedimento para modelos mistos (proc mixed) do SAS (1998), admitindo-se um modelo com medidas repetidas no tempo.

\subsection{Resultados e Discussão}

\subsubsection{Variáveis meteorológicas}

O período experimental foi caracterizado pela ocorrência de chuvas. As precipitações diárias foram registradas por meio de um pluviômetro localizado na fazenda. De acordo com a Figura 10, verificou-se que $52 \%$ das chuvas foram concentradas no mês de janeiro $(410 \mathrm{~mm}), 43 \%$ em fevereiro (401 mm), $35 \%$ em março (178 mm) e 13\% no mês de abril (98 mm). 


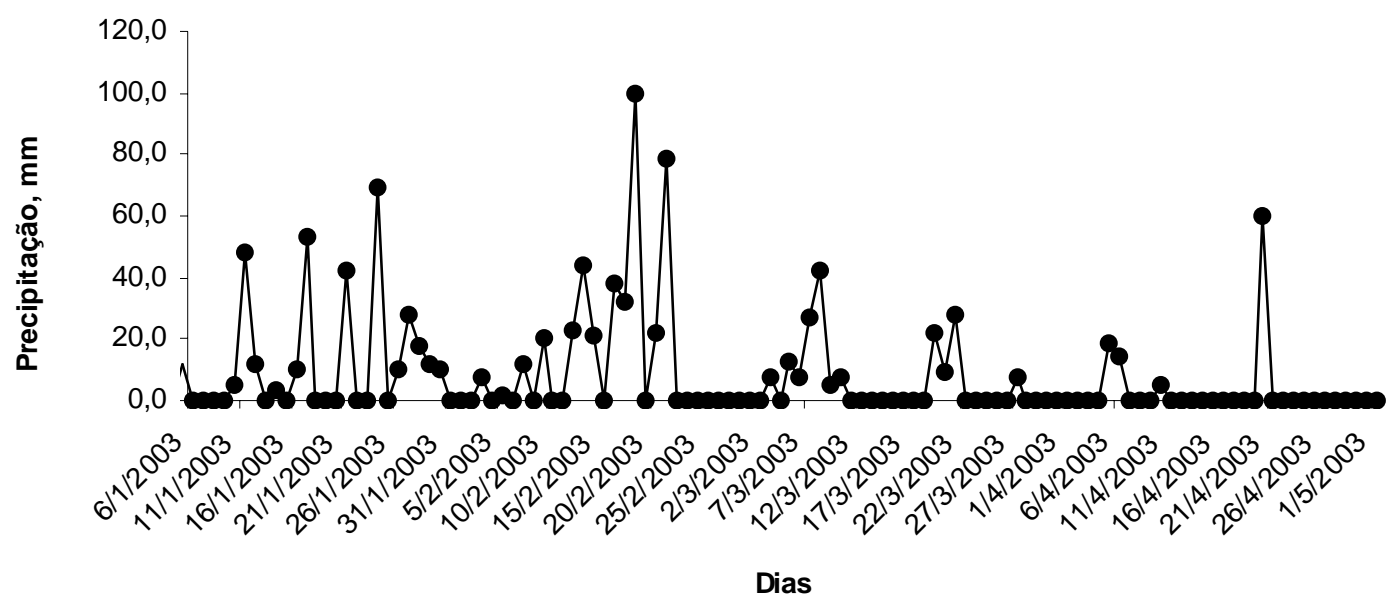

Figura 9 - Precipitações $(\mathrm{mm})$ registradas durante o período experimental

Em função da pluviosidade, ocorreu limitação na utilização do resfriamento adiabático evaporativo, de modo que o sistema não foi acionado diariamente. Desta forma, foram selecionados, para a avaliação do conforto térmico de vacas leiteiras, apenas os dias críticos, sendo estes, caracterizados pela entalpia elevada, cujo valor foi determinado como $63,0 \mathrm{~kJ} \mathrm{~kg} \mathrm{ar} \mathrm{seco-1}$, conforme descrito anteriormente no item 3.2.5.

A Tabela 2 apresenta os valores médios da temperatura de bulbo seco, umidade relativa, temperatura de globo negro, temperaturas mínima e máxima, índice de temperatura e umidade, índice de temperatura de globo negro e umidade e entalpia, registrados durante os períodos estudados.

Quando considerada a faixa de termoneutralidade entre 4 e $26^{\circ} \mathrm{C}$ para a temperatura ambiente (Huber, 1990), verificou-se que os valores médios registrados para esta variável no tratamento $12 \mathrm{~min}$, excederam as condições de conforto térmico, sendo estes superiores até mesmo ao ambiente externo à instalação. A umidade relativa mostrou-se elevada em todos os tratamentos, de maneira geral, os níveis de umidade relativa acima de $50 \%$ reduzem os fatores produtivos em qualquer faixa de temperatura (Nääs e Souza, 2003). 
Tabela 2. Valores médios diários das variáveis meteorológicas e índices de conforto térmico registrados durante o período experimental

\begin{tabular}{lcccc}
\hline Variáveis meteorológicas & \multicolumn{4}{c}{ Tratamentos } \\
\hline & Externo & $12 \mathrm{~min}$ & $14 \mathrm{~min}$ & $16 \mathrm{~min}$ \\
Temperatura de bulbo seco, ${ }^{\circ} \mathrm{C}$ & $24,9 \pm 4,91$ & $27,1 \pm 3,63$ & $23,5 \pm 3,71$ & $24,0 \pm 3,49$ \\
Umidade relativa, \% & $72,9 \pm 19,43$ & $69,9 \pm 16,39$ & $74,9 \pm 14,17$ & $79,3 \pm 13,94$ \\
Temperatura de globo negro, ${ }^{\circ} \mathrm{C}$ & $28,3 \pm 8,68$ & $27,4 \pm 3,86$ & $23,7 \pm 4,01$ & $22,7 \pm 3,74$ \\
Índice de temperatura e umidade & $72,9 \pm 5,07$ & $75,7 \pm 3,50$ & $71,3 \pm 4,02$ & $72,4 \pm 3,81$ \\
Índice de globo negro e umidade & $72,1 \pm 13,35$ & $76,3 \pm 3,73$ & $71,9 \pm 4,31$ & $71,4 \pm 3,83$ \\
Entalpia, kJ kg de ar seco-1 & $77,5 \pm 6,88$ & $83,1 \pm 4,10$ & $75,0 \pm 6,34$ & $78,6 \pm 3,49$ \\
Temperatura mínima, o & $16,4 \pm 4,91$ & $21,3 \pm 3,63$ & $17,5 \pm 3,71$ & $18,3 \pm 6,48$ \\
Temperatura máxima, ${ }^{\circ} \mathrm{C}$ & $36,6 \pm 4,91$ & $33,6 \pm 3,63$ & $30,3 \pm 3,71$ & $31,1 \pm 3,49$ \\
\hline
\end{tabular}

Para o índice de temperatura e umidade, os valores considerados para que as vacas expressem seu máximo potencial produtivo estaria entre 72 unidades, nas condições experimentais, tais situações foram verificadas apenas com a adoção dos tratamentos 14 e 16 min de intermitência.

Sabe-se que os efeitos das condições climáticas sobre o desempenho de vacas leiteiras são marcantes, principalmente nas regiões tropicais e subtropicais. O conhecimento das relações funcionais entre o animal e o meio ambiente permite adotar procedimentos que elevam a eficiência da exploração leiteira (Damasceno et al., 1999).

A Tabela 3 apresenta os valores médios das variáveis meteorológicas e índices de conforto térmico registrados nos tratamentos avaliados no intervalo das 13 às 16 horas. 
Tabela 3. Valores médios e erros padrão da média das variáveis meteorológicas e índices de conforto térmico registrados no intervalo horário das 13 às 16 horas durante o período experimental.

\begin{tabular}{lccc}
\hline Variáveis meteorológicas & \multicolumn{3}{c}{ Tratamentos } \\
\hline & $12 \mathrm{~min}$ & $14 \mathrm{~min}$ & $16 \mathrm{~min}$ \\
Temperatura de bulbo seco, 으 & $31,5 \pm 0,55 \mathrm{a}$ & $28,8 \pm 0,50 \mathrm{~b}$ & $28,9 \pm 0,54 \mathrm{~b}$ \\
Umidade relativa, \% & $51,0 \pm 1,80 \mathrm{a}$ & $60,3 \pm 1,90 \mathrm{~b}$ & $54,6 \pm 1,70 \mathrm{ab}$ \\
Temperatura de globo negro, ${ }^{\circ} \mathrm{C}$ & $32,5 \pm 0,60 \mathrm{a}$ & $27,5 \pm 0,59 \mathrm{~b}$ & $29,2 \pm 0,66 \mathrm{~b}$ \\
Índice de temperatura e umidade & $79,1 \pm 0,46 \mathrm{a}$ & $77,6 \pm 0,38 \mathrm{~b}$ & $77,1 \pm 0,45 \mathrm{~b}$ \\
Índice de globo negro e umidade & $80,9 \pm 0,52 \mathrm{a}$ & $76,5 \pm 0,59 \mathrm{~b}$ & $77,4 \pm 0,51 \mathrm{~b}$ \\
Entalpia, kJ kg de ar seco-1 & $70,5 \pm 1,43 \mathrm{a}$ & $71,1 \pm 1,42 \mathrm{a}$ & $67,0 \pm 1,68 \mathrm{a}$
\end{tabular}

$\overline{\mathrm{a}, \mathrm{b}}$ Médias seguidas por letras minúsculas distintas nas linhas diferem entre si pelo Teste $t$ de Student $(\mathrm{P}<0,05)$.

\subsubsection{Temperatura de bulbo seco (TBS)}

Foram constatadas diferenças $(P<0,05)$ entre os tratamentos para a TBS. A interação tratamento $x$ horário de avaliação não foi significativa $(P>0,05)$, portanto, calculou-se, a média geral dos tratamentos (Figura 10).

Esta variável mostrou-se mais elevada no tratamento 12 min $\left(31,5^{\circ} \mathrm{C}\right)$, quando comparada com os tratamentos $14 \mathrm{~min}\left(28,8^{\circ} \mathrm{C}\right)$ e $16 \mathrm{~min}\left(28,9^{\circ} \mathrm{C}\right)$. Entretanto, os tratamentos 14 e 16 min não diferiram entre si. Provavelmente, essa variação deve-se ao fato de que nesses tratamentos, ocorreu uma evaporação mais rápida, ocasionando a retirada de calor sensível do ar, conseqüentemente, com maior potencial de redução na TBS. 


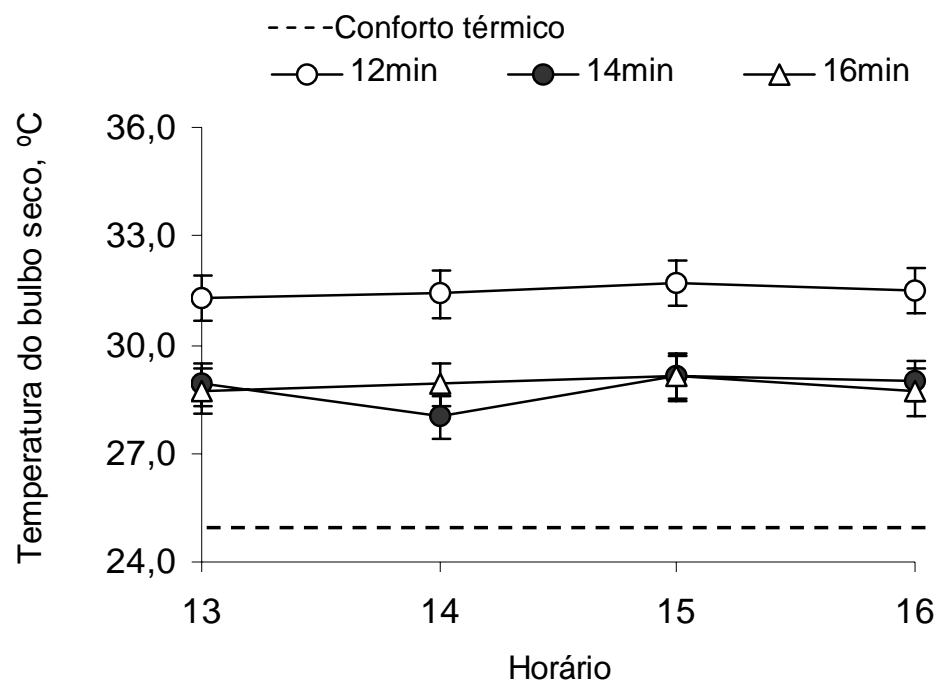

Figura 10 - Valores médios e erro padrão da média da temperatura de bulbo seco nos diferentes tratamentos e horários avaliados

A adoção dos diferentes intervalos de acionamento do SRAE não reduziu a TBS para os níveis de conforto térmico. Entretanto, os resultados obtidos estão de acordo com Bucklin e Bray (1998), pois o sistema de aspersão não tem a finalidade de resfriar o ar, e sim de usar gotas largas de água para molhar o pêlo e a pele, melhorando a sensação térmica das vacas em lactação. Já nos sistemas de nebulização, pequenas gotas de água são aspergidas no ar, resfriando-o, à medida que evaporam. Trabalhos realizados por Turner (1998) apontaram redução na temperatura ambiente em até $4^{\circ} \mathrm{C}$.

Verificou-se, nas condições do presente experimento, que os valores da TBS estiveram acima da faixa de termoneutralidade proposta pela literatura. Fuquay (1987) considerou para o gado europeu valor de temperatura crítica superior entre 25 a $27^{\circ} \mathrm{C}$. Já para Berman et al. (1985), a temperatura crítica superior estaria entre 25 a $26^{\circ} \mathrm{C}$ para vacas em lactação, independente destas de terem sido submetidas à aclimatação prévia, ou nível de produção.

O SRAE geralmente resulta em grandes volumes de águas residuais as quais devem ser processadas. Desta forma, sugere-se que o resfriamento 
deveria ser empregado com a menor taxa de aplicação de água, a fim de se evitar desperdícios desnecessários e ainda preservar esse recurso natural. No resfriamento usado por Strickland et al. (1988) foram empregados 454,2 L por vaca por dia, totalizando $54504 \mathrm{~L}$ por vaca para o período de 120 dias na estação de verão.

Means et al. (1992) avaliaram três taxas de água (313,4; 492,9 e 704,1 L hora $^{-1}$ ) no sistema de aspersão em freestall para vacas em lactação. Os animais eram aspergidos durante 1,5 minutos em cada ciclo de 15 minutos quando a temperatura interna do freestall era superior a $25,6^{\circ} \mathrm{C}$. Os resultados indicaram que a produtividade e o conforto térmico (temperatura retal e taxa respiratória) não foram alterados com a aplicação dos tratamentos.

No presente experimento, a vazão de água empregada foi igual em todos os tratamentos, ou seja, $0,71 \mathrm{~L}$ foram aspergidos no ambiente durante $\mathrm{o}$ intervalo de $1 \mathrm{~min} 25 \mathrm{seg}$, totalizando 42,6 L por hora. Considerando o período de uma hora, e empregando o intervalo de $12 \mathrm{~min}$, o sistema seria acionado cinco vezes, o que resultaria no consumo de 3,6 L por hora. No caso da intermitência de 14 min, o sistema seria acionado 4,3 vezes e, para o intervalo de 16 minutos, seria ligado 3,8 vezes, sendo gastos, respectivamente, $3,1 \mathrm{~L}$ e 2,7 $\mathrm{L}$ de água por hora. No período em questão, o sistema ficou ligado em média nove horas por dia. Dessa forma, tem-se o consumo médio de 32,0 L, 27,5 L e 24,3 L de água por vaca por dia, respectivamente, para os tratamentos $12 \mathrm{~min}, 14 \mathrm{~min}$ e $16 \mathrm{~min}$. Esses valores inferiores ao utilizado pelos autores supracitados.

As recomendações iniciais para a intermitência de acionamento do SRAE sugeriram que o intervalo deveria ser de 15 minutos (Means et al., 1992; Harner et al., 1999; Brouk et al., 2001b). Entretanto, os trabalhos realizados posteriormente, revelaram que estratégias distintas de resfriamento deveriam ser adotadas para diferentes níveis de estresse térmico. Sob condições de estresse severo, a intermitência de cinco minutos, associada à ventilação forçada, seria bastante efetiva. Por outro lado, em período de estresse moderado, a intermitência de dez minutos seria adequada. $O$ aumento no 
intervalo de acionamento, quando as temperaturas são mais amenas, resultaria em decréscimo significativo no uso da água (Frazzi et al., 1998; Brouk et al., 2003a).

\subsubsection{Umidade relativa (UR)}

Foram encontradas diferenças $(\mathrm{P}<0,05)$ entre os tratamentos para a UR. Esta variável mostrou-se mais elevada no tratamento $14 \mathrm{~min}(60,3 \%)$, quando comparada ao tratamento 12 min $(51,0 \%)$. Os resultados obtidos para a análise entre os horários de avaliação apresentaram efeito linear $(P<0,05)$ para todos os tratamentos (Figura 11).

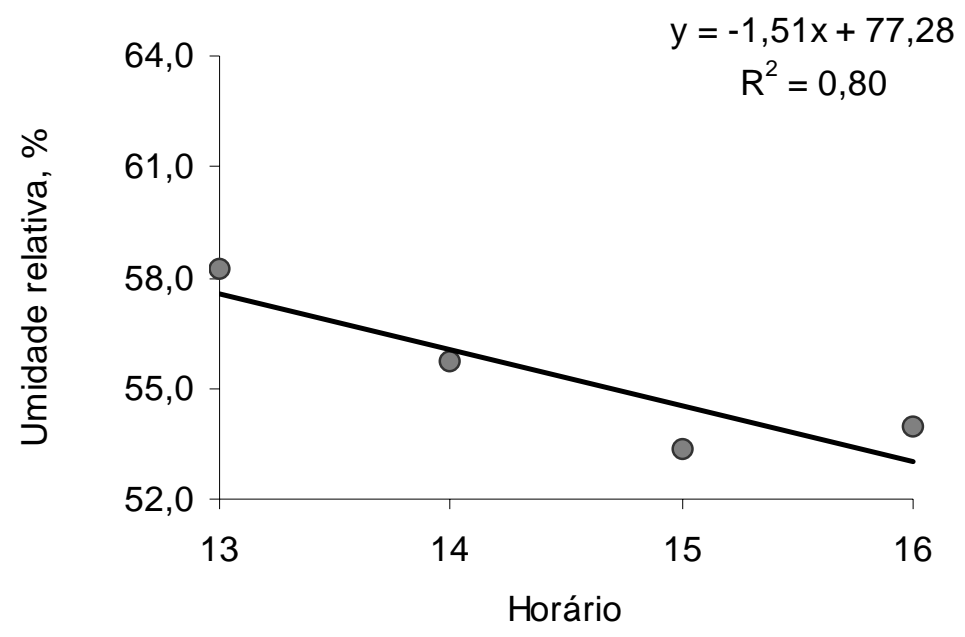

Figura 11 - Equação de regressão ajustada para a UR em função dos horários de avaliação para todos os tratamentos

De maneira geral, os intervalos de intermitência estudados não resultaram em umidade excessiva, ou seja, maior que $70 \%$ dentro da instalação. O volume de água utilizado no sistema de aspersão teve como objetivo o umedecimento da pele/pêlo dos animais. O consumo de água foi 32,0 
L; 27,5 L e 24,3 L por vaca por dia, respectivamente, para os tratamentos 12 $\min , 14 \min$ e 16 min.

Temperatura ambiente e umidade relativa elevada poderiam limitar o desempenho das vacas confinadas, pois diminuem sua habilidade em dissipar calor. Essa redução nas trocas térmicas irá proporcionar aumento na temperatura corporal devido ao armazenamento de calor (Davis, 2001).

Trabalhos realizados por Arcaro Junior et al. (2002) verificaram umidade relativa elevada com emprego do SRAE. Os valores encontrados foram 45,6; 38,9 e $79,8 \%$, respectivamente, para os tratamentos controle, ventilação e ventilação associada à aspersão. Deve-se ressaltar, que neste caso, o SRAE foi aplicado na sala de espera, sendo a instalação parcialmente fechada, o que pode ter contribuído para o aumento da umidade relativa.

Em períodos de temperaturas elevadas e com ocorrência de chuvas, situações características do verão nas condições tropicais, o SRAE poderia aumentar excessivamente a umidade relativa dentro da instalação. Essa umidade deve ser removida por meio de trocas de ar na instalação com um sistema de ventilação adequado (Silva, 1999).

Os sistemas de resfriamento que funcionam de maneira intermitente, ou seja, são acionados durante determinado intervalo e então desligados enquanto os ventiladores movimentam grandes volumes de ar ao redor dos animais, tem se mostrado bastante eficientes (Turner, 2001).

\subsubsection{Temperatura de globo negro (TGN)}

Foram verificadas diferenças $(P<0,05)$ entre os tratamentos para a TGN. A interação tratamento $x$ horário de avaliação não foi significativa $(P>0,05)$, portanto, calculou-se, a média geral dos tratamentos (Figura 12). O tratamento 12 min $\left(32,5^{\circ} \mathrm{C}\right)$ apresentou TGN mais elevada quando comparado ao tratamento $14 \min \left(27,5^{\circ} \mathrm{C}\right)$ e $16 \mathrm{~min}\left(29,2^{\circ} \mathrm{C}\right)$, sendo que esses últimos não diferiram entre si. (Figura 12). 
O termômetro de globo negro fornece, em uma só medida, a indicação dos efeitos combinados da temperatura do ar, temperatura radiante $\mathrm{e}$ velocidade do vento (Bond e Kelly, 1955). Absorve a radiação infravermelha e provê uma medida indireta do calor radiante do ambiente.

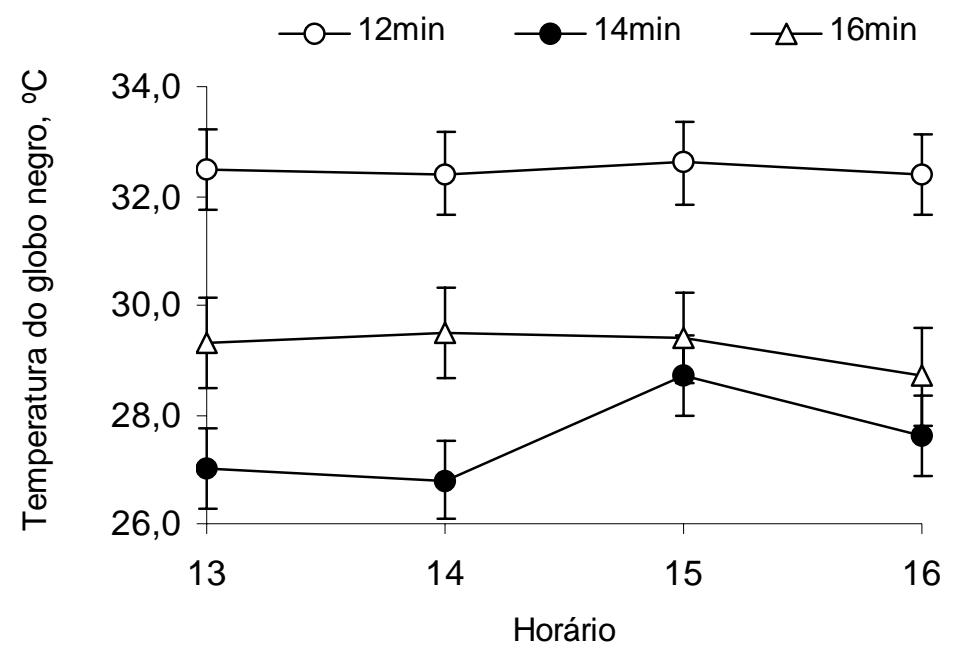

Figura 12 - Valores médios e erro padrão da média da temperatura de globo negro nos diferentes tratamentos e horários avaliados

Os valores de TGN apresentaram o mesmo comportamento verificado para a TBS. Constatou-se mais uma vez que as condições do ambiente foram superiores a zona de termoneutralidade dos animais. Possivelmente, os menores valores de TGN obtidos para os tratamentos 14 min e 16 min podem estar associados ao efeito convectivo promovido pela presença de ventilação nesses tratamentos.

As instalações devem proporcionar abrigo aos animais, de modo que possibilitem o controle de elementos climáticos, principalmente da temperatura ambiente que leva ao conforto térmico, daí a importância da utilização de abrigos bem planejados, quando se deseja aumentar a produção leiteira em ambientes tropicais (Perissinotto, 2003). 


\subsubsection{4 Índice de temperatura e umidade (THI)}

Foram constatadas diferenças $(\mathrm{P}<0,05)$ entre os tratamentos para o $\mathrm{THI}$. A interação tratamento $x$ horário de avaliação não foi significativa $(P>0,05)$, portanto, calculou-se, a média geral dos tratamentos. Este índice mostrou-se mais elevado no tratamento 12 min $(79,1)$ quando comparado ao tratamento 14 min $(77,6)$ e 16 min $(77,0)$, sendo que esses últimos não diferiram entre si. Não foram encontradas diferenças $(P>0,05)$ dentro do mesmo tratamento nos horários de avaliação (Figura 13).

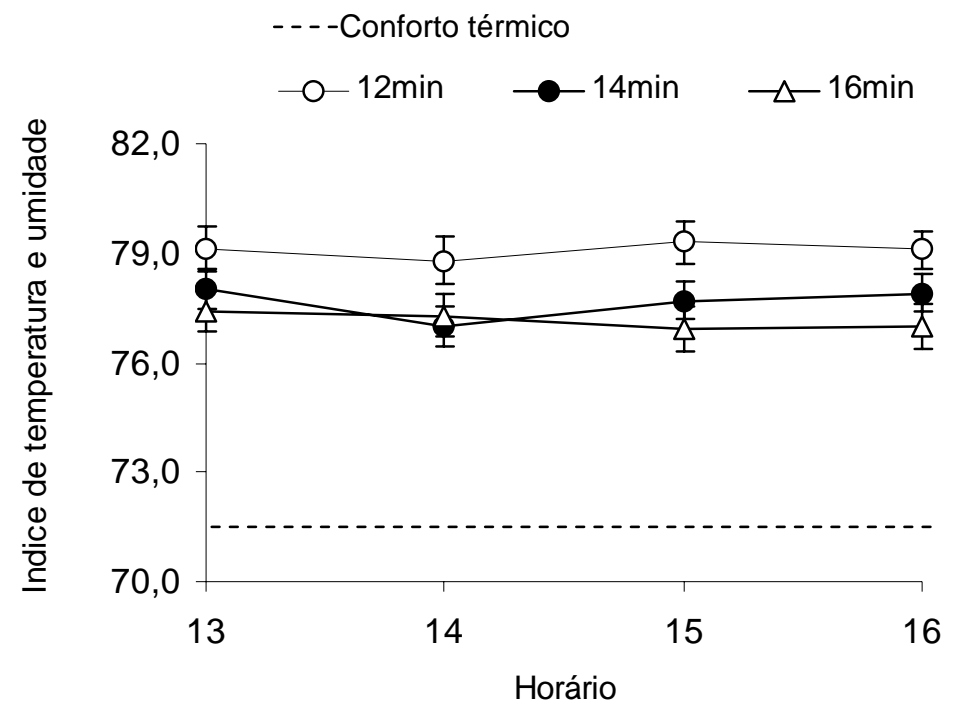

Figura 13 - Valores médios e erro padrão da média do índice de temperatura e umidade nos diferentes tratamentos e horários avaliados

Existem vários relatos sobre os limites do THI. O trabalho clássico de Johnson (1980) relatou que, a partir do valor de 72 unidades, e à medida que este se elevou, a produção de leite foi declinando, sendo este declínio mais acentuado em vacas de alta produção. Quanto maior a produção de leite de uma vaca, maior sua taxa metabólica e maior também sua susceptibilidade ao estresse térmico. O declínio acentuou-se a partir de valores entre 76 e 78. 
Trabalhos realizados posteriormente determinaram que os valores críticos para o mínimo, médio e máximo THI seriam, respectivamente, 64, 72 e 76 (Igono e Johnson, 1992). O estresse severo pode levar os animais a óbito, quando o THI for superior a 84 e se não ocorrer recuperação durante o período noturno, ou seja, se o THI não for inferior a 74 (Hahn e Mader, 1997).

Os valores do $\mathrm{THI}$ aqui verificados permaneceram na faixa considerada crítica, e o maior valor de THI encontrado para a intermitência de 12 min devese possivelmente a TBS elevada registrada nesse tratamento.

De maneira geral, constatou-se que os equipamentos de climatização não possibilitaram o condicionamento ambiental satisfatório nas horas mais quentes do dia, culminando com valores de TBS e THI acima dos recomendados pela literatura. Esse fato confirma que o SRAE por aspersão realmente não tem a finalidade de promover melhorias no ambiente físico da instalação.

\subsubsection{5 Índice de globo negro e umidade (BGHI)}

Foram observadas diferenças $(P>0,05)$ entre os tratamentos para 0 BGHI. A interação tratamento $x$ horário de avaliação não foi significativa ( $P>0,05)$, portanto, calculou-se, a média geral dos tratamentos (Figura 14).Tal

índice apresentou-se mais elevado no tratamento $12 \mathrm{~min}(80,9)$, quando comparado ao tratamento $14 \mathrm{~min}(76,5)$ e $16 \mathrm{~min}(77,4)$, sendo que esses últimos não diferiram entre si.

O BGHI apresentou o mesmo comportamento verificado para a TGN, assim, o maior valor determinado para a intermitência de 12 min estaria associada à TGN elevada registrada nesse tratamento. O BGHI foi reduzido em 4,4 e 3,5 unidades em relação à intermitência de $12 \mathrm{~min}$, respectivamente, quando empregados os intervalos de 14 e 16 min. 


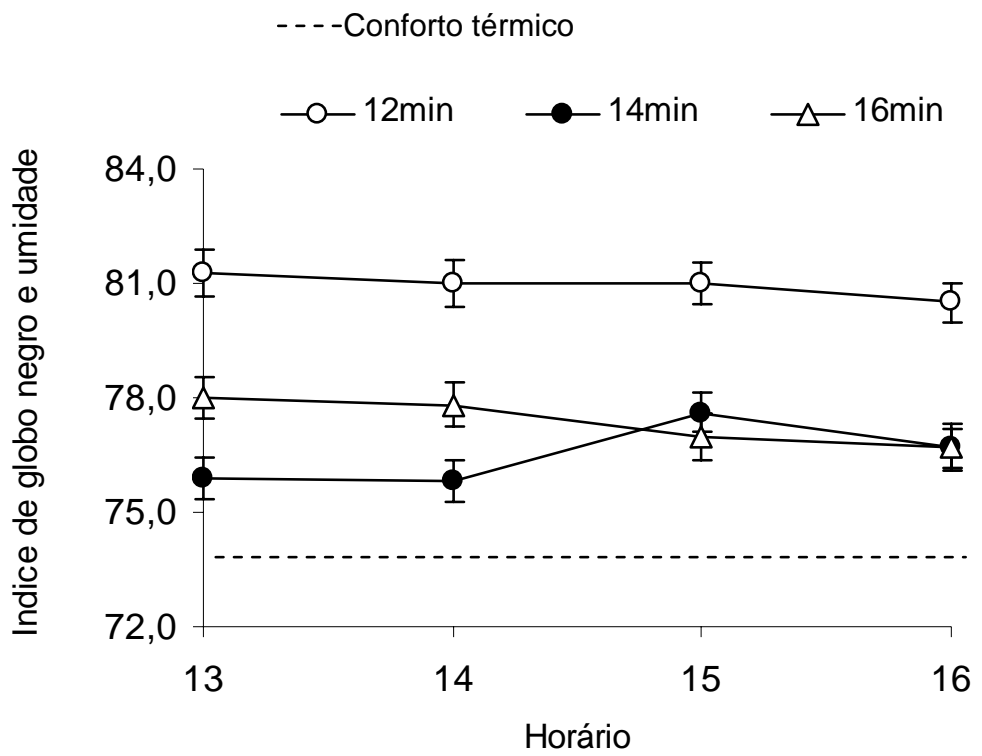

Figura 14 - Valores médios e erro padrão da média do índice de globo negro e umidade nos diferentes tratamentos e horários avaliados

Conforme citado por Baêta e Souza (1985), os valores de BGHI até 74 definem condição de conforto para os bovinos, entre 75 e 78 a situação é de alerta, 79 a 84 caracterizam perigo e acima deste, depara-se com situação de emergência.

Já quando empregado o SRAE por nebulização, Martello (2002) reportou menores valores para o $\mathrm{BGHI}$, sendo esses correspondentes a 77, 74,7 e 77,8 unidades, respectivamente, para o tratamento sem climatização, nebulização e malha de sombreamento.

\subsubsection{Entalpia (H)}

A quantidade de calor presente na massa de ar seco, que é expressa pela variável $H$, não diferiu $(P>0,05)$ entre os tratamentos. Os valores médios encontrados foram 70,$5 ; 71,1$ e $67,9 \mathrm{~kJ} \mathrm{~kg}$ de ar seco $^{-1}$, respectivamente, para os tratamentos 12, 14 e 16 min. Os resultados observados entre os horários de 
avaliação mostraram efeito linear $(\mathrm{P}<0,05)$ para todos os tratamentos (Figura 15).

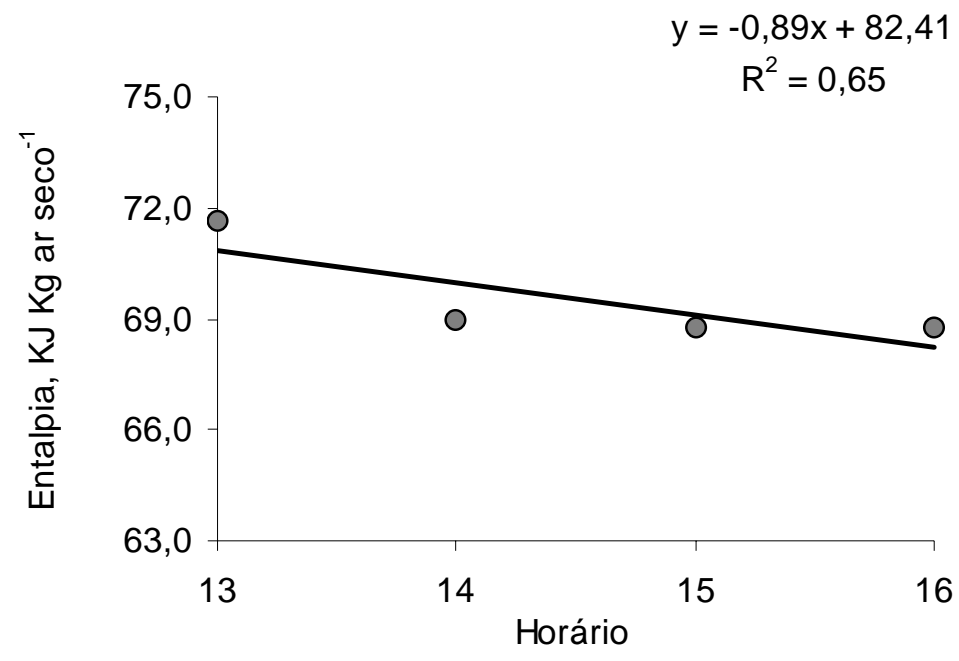

Figura 15 - Equação de regressão ajustada para a $\mathrm{H}$ em função dos horários de avaliação para todos os tratamentos

De acordo com a Johnson e Vanjonack (1976), a entalpia crítica ocorreria quando a TBS fosse igual ou superior a $24^{\circ} \mathrm{C}$ e a UR igual a $76 \%$. Nas condições do presente experimento, a entalpia verificada na faixa de termoneutralidade descrita corresponderia a $63,0 \mathrm{KJ} \mathrm{Kg}$ ar seco-1, conforme a pressão baromérica local igual a $708 \mathrm{~mm} \mathrm{Hg}$.

Os resultados obtidos apontaram valores de $\mathrm{H}$ superiores aos sugeridos pela literatura. Verificou-se $\mathrm{H}$ elevada às $13 \mathrm{~h}(70,84 \mathrm{KJ} \mathrm{Kg}$ ar seco-1 $)$ seguido de decréscimo nos horários seguintes, em que se determinou 69,9; 69,1 e 68,2 $\mathrm{KJ} \mathrm{Kg}$ ar seco-1 $^{-1}$, respectivamente às 14,15 e $16 \mathrm{~h}$. Nestas situações, os tratamentos adotados não foram significativos, a ponto de promover mudanças na quantidade de calor no interior do freestall. Provavelmente, a eficiência desses sistemas esteja relacionada com o efeito convectivo promovido pela movimentação de ar e na evaporação do vapor d'água, a qual deveria ser 
aumentada, a fim de facilitar a dissipação do calor gerado no microclima interno da instalação.

Em função dos resultados encontrados não apresentarem diferenças entre os tratamentos para a quantidade de calor existente no microclima do freestall, deve-se considerar o menor consumo de água e energia despendidos pelos sistemas de climatização e adotar a intermitência de 16 minutos.

As estratégias de manejo ambiental têm sido amplamente difundidas, no sentido de melhorar as condições de conforto animal, em função da susceptibilidade dos animais às influências das variáveis meteorológicas prejudicar seu desempenho.

Quando um animal é mantido em ambiente inadequado, os diversos constituintes de meio, isolados ou combinados entre si, são fatores de estresse, que, atuando sobre o organismo, desencadeiam uma série de reações não específicas de adaptação, ativando mecanismos físicos e fisiológicos, na tentativa de restabelecer o equilíbrio orgânico (Costa e Silva, 2003).

\subsubsection{Variáveis fisiológicas}

\subsubsection{Temperatura retal (TR)}

A medida da temperatura retal é usada freqüentemente como índice de adaptabilidade fisiológica aos ambientes quentes, pois seu aumento mostra que os mecanismos de liberação de calor tornaram-se insuficientes para manter a homeotermia (Mota, 1997). Na Tabela 4 são apresentados os valores médios e erros padrão da média verificados para a temperatura retal (TR) durante 0 período experimental. 
Tabela 4. Valores médios e erros padrão da média de temperatura retal (TR) das vacas em lactação mensuradas das 13 às $16 \mathrm{~h}$

\begin{tabular}{lcccccl}
\hline TR & $13 \mathrm{~h}$ & $14 \mathrm{~h}$ & $15 \mathrm{~h}$ & $16 \mathrm{~h}$ & Média & Efeito \\
\hline 12 min & $39,0 \pm 0,11 \mathrm{a}$ & $39,1 \pm 0,11 \mathrm{a}$ & $39,3 \pm 0,11 \mathrm{a}$ & $39,1 \pm 0,11 \mathrm{a}$ & $39,1 \pm 0,10$ & Cúbico $^{1}$ \\
14 min & $38,8 \pm 0,11 \mathrm{a}$ & $38,7 \pm 0,11 \mathrm{~b}$ & $38,8 \pm 0,11 \mathrm{~b}$ & $38,8 \pm 0,11 \mathrm{ab}$ & $38,8 \pm 0,10$ & NS \\
16 min & $38,8 \pm 0,11 \mathrm{a}$ & $38,7 \pm 0,11 \mathrm{~b}$ & $38,7 \pm 0,11 \mathrm{~b}$ & $38,7 \pm 0,11 \mathrm{~b}$ & $38,7 \pm 0,10$ & Linear $^{2}$ \\
\hline
\end{tabular}

$\bar{a}, \mathrm{~b}$, Médias seguidas por letras minúsculas distintas nas colunas diferem pelo Teste $t$ de Student $(\mathrm{P}<0,05)$; ${ }^{1} Y=-0,08 x^{3}+3,55 x^{2}-50,17 x+274,30\left(R^{2}=0,99\right)$

${ }^{2} Y=-0,03 x+39,16\left(R^{2}=0,60\right)$

A análise dos dados identificou a presença de interação entre tratamento e hora $(P<0,05)$. Sendo assim, os tratamentos apresentaram comportamentos diferentes sobre a TR, em função dos horários em que foram avaliados. $O$ desdobramento da interação mostrou-se significativo $(\mathrm{P}<0,05)$ para os horários das 14,15 e $16 \mathrm{~h}$. Quando os animais foram submetidos ao tratamento $12 \mathrm{~min}$, os valores de TR foram maiores $\left(39,1^{\circ} \mathrm{C}\right)$ do que quando aplicados os tratamentos $14 \min \left(38,7^{\circ} \mathrm{C}\right)$ e $16 \mathrm{~min}\left(38,7^{\circ} \mathrm{C}\right)$; esse efeito foi verificado para $\mathrm{o}$ horário das $14 \mathrm{~h}$ e $15 \mathrm{~h}$. Por outro lado, às $16 \mathrm{~h}$, os animais mantidos no tratamento 12 min apresentaram maior TR $\left(39,1^{\circ} \mathrm{C}\right)$, quando comparados com a aplicação do intervalo de $16 \mathrm{~min}\left(38,7^{\circ} \mathrm{C}\right)$.

Os resultados observados entre os horários de avaliação revelaram efeito cúbico $(\mathrm{P}<0,05)$ para $\mathrm{o}$ tratamento $12 \mathrm{~min}$ e linear $(\mathrm{P}<0,05)$ para 0 tratamento 16 min (Figura 16). 


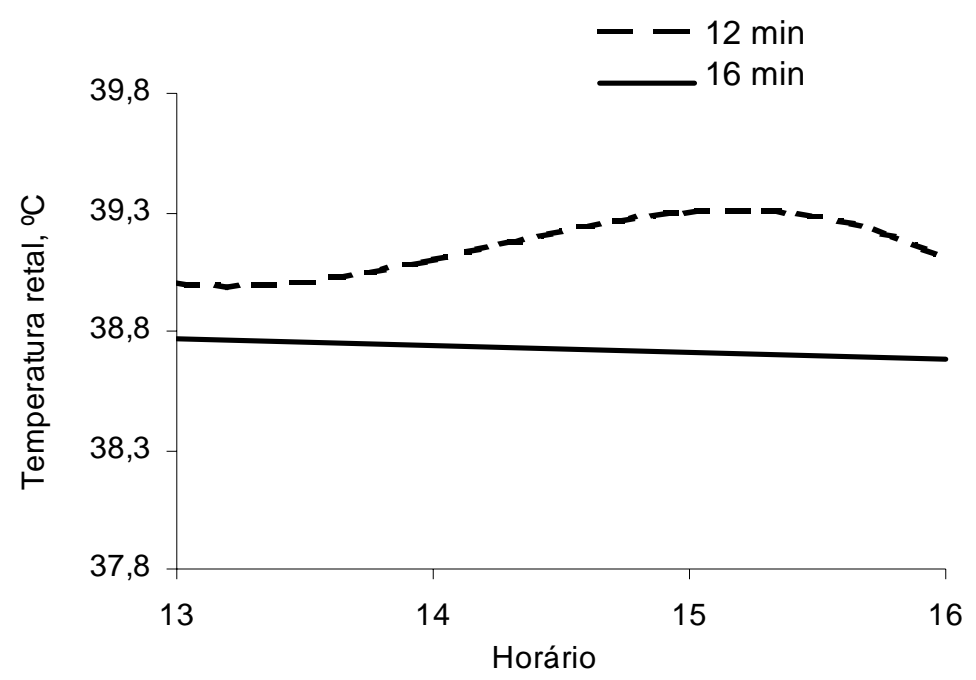

Figura 16 - Equação de regressão ajustada para a TR em função dos horários de avaliação nos tratamentos adotados

A TR apresentou valores mais elevados a partir das $13 \mathrm{~h}$ no tratamento 12 min. Esses dados corroboram o trabalho de Baccari Junior et al. (1979) que em condições de termoneutralidade, encontraram que a TR de bovinos holandeses apresentava correlação mais alta $(r=0,96)$ com a hora do dia do que com a temperatura do ar $(r=0,71)$. A temperatura corporal é um evento biológico de recorrência periódica, obedecendo a um ritmo circadiano, ou seja, ritmo que se repete a cada 24 horas. A flutuação diária é geneticamente determinada. Seu objetivo é preparar o organismo antecipadamente para as mudanças previsíveis da alternância do dia e da noite (Cipola-Neto et al., 1988).

Nas condições de termoneutralidade, a temperatura retal de bovinos holandeses está entre 38 e 39,5ㄷ (Du Preez, 2000). Uma vez considerada a classificação de Bianca (1961) sobre as respostas termorregulatórias, pode-se inferir que, nas condições do presente experimento, os animais, quando mantidos nos tratamentos 14 ou 16 min encontravam-se em estresse brando, uma vez que os mecanismos termorregulatórios foram eficientes em manter a temperatura corporal na faixa de normalidade. Por outro lado, quando mantidos no tratamento $12 \mathrm{~min}$, possivelmente, encontraram-se em estresse moderado, 
já que os mecanismos termorregulatórios foram intensificados e a temperatura corporal se estabilizou, porém, em nível mais elevado.

A freqüência e duração da aspersão são variáveis críticas para garantir a efetividade do sistema de resfriamento. Molhar a vaca a cada 15, 30 e 45 minutos reduziu a temperatura retal, respectivamente, em 0,$6 ; 0,7$ e $1,0^{\circ} \mathrm{C}$. Assim, o período de tempo em que o sistema fica ligado para promover o umedecimento do pêlo do animal, bem como a taxa de ventilação, teve efeitos dramáticos no resfriamento corporal encontrado (Flamenbaum et al., 1986)

Os estudos realizados por Miltlöhner et al. (2000), que avaliaram o efeito da aspersão direta sobre os animais, adotando um fluxo de 5,7 $\mathrm{L} \mathrm{min}{ }^{-1}$ a cada intervalo de $30 \mathrm{~min}$, não verificaram respostas positivas com o resfriamento evaporativo para as variáveis fisiológicas.

\subsubsection{Freqüência respiratória (FR)}

Para se defender contra o estresse térmico, os bovinos recorrem a mecanismos adaptativos fisiológicos de perda de calor corporal para evitar a hipertermia. Desta forma, aumentam a freqüência respiratória, apresentando taquipinéia, como complemento na perda de calor por sudação, constituindo, meios importantes de perda de calor por evaporação (Baccari Junior, 2001). Os valores médios verificados para a freqüência respiratória $(F R)$ durante o período experimental são apresentados na Tabela 5. 
Tabela 5. Valores médios e erros padrão da média da freqüência respiratória (FR) das vacas em lactação mensuradas das 13 às $16 \mathrm{~h}$

\begin{tabular}{lcccccc}
\hline FR & $13 h$ & $14 h$ & $15 h$ & $16 h$ & Média & Efeito \\
\hline 12 min & $80,0 \pm 0,68$ & $76,0 \pm 0,68$ & $76,0 \pm 0,68$ & $68,0 \pm 0,11$ & $76,0 \pm 0,61 \mathrm{a}$ & Linear $^{1}$ \\
14 min & $60,0 \pm 0,68$ & $60,0 \pm 0,68$ & $60,0 \pm 0,68$ & $60,0 \pm 0,11$ & $60,0 \pm 0,61 \mathrm{~b}$ & Linear $^{1}$ \\
16 min & $64,0 \pm 0,68$ & $60,0 \pm 0,68$ & $60,0 \pm 0,68$ & $56,0 \pm 0,11$ & $60,0 \pm 0,61 \mathrm{~b}$ & Linear $^{1}$ \\
\hline
\end{tabular}

$\overline{a, b}$, Médias seguidas por letras minúsculas distintas nas colunas diferem pelo Teste $t$ de Student $(P<0,05)$;

A freqüência respiratória diferiu $(P>0,05)$ entre os tratamentos avaliados. A FR dos animais no tratamento $12 \mathrm{~min}$, foi maior $\left(76 \mathrm{mov} \mathrm{min}^{-1}\right)$ do que quando foram submetidos à intermitência de 14 (60 mov min'1) ou 16 min (60 mov min-1). Os resultados observados entre os horários de avaliação revelaram efeito linear $(P<0,05)$ para todos os tratamentos (Figura 17).

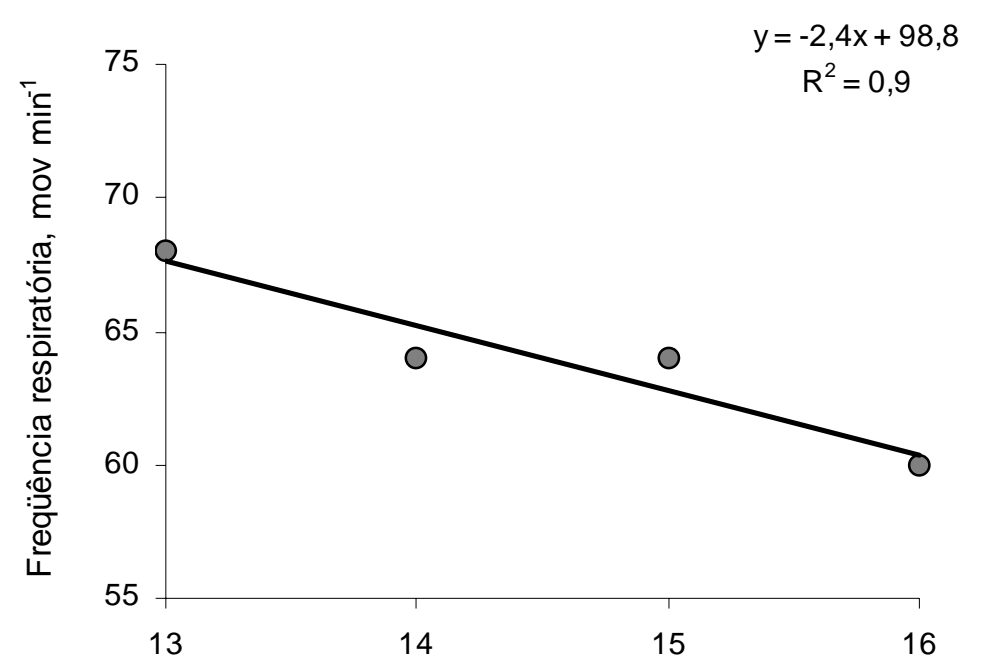

Figura 17 - Equação de regressão ajustada para a FR em função dos horários de avaliação nos tratamentos adotados 
A FR de 60 movimentos por minuto indica animais com ausência de estresse térmico ou este é mínimo (Hahn e Mader 1997). Nas condições do presente experimento os valores de FR aqui encontrados nos tratamentos $14 \mathrm{e}$ 16 min foram iguais a esses, por outro lado, para a intermitência de 12 min

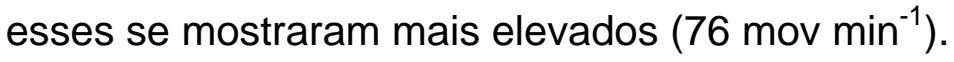

O aumento da freqüência respiratória, quando considerada por curto período, caracteriza-se como um mecanismo eficiente de perda de calor. Entretanto, quando este mecanismo passa a ser exigido durante períodos prolongados, pode acarretar problemas aos animais, tais como: interferir na ingestão de alimentos e ruminação, proporcionar calor endógeno adicional em função da atividade muscular (ofegação), desviar energia de outros processos metabólicos e, ainda, redução da capacidade combinante do $\mathrm{CO}_{2}$ com conseqüente diminuição na concentração de ácido carbônico no sangue, resultando em alcalose respiratória (Benjamin, 1981).

Pesquisas conduzidas por Frazzi et al. (1998) concluíram que a utilização de sistemas de acondicionamento ambiental em instalações para vacas leiteiras proporciona a diminuição da temperatura retal, a redução da taxa respiratória, a melhora no rendimento produtivo e nas características do leite das horas mais quentes do dia, se comparadas com vacas de instalações que possuem apenas ventilação natural.

\subsubsection{Temperatura da superfície da pele (TP)}

A pele protege o organismo do frio e do calor e sua temperatura depende, principalmente, das condições de temperatura ambiente, umidade e características fisiológicas como vascularização e evaporação do suor. Desta forma, contribui para a manutenção da temperatura corporal mediante trocas de calor com o ambiente (Baccari Junior, 2001). Os valores médios e erros padrão da média verificados para a temperatura do pelame (TP) durante o período experimental são apresentados na Tabela 6. 
Tabela 6. Valores médios e erros padrão da média da temperatura do pelame (TP) das vacas em lactação mensuradas das 13 às $16 \mathrm{~h}$

\begin{tabular}{lcccccl}
\hline TP & $13 \mathrm{~h}$ & $14 \mathrm{~h}$ & $15 \mathrm{~h}$ & $16 \mathrm{~h}$ & Média & Efeito \\
\hline $12 \mathrm{~min}$ & $31,7 \pm 0,22 \mathrm{a}$ & $31,7 \pm 0,22 \mathrm{a}$ & $31,5 \pm 0,22 \mathrm{a}$ & $31,3 \pm 0,22 \mathrm{a}$ & $31,6 \pm 0,16$ & Linear $^{1}$ \\
$14 \min$ & $31,2 \pm 0,22 \mathrm{ab}$ & $31,9 \pm 0,22 \mathrm{a}$ & $30,9 \pm 0,22 \mathrm{c}$ & $31,3 \pm 0,22 \mathrm{a}$ & $31,3 \pm 0,16$ & Cúbico $^{2}$ \\
$16 \min$ & $30,7 \pm 0,22 \mathrm{~b}$ & $30,7 \pm 0,22 \mathrm{~b}$ & $30,2 \pm 0,22 \mathrm{~b}$ & $28,9 \pm 0,22 \mathrm{~b}$ & $30,4 \pm 0,16$ & Linear $^{3}$
\end{tabular}

$\overline{a, b}$, Médias seguidas por letras minúsculas distintas nas colunas diferem pelo Teste $t$ de Student $(P<0,05)$; ${ }^{1} Y=-0,14 x+33,58\left(R^{2}=0,89\right)$;

${ }^{2} Y=0,35 x^{3}-15,05 x^{2}+214,60 x-983,10\left(R^{2}=0,99\right)$;

${ }^{3} Y=-0,32 x+34,99\left(R^{2}=0,90\right)$

A análise dos dados identificou a presença de interação entre tratamento e horário de avaliação $(P<0,05)$. Portanto, os tratamentos apresentaram comportamentos diferentes sobre a TP, em função dos horários em que foram avaliados. O desdobramento da interação mostrou-se significativo $(P<0,05)$ para todos os horários avaliados. Em todos esses instantes, as vacas em lactação submetidas à intermitência de 12 min apresentaram maiores valores para a TP, quando comparada com a aplicação do tratamento 16 min. Ainda, às $15 \mathrm{~h}$ a TP dos animais do tratamento $12 \mathrm{~min}$ foi maior que as do tratamento 14 min. Quando aplicado o tratamento 14 min, verificaram-se às $14 \mathrm{~h}\left(31,9^{\circ} \mathrm{C}\right)$, às $15 \mathrm{~h}\left(30,9^{\circ} \mathrm{C}\right)$ e $16 \mathrm{~h}\left(31,3^{\circ} \mathrm{C}\right)$ maiores valores de TP, quando comparado ao 16 $\min$.

Os resultados observados entre os horários de avaliação revelaram efeito linear $(P<0,05)$ para os tratamentos 12 e 16 min, sendo que a TP diminuiu ao longo do dia. $O$ efeito cúbico $(\mathrm{P}<0,05)$ foi verificado para a intermitência de 14min, uma vez que a TP oscilou durante o dia, apresentando-se mais elevada às 14 e 15 horas, com ligeiro decréscimo, a partir das $15 \mathrm{~h}$ (Figura 18). 


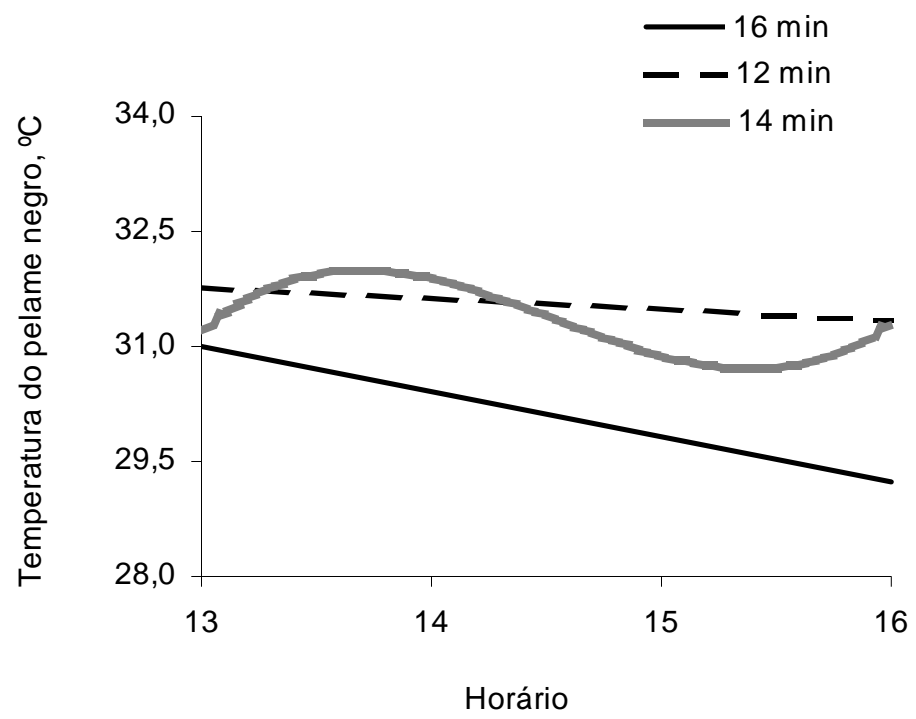

Figura 18 - Equações de regressão ajustadas para a TP em função dos horários de avaliação nos tratamentos adotados

A aspersão de água sobre o animal resfria imediatamente a superfície do corpo em até $4^{\circ} \mathrm{C}$ e reduz a taxa respiratória a 18 movimentos por min. A perda de calor por evaporação é favorecida quando a pele está molhada, representando $82 \%$ da perda total. Os mesmos autores estimaram ser 0,9 L o volume de água exigido para saturar o pêlo do dorso de uma vaca Holandesa de $600 \mathrm{~kg}$. Os bicos devem ter uma taxa de 0,45 a 1,9 $\mathrm{L} \mathrm{min}^{-1}$ e o tempo de aspersão de água deve ser de 0,5 a 2 min (Chastain e Turner, 1994).

A quantidade de água adotada no presente experimento foi $0,71 \mathrm{~L}$ durante o intervalo de $1 \mathrm{~min}$ 25seg. Em função do tipo de bico aspersor empregado no SRAE, tal taxa permitiu que o pêlo e a pele da região dorsal do animal fossem saturados nesse intervalo, evitando assim, gastos de água desnecessários. Em média a TP foi reduzida em 1,05ํㅡ quando utilizada a intermitência de 16 min em relação aos demais intervalos.

Quando a aspersão é associada à ventilação, ocorre inicialmente o umedecimento do pêlo do animal seguido da remoção da camada de ar da 
superfície da pele. Dessa forma, as taxas de evaporação são favorecidas, menores temperaturas de pele e corporal são verificadas (Stowell et al, 2003).

Diferentes intervalos de acionamento para a aspersão, sem molhar, molhando a cada 20 e 40 min foram avaliados por Hillman et al. (2001). A água era aplicada durante 1,5 min até que o excesso escorresse pelo flanco da vaca, e as intermitências foram associadas a diferentes fluxos de ar: desligado, 0,1; $0,9 \mathrm{~m} \mathrm{~s}^{-1}$ e 2,2 $\mathrm{m} \mathrm{s}^{-1}$. A temperatura da pele caiu rapidamente quando a intermitência foi 20 min e fluxo de ar igual a 2,2 $\mathrm{m} \mathrm{s}^{-1}$.

As diferenças verificadas na atividade metabólica dos tecidos fazem com que a temperatura não seja homogênea no corpo todo e apresente variações de acordo com a região anatômica. A superfície corporal apresenta temperatura mais variável e mais sujeita às influencias do ambiente externo (Silva, 2000).

\subsection{Conclusões}

Conforme os resultados verificados nas condições do presente experimento, pode-se concluir que:

a. A intermitência de 16 minutos resultou em menor consumo de água bem como melhores condições de conforto para as vacas em lactação, podendo ser empregado a fim de evitar desperdícios desnecessários pelo sistema de resfriamento adiabático evaporativo;

b. As intermitências de 14 e 16 minutos proporcionaram menores valores para as variáveis termorregulátorias temperatura retal, freqüência respiratória e temperatura da superfície do pelame. 


\section{EFICIÊNCIA DE SISTEMAS DE CLIMATIZAÇÃO NA ÁREA DE DESCANSO EM INSTALAÇÕES DO TIPO FREESTAL E SUA INFLUÊNCIA NAS RESPOSTAS PRODUTIVAS E FISIOLÓGICAS DE VACAS EM LACTAÇÃO}

\section{Resumo}

O trabalho teve como objetivo avaliar a eficiência de sistemas de climatização na área de descanso em instalação do tipo freestall e seus reflexos nas repostas produtivas e fisiológicas de vacas em lactação. O período experimental teve duração de 28 dias consecutivos do mês de novembro de 2003. Foram utilizadas 15 vacas em lactação, multíparas, com produção média de $20 \mathrm{~kg}$ de leite dia-1. Os tratamentos adotados foram: ausência de ventilação (V0), ventilação (V) e ventilação + nebulização (VN) posicionados na cama dos animais. Os dados referentes à temperatura do bulbo seco (TBS), umidade relativa do ar (UR) e temperatura de globo negro (TGN) no interior da instalação e no ambiente externo foram mensurados a cada 15 minutos ao longo das 24 horas. A ordenha foi realizada à 1 , às 9 e às 17 horas, e as produções diárias registradas. A alimentação era fornecida duas vezes ao dia (10 e 16 horas) e a quantidade de alimento oferecida e das sobras, foi registrada diariamente. As medidas fisiológicas, como freqüência respiratória (FR), temperatura retal (TR) e temperatura da pele (TP) de cinco animais em cada tratamento foram realizadas às $9,11,13,15$ e 17 horas. A UR mostrou-se mais elevada nos tratamentos V0 $(61,8 \%)$ e VN $(61,8 \%)$ quando comparada ao tratamento $\mathrm{V}(60,3 \%)$. A instalação na qual foi empregado $\mathrm{V}\left(27,4^{\circ} \mathrm{C}\right)$ apresentou TGN mais 
elevada, quando comparada ao tratamento V0 $\left(27,1^{\circ} \mathrm{C}\right)$. Também o THI mostrou-se mais elevado em $\mathrm{V}(75,0)$, quando comparado ao tratamento $\mathrm{V} 0$ $(74,5)$ e VN $(74,3)$. Para as variáveis fisiológicas, verificou-se que as vacas em lactação que receberam o tratamento V0 apresentaram menor temperatura retal às 11,13 e $17 \mathrm{~h}$. Os valores encontrados para a freqüência respiratória e temperatura do pelame estiveram dentro da faixa de termonormalidade em todos os tratamentos. Os animais mantidos nos tratamentos V0 $(20,5 \mathrm{~kg}$ MS $\left.\mathrm{dia}^{-1}\right)$ e $\mathrm{V}\left(21,3 \mathrm{~kg} \mathrm{MS} \mathrm{dia}^{-1}\right)$ apresentaram maior consumo de matéria seca, entretanto, este não refletiu em maior produção de leite.

\section{THERMAL CONDITIONED IN RESTING AREA OF FREESTALL FACILITIES AND ITS CONSEQUENCES ON PRODUCTIVE AND PHYSIOLOGICAL RESPONSES IN DAIRY COWS}

\section{Summary}

This work aimed to evaluate the efficiency of thermal conditioned in resting area of freestall facilities and its consequences on productive and physiological responses in dairy cows. Experimental period was 28 consecutive days of November 2003. Third dairy multiple cows with mean milk production of 20 kg.day $^{-1}$. Treatments were: non-fan (NF), fan (F) and fan + misting (FM) in direction to animal bedding. Dry bulb temperature (DBT), air relative humidity $(\mathrm{RH})$ and black globe temperature (BGT) inside and outside of facilities were measured every 15 minutes through a period of 24 hours. Milking was realized at 1,9 and 17 hours and registering daily production. Animals were fed twice a day (10 and 15 hours) and amounts of offered and rejected feed were daily registered. Physiological data, as respiratory frequency (RF), rectal temperature (RT) and skin temperature (ST), were taken at 9, 11, 13, 15 and 17h. The $\mathrm{RH}$ was higher in V0 (61.8\%) and VN (61.8\%) treatments than in V $(60.3 \%)$. The facilities (V) where it was used had higher BGT $\left(27.4^{\circ} \mathrm{C}\right)$ in relation to V0 
$\left(27.1^{\circ} \mathrm{C}\right)$. Also, $\mathrm{THI}$ was higher in $\mathrm{V}(75.0)$ than in $\mathrm{VO}(74.5)$ and $\mathrm{VN}(74.3)$ treatments. In relation to physiological parameters, lactating cows of V0 treatment had lower rectal temperature at 11, 13 and 17h. Respiratory frequencies and skin temperature were within normal variation in all treatments. Higher feed intakes were observed in animals of V0 (20.5 kg DM.day $\left.{ }^{-1}\right)$ and V $\left(21.3 \mathrm{~kg} \mathrm{DM} \mathrm{day}^{-1}\right)$ treatments, but it did not increase milk productions.

\subsection{Introdução}

O conceito de climatização está diretamente relacionado com a qualidade ideal do ambiente, espécie nele inserido e aos princípios básicos de conforto térmico que estão associados ao microclima interno da instalação (Silva, 1998).

O microclima gerado dentro de uma instalação é definido pela combinação de elementos com variáveis termodinâmicas do ar ambiente, chuva, luz, som, poluição, densidade animal, equipamentos e manejo (Silva, 1999).

O conforto térmico de uma instalação é função basicamente do isolamento térmico e da ventilação. A radiação solar incidente e o calor gerado pelos animais constituem as principais fontes de calor nas edificações. $O$ primeiro pode ser controlado pelo isolamento térmico, e o segundo pela ventilação (Watson, 1971).

A renovação do ar, proporcionada pela ventilação, permite a dissipação do calor, e também de poeira e gases poluentes. Entretanto, a excelência da ventilação está no fato de que, se for utilizada de maneira adequada, consegue dissipar o calor concentrado no interior do abrigo nas épocas mais quentes do ano (Moura, 1999).

A adoção de recursos naturais pode não conseguir, em condições extremas, um bom desempenho térmico nas instalações, levando à necessidade de utilização de sistemas mecânicos. Esses sistemas têm como 
principal vantagem ser independentes das condições atmosféricas e proporcionar melhor distribuição de ar no galpão. Os ventiladores são utilizados para criar uma diferença de pressão entre o exterior e interior da instalação, incrementando a movimentação do ar (Stowell et al., 2003).

Muitas vezes, somente a presença de ventiladores não é suficiente para alcançar as condições ideais mínimas de conforto, havendo a necessidade de recorrer ao uso de sistemas de resfriamento adiabático evaporativo (SRAE). A função da nebulização é reduzir a temperatura interna da instalação. Seu limite de eficiência está diretamente associado aos valores de umidade relativa dentro da instalação, bem como ao manejo do próprio freestall (Nääs e Rodrigues, 1999).

Atualmente tem surgido o interesse em outros sistemas de resfriamento para serem empregados no confinamento de vacas em lactação. Túneis de vento associados ao resfriamento evaporativo, ventiladores conjugados a bicos ejetores de alta pressão, a combinação de sistemas de resfriamento na linha de alimentação e no freestall têm sido as alternativas recentemente investigadas (West, 2003).

Diversos trabalhos têm demonstrado que o resfriamento evaporativo por meio da aspersão ou nebulização melhora a sanidade e o desempenho dos bovinos de leite. O resfriamento evaporativo tem sido relatado, por permitir a manutenção da ingestão de matéria seca e a produção de leite, entretanto, as vacas podem responder de maneira distinta em função do sistema empregado (Stowell et al., 2003).

Essa nova tendência de distribuição dos sistemas de resfriamento adiabático evaporativo em freestall com camas dispostas frente a frente foi avaliada por Brouk et al. (2001a). Os três tratamentos foram: ventiladores distribuídos ao longo do freestall; ventiladores na linha de alimentação e ao longo do freestall e ventiladores mais aspersores ao longo do freestall. A taxa de água do sistema de aspersão foi 94,6 $\mathrm{L}$ hora $^{-1}$ com intermitência de 15 minutos, sendo 3 minutos ligados e 12 desligados. Os resultados encontrados 
não apontaram diferenças entre os tratamentos para a produção de leite ou ingestão de matéria seca, entretanto, o uso de aspersores na linha de alimentação é recomendado, por aumentar a perda de calor na superfície corporal do animal.

Estudos realizados por Calegari et al. (2003) revelaram que a presença do resfriamento evaporativo na linha de alimentação melhorou a dissipação de calor das vacas em lactação, minimizando os efeitos do estresse térmico. $O$ emprego da nebulização permitiu que os animais submetidos a esse tratamento produzissem $3 \mathrm{~kg}$ de leite por dia a mais que os mantidos no grupo controle. Os animais do tratamento com nebulização apresentaram maior tempo despendido em pé, na área de alimentação. Esta se mostrou uma situação indicativa de estresse térmico, uma vez que as vacas tenderam a ficar com maior área de superfície corporal exposta, a fim de facilitar as trocas de calor. Verificou-se que existe a possibilidade de aliviar esses efeitos indesejáveis estendendo o SRAE nas demais instalações, como, por exemplo, na sala de ordenha e área de descanso, evitando assim, que ocorra aglomeração na área de alimentação.

Seguindo as tendências das pesquisas atuais, e com a perspectiva de adequar e mesmo proporcionar melhorias nos sistemas de resfriamento comumente empregados na produção intensiva de leite, o presente trabalho teve como objetivo avaliar a eficiência de sistemas de climatização na área de descanso em instalação do tipo freestall e seus reflexos nas repostas produtivas e fisiológicas de vacas em lactação.

\subsection{Material e Métodos}

\subsubsection{Local e instalações}

O experimento foi conduzido com rebanho comercial de gado Holandês, localizado no município de São Pedro, SP, a altitude de $580 \mathrm{~m}$ e coordenadas $222^{\circ} 33^{\prime} 02^{\prime \prime}$ de latitude Sul e $47^{\circ} 38^{\prime} 05^{\prime \prime}$ de longitude Oeste. O clima da região é 
do tipo Cwa da classificação Köppen, ou seja, quente e úmido com estação chuvosa no verão e seco no inverno. A temperatura média anual é de $22^{\circ} \mathrm{C}$, a pluviosidade média anual está próxima de $1200 \mathrm{~mm}$ e os ventos são predominantes do sudeste.

A instalação apresentava as seguintes características construtivas: $80 \mathrm{~m}$ de comprimento e $28 \mathrm{~m}$ de largura, laterais abertas, orientação leste-oeste, corredor central de 3,0 m, pé-direito central de $9 \mathrm{~m}$, telhado de duas águas com cobertura de telha de barro e sistema de lanternim vazado. O piso era de concreto e apresentava ranhuras de $0,5 \mathrm{~cm}$ espaçadas $7 \mathrm{~cm}$ entre si. A linha de alimentação tinha a extensão de todo galpão. Os bebedouros eram de alvenaria, localizados estrategicamente nas laterais do galpão, com dimensões de $2,8 \mathrm{~m}$ de comprimento, $0,8 \mathrm{~m}$ de largura, $0,31 \mathrm{~m}$ de profundidade $\mathrm{e}$ capacidade de $0,8 \mathrm{~m}^{3}$ de água.

Foram utilizados dois galpões (A e B) para a condução do experimento. Realizou-se inicialmente um monitoramento ambiental (temperatura de bulbo seco, umidade relativa) nas duas instalações para verificar possíveis diferenças no microclima interno. Esta avaliação teve a duração de 27 dias, nos quais os equipamentos de climatização não foram acionados (Anexo $A$ ).

O freestall A foi dividido em duas seções com 120 baias cada, sendo que foi utilizado para o experimento apenas uma delas. Optou-se por empregar no estudo apenas uma seção, pois essa separação foi realizada em função da ordem de parição das vacas, sendo assim, em um lote estavam alojadas as vacas primíparas e no outro as multíparas (Figura 19). Já o freestall B foi dividido em quatro seções com 60 baias, neste caso, foram destinadas ao experimento duas seções. 
Freestall A

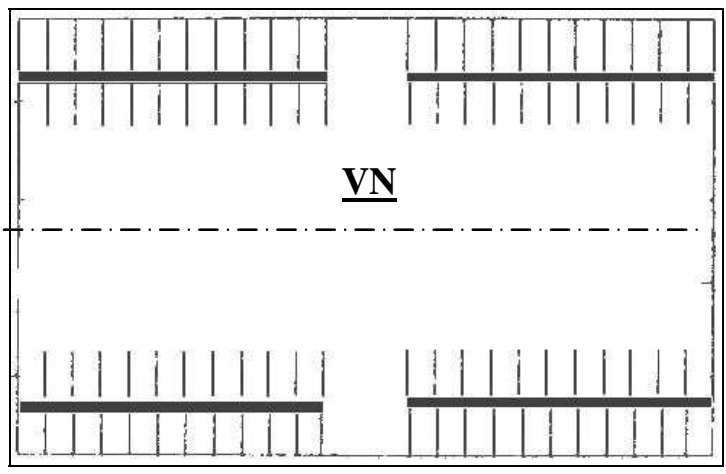

Freestall B

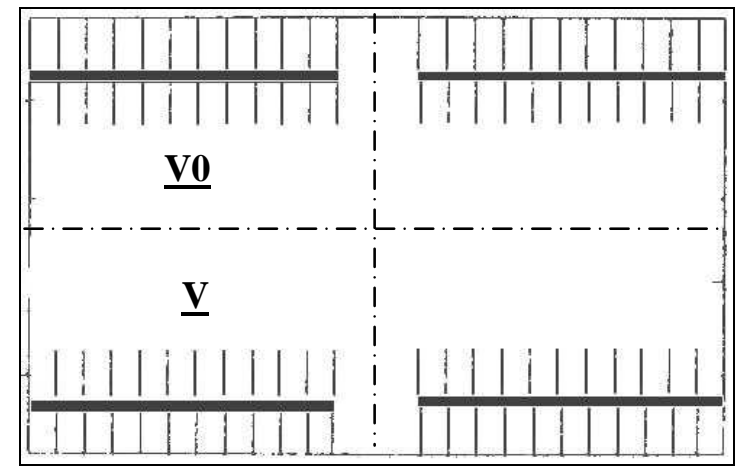

Figura 19 - Representação esquemática dos galpões e das seções empregadas

\subsubsection{Caracterização dos animais e manejo}

Foram utilizadas 15 vacas Holandesas, multíparas, em lactação, com peso médio de $600 \mathrm{~kg}$ e produção média de $20 \mathrm{~kg}$ de leite por dia. Os animais permaneceram durante todo dia com livre acesso às camas e demais áreas do abrigo, mas sem acesso as pastagens.

O manejo dos animais durante a fase experimental consistiu de dois horários de alimentação (10 e 16 horas) a qual foi fornecida na forma de dieta completa e de maneira a atender as exigências nutricionais para a manutenção e produção de leite, de acordo com o NRC (2001). A oferta de alimento e sobras foi registrada diariamente e amostradas a cada semana para posterior análise no Laboratório de Bromatologia da ESALQ/USP. Os animais foram ordenhados e suas produções registradas, diariamente, três vezes ao dia (1, 9 e 17 horas).

\subsubsection{Tratamentos}

O período experimental teve a duração de 28 dias consecutivos no mês de novembro de 2003 , dos quais sete dias foram destinados à adaptação dos 
animais ao tratamento e manejo empregado, e 21 dias para registro dos dados referentes as variáveis ambientais, produtivas e fisiológicas das vacas em lactação.

O freestall foi equipado com sistemas de aspersão e ventilação forçada na linha de alimentação em toda extensão. Os tratamentos foram aplicados aleatoriamente na área de descanso dos animais da seguinte maneira:

$>$ Tratamento 1: sem ventilação (V0);

> Tratamento 2: ventilação forçada (V);

> Tratamento 3: ventilação forçada adicionada de linha de nebulização (VN).

A Figura 20 ilustra a disposição dos tratamentos 2 e 3 no freestall.
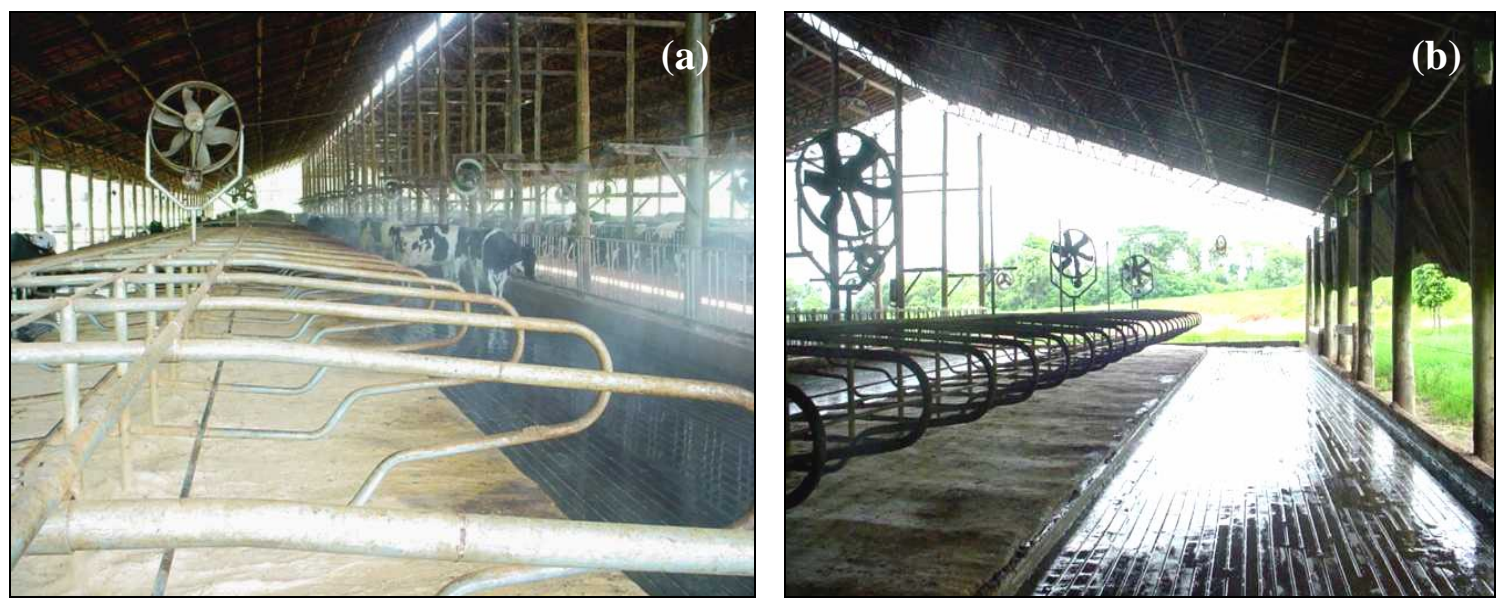

Figura 20 - Vista geral do tratamento 2 com ventiladores sobre a área de descanso (a) e tratamento $3 \mathrm{com}$ ventiladores e nebulizadores (b)

\subsubsection{Sistema de resfriamento}

No SRAE utilizaram-se ventiladores com diâmetro de 0,9 m, espaçados a cada $11 \mathrm{~m}$, equipados com motor de $1 / 4 \mathrm{CV}$, vazão de $300 \mathrm{~m}^{3}$ hora $^{-1}$, $495 \mathrm{RPM}$, e capacidade de produzir movimentação de ar de até $2,5 \mathrm{~m} \mathrm{~s}^{-1}$. $\mathrm{Na}$ área de alimentação esses ventiladores foram fixados a altura de 2,5 $\mathrm{m}$ e na área de descanso a $2 \mathrm{~m}$. O sistema de aspersão foi montado em toda extensão do 
galpão, a altura de 2,5 m acima da linha de alimentação e era constituído por tubo PVC, com espaçamento entre bicos de $1 \mathrm{~m}$. Esse sistema era acionado por uma bomba com motor trifásico cujo consumo de energia era equivalente a 1,48 $\mathrm{kW} \mathrm{h} \mathrm{h}^{-1}$. A vazão de água na linha de aspersão foi de $30 \mathrm{~L} \mathrm{hora}^{-1}$ e a intermitência foi de 12 min. O sistema de nebulização foi montado a altura de 3,7 m acima da área de descanso dos animais e era constituída por tubo PVC, com espaçamento entre bicos de $1 \mathrm{~m}$. A vazão de água na linha de nebulização foi de $3 \mathrm{~L}$ hora $^{-1}$ e a intermitência foi a mesma do sistema de aspersão (12 min) uma vez que eram alimentados pela mesma bomba. Esse sistema era alimentado por uma bomba com motor trifásico cujo consumo de energia era equivalente a $0,74 \mathrm{~kW}$ hora $^{-1}$. O SRAE e os ventiladores foram acionados por meio de termostato toda a vez que a temperatura no interior do freestall atingia $25^{\circ} \mathrm{C}$.

\subsubsection{Variáveis meteorológicas}

As variáveis registradas no interior das instalações e no ambiente externo foram temperatura do bulbo seco (TBS), umidade relativa do ar (UR\%) e temperatura do globo negro (TGN). As leituras foram realizadas a cada 15 minutos e então estimada a média horária. A aquisição dos dados foi realizada por sensores acoplados a um sistema eletrônico (HOBO $\left.{ }^{\circledR} \mathrm{H} 8\right)$. A estação autmomática foi fixada a altura de $2,5 \mathrm{~m}$ do piso, a fim de protegê-los dos animais. A partir dos valores encontrados para as variáveis meteorológicas, foram calculados os índices de conforto térmico THI (Thom, 1959) e BGHI (Buffington et al., 1981) e a entalpia. A entalpia (H) é uma variável física que indica a quantidade de energia contida em uma mistura de vapor d'água. Nos casos de mudança de umidade relativa, para uma mesma temperatura, a energia envolvida nesse processo se altera, e, conseqüentemente, a troca que ocorre no ambiente também sofre alteração (Nääs et al., 1995). 
Para cálculo da entalpia a equação foi descrita por Villa Nova (1999), citado por Furlan (2001), como:

$$
\left.H=6,37+0,243 \mathrm{~T}+\left\{\mathrm{UR} / 100 \times 10^{\wedge}[(7,5 \mathrm{~T}) / 237,3+\mathrm{T})\right]\right\}
$$

em que: $\mathrm{H}=\mathrm{kcal} \mathrm{kg}$ ar seco $^{-1}$;

$\mathrm{T}=$ temperatura do termômetro de bulbo seco, ${ }^{\circ} \mathrm{C}$;

$\mathrm{UR}=$ umidade relativa do $\mathrm{ar}, \%$.

\subsubsection{Variáveis Fisiológicas}

As variáveis fisiológicas mensuradas foram temperatura retal (Figura 21a), temperatura do pelame (Figura 21b) e freqüência respiratória.
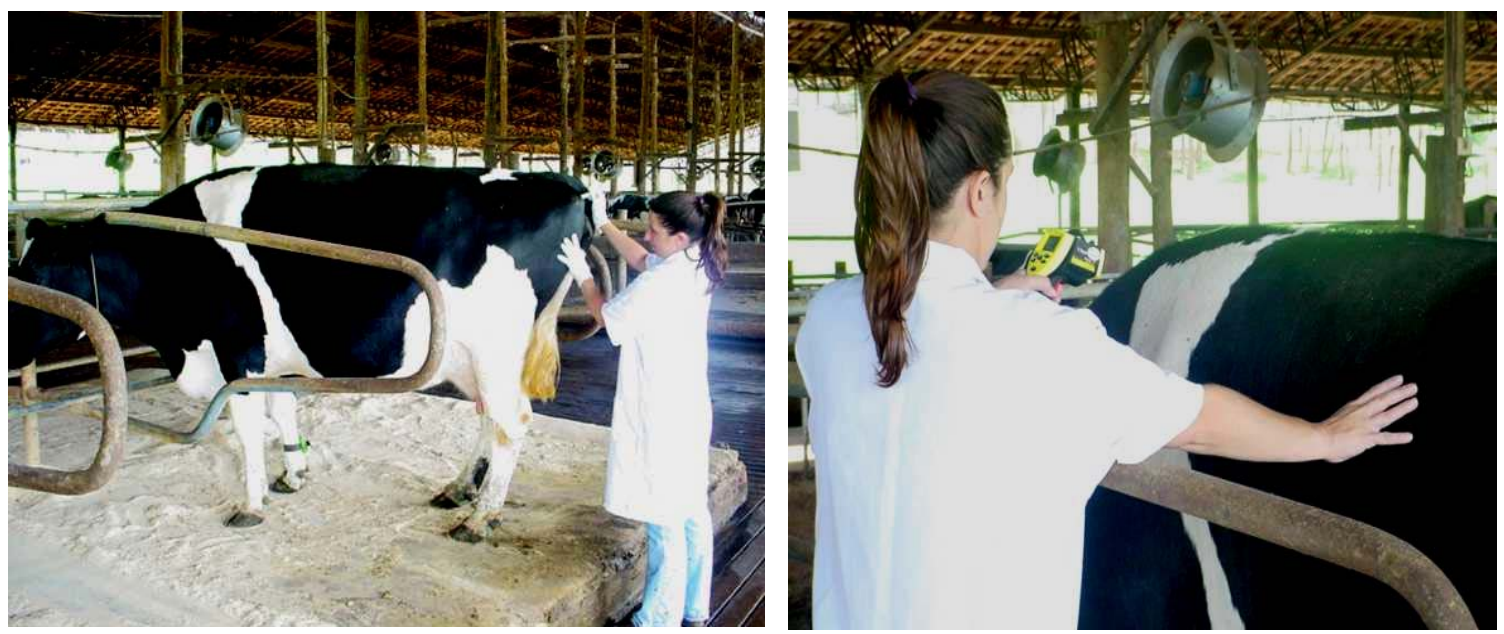

Figura 21 - Mensuração da temperatura retal (a) e temperatura do pelame (b)

\subsubsection{Temperatura Retal}

A medida da temperatura retal (TR) foi realizada durante sete dias do período experimental, sempre nos mesmos cinco animais submetidos a cada tratamento às $9,11,13,15$ e 17 h. A TR foi tomada com termômetro clínico digital, inserido no reto. 


\subsubsection{Freqüência Respiratória}

A freqüência respiratória $(\mathrm{FR})$ foi realizada durante sete dias do período experimental, sempre nos mesmos cinco animais submetidos a cada tratamento às $9,11,13,15$ e $17 \mathrm{~h}$, mediante a contagem dos movimentos na região do flanco, durante 15 segundos.

\subsubsection{Temperatura do pelame}

A medida da temperatura do pelame (TP) foi tomada na região dorsolombar do animal, nas malhas branca e negra durante sete dias do período experimental às $9,11,13,15$ e 17 horasnos cinco animais submetidos ao tratamento. A leitura foi realizada com termômetro de infravermelho empregando-se 0 valor de emissividade $(\varepsilon=0,9)$ para as medidas no pelame negro e $\varepsilon=0,5$ para o pelame branco conforme descrito em Baêta e Souza (1985).

\subsubsection{Análises estatísticas}

Para a análise das variáveis ambientais (TBS, UR, THI, BGHI, TGN e H) adotou-se um delineamento experimental em blocos casualizados, com os dias sendo usados como repetições. O modelo de análise incluiu como causas de variação os tratamentos (V0, V e VN), os horários $(9,11,13,15$ e 17 horas) e a interação entre os tratamentos e os horários.

Para as variáveis fisiológicas (TR, FR e TP) adotou-se um delineamento experimental inteiramente casualizado com os animais sendo usados como repetições. O modelo incluiu como causas de variação, os tratamentos (V0, V e VN), os horários (13,14, 15, 16 e 17 horas) e a interação entre os tratamentos os horários. Quando a interação foi significativa, ela foi desdobrada com o 
intuito de comparar os efeitos dos tratamentos em cada horário, utilizando o Teste $t$ de Student, e comparar os efeitos dos horários de avaliação em cada tratamento, utilizando a análise de regressão (contrastes ortogonais).

Para ingestão de matéria seca (IMS) e produção de leite (PL) adotou-se um delineamento experimental inteiramente casualizado, sendo as comparações das médias realizadas pelo Teste de Tukey ao nível de significância de 5\%.

As análises foram realizadas com o procedimento para modelos mistos (proc mixed) do SAS (1998), admitindo-se um modelo com medidas repetidas no tempo.

\subsection{Resultados e discussão}

\subsubsection{Variáveis meteorológicas}

Os valores médios da temperatura de bulbo seco, umidade relativa, temperatura de globo negro, temperaturas mínima e máxima, índice de temperatura e umidade, índice de temperatura de globo negro e umidade e entalpia, registrados durante o período experimental nos tratamentos e no ambiente externo à instalação são apresentados na Tabela 7.

Verificou-se que os valores médios encontrados para as variáveis meteorológicas e índices de conforto térmico, ao longo das 24 horas, permaneceram na zona de termoneutralidade. Entretanto, as temperaturas máximas excederam as condições de conforto térmico, apresentando maior valor numérico para o tratamento sem ventilação, a qual superou até mesmo o ambiente externo. Tal fato pode ter ocorrido, possivelmente devido à maior quantidade de calor acumulado no microclima interno da instalação. 
Tabela 7. Valores médios diários das variáveis meteorológicas e índices de conforto térmico registrados durante o período experimental

\begin{tabular}{lcccc}
\hline Variáveis meteorológicas & \multicolumn{4}{c}{ Tratamentos } \\
\hline & Externo & V0 & V & VN \\
Temperatura de bulbo seco, ${ }^{\circ} \mathrm{C}$ & $24,4 \pm 0,15$ & $24,5 \pm 0,15$ & $24,1 \pm 0,15$ & $24,3 \pm 0,15$ \\
Umidade relativa, \% & $69,0 \pm 0,73$ & $68,1 \pm 0,73$ & $69,9 \pm 0,73$ & $69,0 \pm 0,73$ \\
Temperatura de globo negro, ${ }^{\circ} \mathrm{C}$ & $\mathrm{nd}^{*}$ & $19,4 \pm 2,45$ & $24,3 \pm 2,45$ & $21,9 \pm 2,45$ \\
Índice de temperatura e umidade & $72,7 \pm 0,12$ & $72,1 \pm 0,12$ & $72,4 \pm 0,12$ & $72,2 \pm 0,12$ \\
Índice de globo negro e umidade & $\mathrm{nd}^{*}$ & $67,3 \pm 2,55$ & $72,4 \pm 2,55$ & $69,9 \pm 2,55$ \\
Entalpia, kJ kg de ar seco ${ }^{-1}$ & $75,8 \pm 0,39$ & $75,6 \pm 0,39$ & $74,9 \pm 0,39$ & $75,4 \pm 0,39$ \\
Temperatura mínima, ${ }^{\circ} \mathrm{C}$ & $19,8 \pm 1,77$ & $16,0 \pm 1,77$ & $19,7 \pm 1,77$ & $18,5 \pm 1,77$ \\
Temperatura máxima, ${ }^{\circ} \mathrm{C}$ & $30,6 \pm 2,13$ & $34,4 \pm 2,13$ & $29,4 \pm 2,13$ & $29,2 \pm 2,13$ \\
\hline nd" não determinado & & & &
\end{tabular}

A umidade relativa esteve próxima de $70 \%$. Nesses casos, o sistema de climatização proposto deveria favorecer a dissipação de calor no interior do freestall uma vez que a UR elevada, tornaria o ambiente ainda mais estressante para o animal. Os valores do THI considerados como adequados para as vacas em lactação, seria de 72 unidades. Pode-se constatar que nas condições ambientais em que o experimento foi conduzido, este índice caracterizava ausência de estresse térmico.

A Tabela 8 apresenta os valores médios das variáveis ambientais, durante o período experimental, no intervalo horário das 9 às 17 horas nos tratamentos estudados. 
Tabela 8. Valores médios e erros padrão da média das variáveis meteorológicas e índices de conforto térmico registrados no intervalo horário das 9 às 17 horas durante 0 período experimental.

\begin{tabular}{lccc}
\hline Variáveis meteorológicas & \multicolumn{3}{c}{ Tratamentos } \\
\hline & V0 & $\mathrm{V}$ & $\mathrm{VN}$ \\
Temperatura de bulbo seco, ${ }^{\circ} \mathrm{C}$ & $26,6 \pm 0,11 \mathrm{a}$ & $26,8 \pm 0,11 \mathrm{a}$ & $26,6 \pm 0,11 \mathrm{a}$ \\
Umidade relativa, \% & $61,8 \pm 0,34 \mathrm{a}$ & $60,3 \pm 0,34 \mathrm{~b}$ & $61,8 \pm 0,34 \mathrm{a}$ \\
Temperatura de globo negro, ${ }^{\circ} \mathrm{C}$ & $27,1 \pm 0,08 \mathrm{a}$ & $27,4 \pm 0,34 \mathrm{~b}$ & $27,2 \pm 0,34 \mathrm{ab}$ \\
Índice de temperatura e umidade & $74,5 \pm 0,14 \mathrm{a}$ & $75,0 \pm 0,14 \mathrm{~b}$ & $74,3 \pm 0,14 \mathrm{a}$ \\
Índice de globo negro e umidade & $75,3 \pm 0,13 \mathrm{a}$ & $75,3 \pm 0,13 \mathrm{a}$ & $75,2 \pm 0,13 \mathrm{a}$ \\
Entalpia, kJ kg de ar seco ${ }^{-1}$ & $77,7 \pm 0,30 \mathrm{a}$ & $77,4 \pm 0,30 \mathrm{a}$ & $77,7 \pm 0,30 \mathrm{a}$ \\
\hline a,b Médias seguidas por letras minúsculas distintas nas linhas diferem entre si pelo Teste $t$ de Student $(\mathrm{P}<0,05)$.
\end{tabular}

\subsubsection{Temperatura de bulbo seco (TBS)}

Não foram observadas diferenças $(P>0,05)$ entre os tratamentos para a TBS. Os valores médios encontrados foram 26,6; 26,8 e $26,6^{\circ} \mathrm{C}$, respectivamente, para os tratamentos $\mathrm{V} 0, \mathrm{~V}$ e VN. Os resultados observados entre os horários de avaliação mostraram efeito quadrático $(P<0,05)$ para todos os tratamentos. O maior valor registrado para a TBS $\left(27,2^{\circ} \mathrm{C}\right)$ foi verificado às 13,8 horas (Figura 22).

Os valores relatados na literatura indicam grande variação na temperatura crítica superior para as vacas em lactação. Benjamim (1985) apontaram valores entre 25 e $26^{\circ} \mathrm{C}$, por outro lado, Huber (1990) citou a faixa de 4 a $26^{\circ} \mathrm{C}$ como de conforto térmico para as vacas em lactação. 


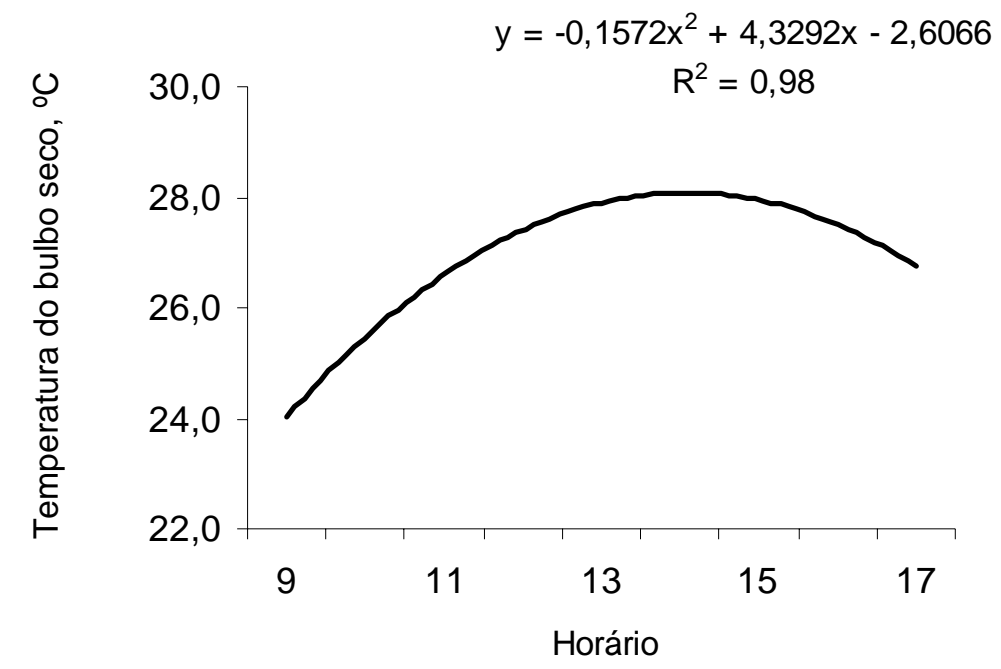

Figura 22 - Equação de regressão ajustada para a TBS em função dos horários de avaliação nos tratamentos adotados

Nas condições do presente experimento, verificou-se que os valores da TBS estiveram dentro do padrão de termoneutralidade. Sendo assim, era de se esperar que os tratamentos aplicados na área de descanso proporcionassem benefícios restritos ao microclima interno da instalação, uma vez que, quanto maior a depressão psicrométrica local, maior a eficiência do sistema de resfriamento adiabático evaporativo. Já o trabalho realizado por Turner (1998), o qual empregou a nebulização conjugada à ventilação forçada, apontou redução na temperatura do ar em até $4^{\circ} \mathrm{C}$.

Além das condições satisfatórias de temperatura ambiente, o trabalho inicial realizado no local do experimento contou com a instalação do sistema de aspersão ao longo da linha de alimentação do freestall. Acredita-se que essa ocorrência por si tenha sido responsável por uma melhoria geral nas condições internas da instalação.

A adição da linha de nebulização associada ao ventilador não resultou em decréscimo na TBS, conforme era esperado. Tal fato pode estar associado à altura $(3,7 \mathrm{~m})$ e mesmo à disposição da linha. Verificou-se que o sistema de 
nebulização estava muito próximo ao telhado, e ainda, a linha estava disposta numa posição tal que deixava toda névoa à deriva.

Lin et al. (1998) relataram que quanto ao posicionamento dos nebulizadores, esses são mais efetivos quando montados próximos do animal e menos efetivos quando instalados a alturas elevadas na instalação.

Além da altura elevada da linha de nebulização, possivelmente, a intermitência empregada pode ter contribuído para que não fosse verificado o decréscimo na TBS. Na presente condição, o ciclo adotado foi de 12 minutos, ou seja, o sistema permaneceu 11 minutos desligado e um minuto ligado, com fluxo de água igual a $3 \mathrm{~L}$ hora $^{-1}$. A redução deste intervalo poderia contribuir para a melhoria das propriedades psicrométricas do ar, favorecendo a troca de calor sensível e resultando em decréscimo da temperatura do ambiente.

\subsubsection{Umidade relativa (UR)}

Verificaram-se diferenças $(P<0,05)$ entre os tratamentos na UR. Esta variável mostrou-se mais elevada nos tratamentos $\mathrm{V} 0$ e $\mathrm{VN}$, quando comparada ao tratamento $\mathrm{V}(60,3 \%)$. Entretanto, os tratamentos $\mathrm{V} 0$ e $\mathrm{VN}$ não diferiram entre si apresentando valores correspondentes a $61,8 \%$ de UR.

Quando comparados os resultados entre os horários de avaliação, verificou-se efeito quadrático $(\mathrm{P}<0,05)$ para todos os tratamentos. O menor valor registrado para a UR (55,8 \%) foi verificado às 14,5 horas(Figura 23$)$.

A melhor maneira de resfriar o ambiente destinado aos animais em lactação seria com o uso da água, desde que a umidade relativa estivesse até o limite aproximado de $70 \%$ (Nääs e Arcaro Júnior, 2001). Valores superiores a este foram verificados entre 9 e $10 \mathrm{~h}$. A partir daí, os teores de umidade encontrados permaneceram dentro desta faixa. 


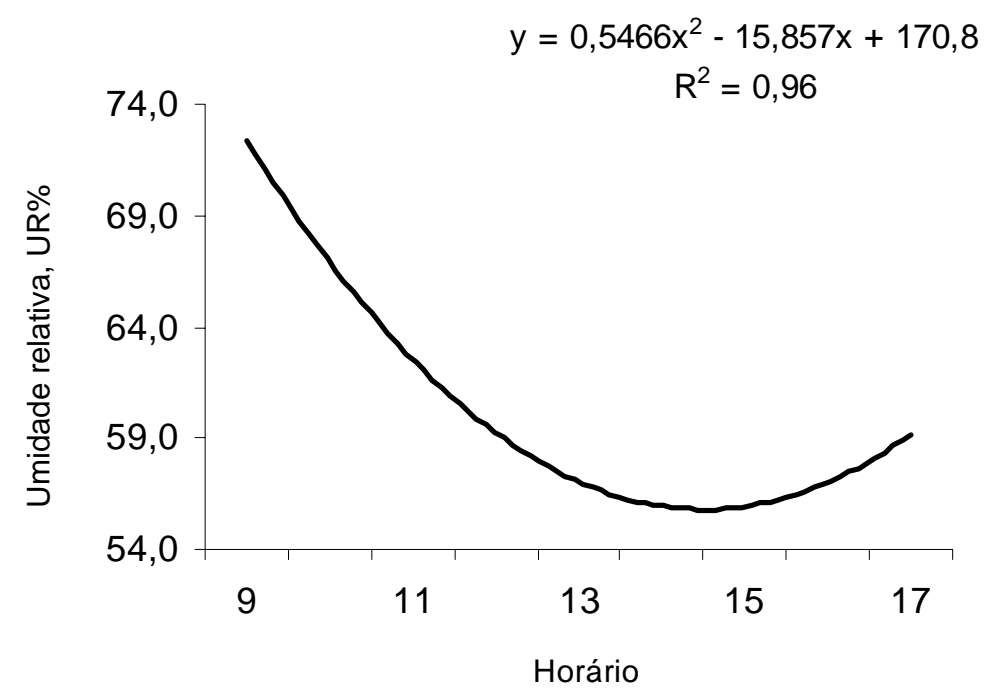

Figura 23 - Equação de regressão ajustada para a UR em função dos horários de avaliação nos tratamentos adotados

É importante salientar que, em condições de umidade elevada, o ar saturado irá inibir a evaporação da água pela pele e sistema respiratório, proporcionando um ambiente ainda mais estressante para o animal (Sota, 1996).

O aumento da UR verificado no tratamento VN deve-se ao fato do resfriamento evaporativo consistir em um processo de saturação adiabática, em que não há perda nem ganho de calor. Neste caso, ocorre a mudança do ponto de estado psicrométrico do ar, verificando-se elevação da umidade relativa, mediante o contato do ar com uma superfície umedecida ou líquida (Wiersma e Stott, 1983).

Por outro lado, a UR também elevada, verificada no tratamento V0, devese ao grande volume de vapor d'água (respiração) e urina produzido pelas vacas em lactação. Essa umidade deve ser removida por meio de trocas de ar na instalação (Brouk et al., 2001b).

Frazzi et al. (1998) verificaram aumento da umidade relativa em 10-15\% com o uso do sistema de nebulização de alta pressão, indicando ainda que a velocidade do ar facilitou a dissipação de calor. 
A fim de eliminar o calor produzido pelos animais e evitar temperatura excessiva dentro da instalação, deve-se aumentar a taxa de ventilação. A ventilação destes ambientes pode promover melhorias nas condições termohigrométricas, podendo representar um fator de conforto térmico de verão, ao incrementar as trocas de calor por convecção e evaporação (Silva, 1999).

\subsubsection{Temperatura de globo negro (TGN)}

Foram encontradas diferenças $(\mathrm{P}<0,05)$ entre os tratamentos para a TGN. A instalação na qual foi empregado o tratamento $V\left(27,4^{\circ} \mathrm{C}\right)$ apresentou TGN mais elevada, quando comparada ao tratamento $\mathrm{V} 0\left(27,1^{\circ} \mathrm{C}\right)$. Por outro lado, ambos não diferiram do tratamento VN $\left(27,2^{\circ} \mathrm{C}\right)$. Quando comparados os resultados entre os horários de avaliação, verificou-se efeito quadrático $(\mathrm{P}<0,05)$ para todos os tratamentos. O maior valor registrado para o TGN $\left(28,7^{\circ} \mathrm{C}\right)$ foi verificado às 14 horas (Figura 24$)$.

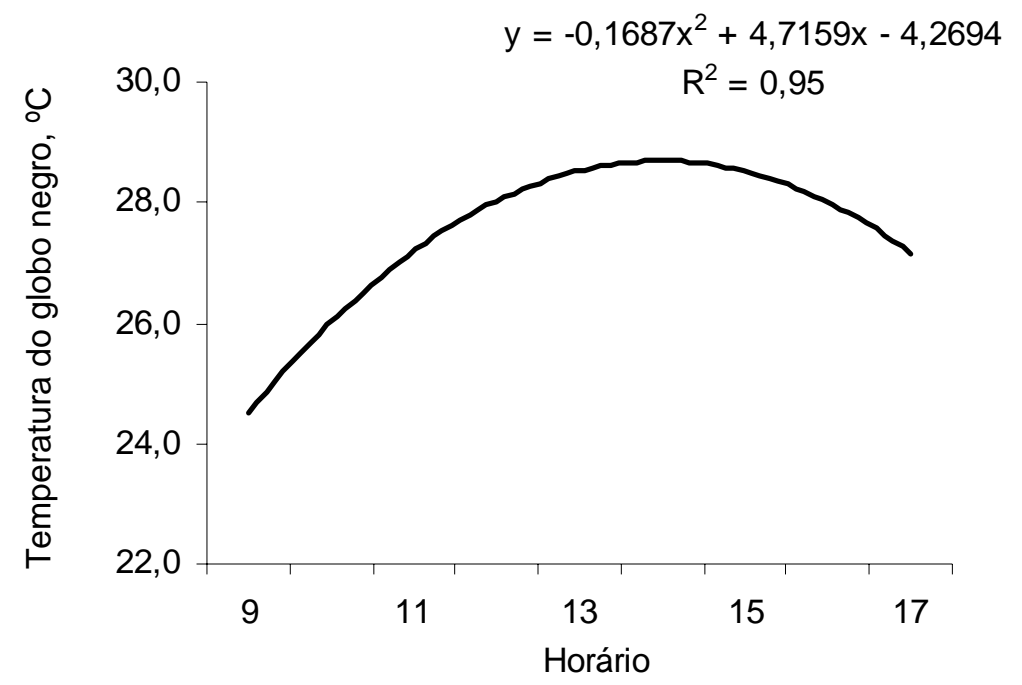

Figura 24 - Equação de regressão ajustada para a TGN em função dos horários de avaliação nos tratamentos adotados 
Não era esperado que o tratamento $\mathrm{V}$ proporcionasse maior valor de TGN. Entretanto, em função da instalação apresentar o lanternim vazado, o termômetro de globo negro estava sujeito à ação da radiação solar direta durante várias horas do dia, podendo tal efeito ter contribuído para a ocorrência da temperatura elevada nesse tratamento.

O efeito do resfriamento por nebulização de alta pressão sobre 0 ambiente físico do freestall foi verificado por Roma Júnior et al. (2001). Os autores encontraram que as temperaturas do ar e do termômetro de globo negro reduziram em 1,5 e $1,0^{\circ} \mathrm{C}$, respectivamente, com o emprego da nebulização. Também Perissinotto (2003) empregou o sistema de resfriamento evaporativo por nebulização associado à ventilação forçada na linha de alimentação e encontrou valores de TGN correspondentes a $27,1^{\circ} \mathrm{C}$.

\subsubsection{4 Índice de temperatura e umidade (THI)}

Verificaram-se diferenças $(P<0,05)$ entre os tratamentos para o THI. Este índice mostrou-se mais elevado no tratamento V $(75,0)$, quando comparado ao tratamento V0 $(74,5)$ e VN $(74,3)$, sendo que esses últimos não diferiram entre si. Quando comparados os resultados entre os horários de avaliação, verificouse efeito quadrático $(\mathrm{P}<0,05)$ para todos os tratamentos. $O$ maior valor determinado para o THI $(75,8)$ foi verificado às 14,1 horas (Figura 25 ).

De acordo com Hahn (1985), um THI igual ou menor a 70 expressa uma condição normal; um valor entre 71 e 78 é crítico; entre 79 e 83 a situação é de perigo e, acima de 83, uma situação de emergência está presente. $O$ estresse severo pode levar os animais a óbito, quando o THI for superior a 84 e não ocorrer recuperação durante o período noturno, ou seja, se o THI não for inferior a 74 (Hahn e Mader, 1997). 


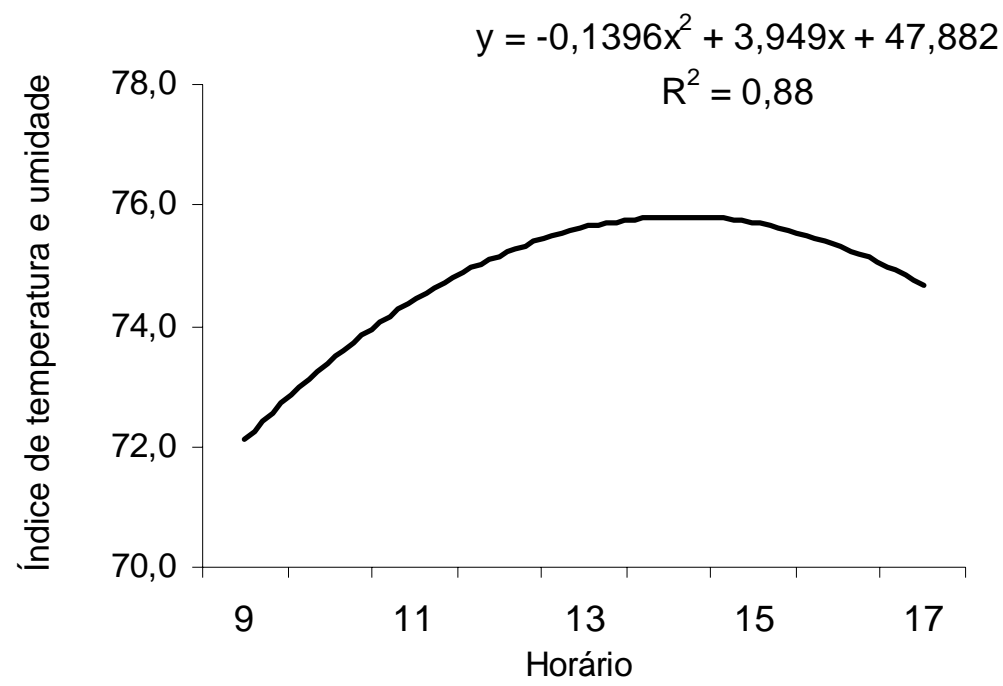

Figura 25 - Equação de regressão ajustada para a THI em função dos horários de avaliação nos tratamentos adotados

Nas condições do presente experimento, verificou-se que o THI permaneceu na faixa considerada crítica. Sendo assim, os equipamentos de climatização não possibilitaram o condicionamento ambiental relativamente eficiente nas horas mais quentes do dia.

Em determinadas condições ambientais, o resfriamento evaporativo pode reduzir o número de horas com THI elevado. Tem sido usado com sucesso em situações de clima seco (Huhnke e Monty Jr., 2001).

As vacas em lactação mantidas em sistema intensivo de produção podem vivenciar os efeitos do estresse térmico, quando submetidas a temperaturas elevadas durante o dia, e então, presenciando temperatura noturna inferior a $18^{\circ} \mathrm{C}$, conferindo tolerância em curto prazo ao estresse térmico (Akari et al., 1987).

Tal situação pode ser comparada ao que ocorreu nas condições do presente experimento em que o THI se mostrou crítico para a produção de leite durante o dia. Entretanto, as temperaturas mínimas verificadas para todos os tratamentos estiveram dentro da faixa considerada adequada para que os 
animais conseguissem se recuperar do estresse, sem trazer maiores prejuízos para a produção de leite. Esse fenômeno pode ser explicado pelo padrão circadiano, caracterizado por temperatura corporal elevada entre 17 e 19 horas e mínima entre 4 e 6 horas (Bitman et al., 1984).

\subsubsection{5 Índice de temperatura de globo e umidade (BGHI)}

Não foram observadas diferenças $(P>0,05)$ entre os tratamentos para 0 BGHI. Os valores médios encontrados foram, 75,3; 75,3 e 75,2 unidades respectivamente, para os tratamentos $\mathrm{V} 0, \mathrm{~V}$ e $\mathrm{VN}$. Os resultados observados entre os horários de avaliação mostraram efeito quadrático $(P<0,05)$ para todos os tratamentos. $O$ maior valor estimado para o $\mathrm{BGHI}(76,2)$ foi verificado às 14,1 horas (Figura 26).

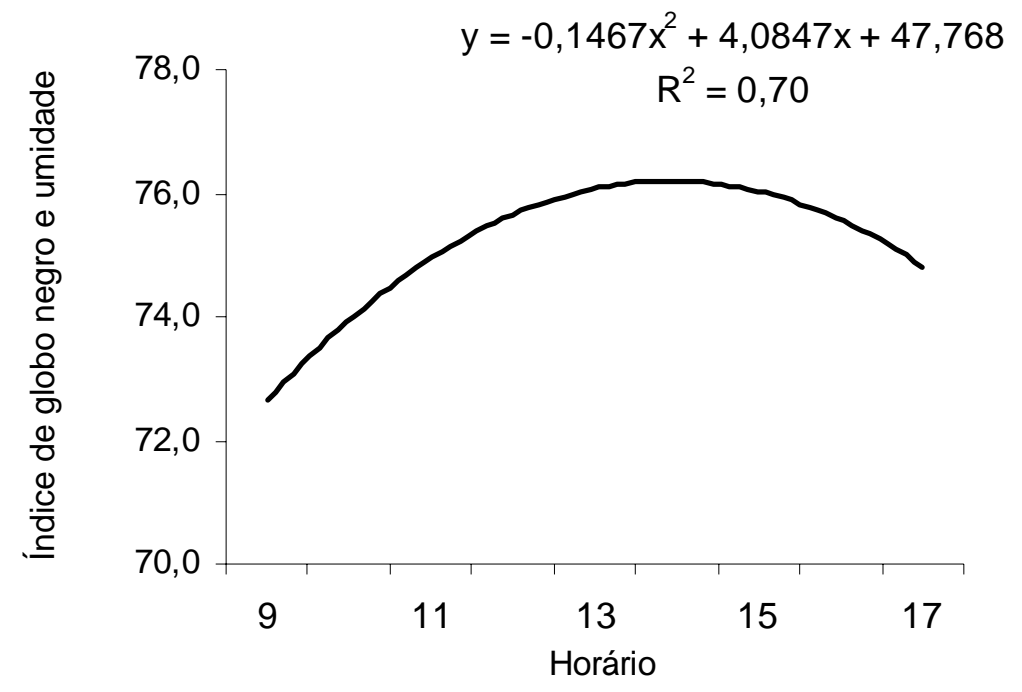

Figura 26 - Equação de regressão ajustada para o BGHI em função dos horários de avaliação nos tratamentos adotados 
Os valores de BGHI até 74 definem condição de conforto para os bovinos, entre 75 e 78 a situação é de alerta, 79 a 84 caracterizam perigo e acima deste, depara-se com situação de emergência (Baeta e Souza, 1985).

Embora tenha sido verificado que os valores do BGHI permaneceram na faixa de alerta, as condições encontradas no interior das instalações estiveram próximas do conforto animal. Cabe ressaltar que o BGHI é um índice para vacas leiteiras expostas à radiação solar direta. Entretanto, este se mostrou um indicador mais acurado que o THI sob condições severas de estresse pelo calor. Já em condições de estresse moderado, esses índices se equivalem, e, à sombra, são correlacionados à produção, na mesma magnitude (Baccari Junior, 2001).

A correta identificação dos fatores que influem na vida produtiva do animal, tais como o estresse imposto pelas flutuações estacionais do meio ambiente, poderia permitir ajustes nas práticas de manejo de um sistema de produção (Turco et al., 1999).

\subsubsection{Entalpia $(\mathrm{H})$}

A quantidade de calor presente no ar expressa pela variável $\mathrm{H}$ não diferiu $(P>0,05)$ entre os tratamentos. Os valores médios encontrados foram 77,$7 ; 77,4$ e $77,7 \mathrm{~kJ} \mathrm{~kg} \mathrm{de} \mathrm{ar} \mathrm{seco-1}$, respectivamente, para os tratamentos V0, V e VN. Os resultados observados entre os horários de avaliação mostraram efeito cúbico $(\mathrm{P}<0,05)$ para todos os tratamentos (Figura 27). 


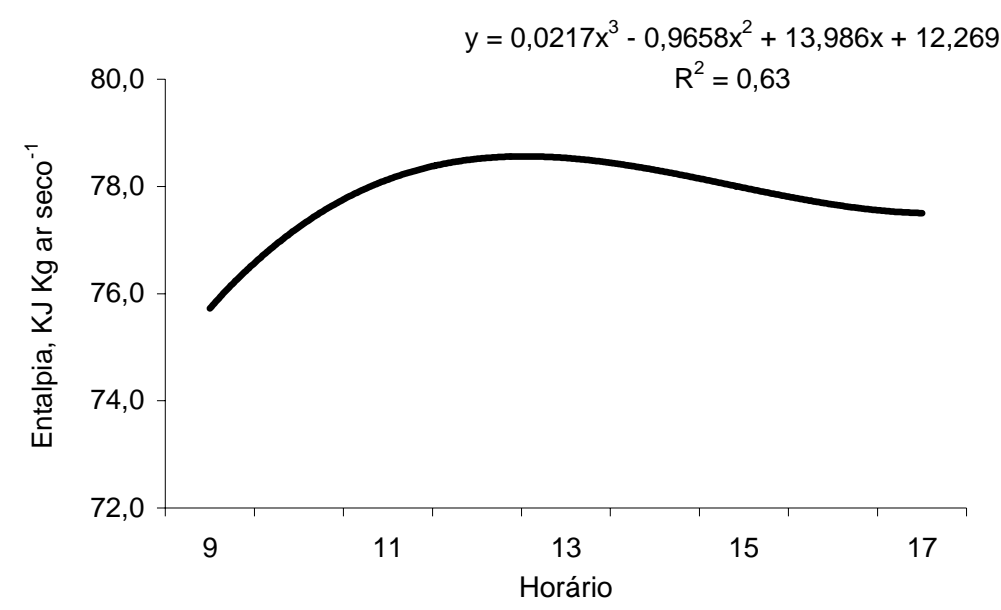

Figura 27 - Equação de regressão ajustada para a $\mathrm{H}$ em função dos horários de avaliação nos tratamentos adotados

A zona de termoneutralidade proposta por Johnson e Vanjonack (1976) apontou que a entalpia crítica ocorreria quando a TBS fosse igual ou superior a $24^{\circ} \mathrm{C}$ e a UR igual a $76 \%$. Sendo assim, nas condições do presente experimento, a entalpia verificada na faixa de normalidade descrita corresponderia a $63,0 \mathrm{~kJ} \mathrm{~kg}$ ar seco-1.

De acordo com os resultados obtidos, os valores de $\mathrm{H}$ foram superiores aos sugeridos pela literatura. Verificou-se aumento acentuado da $\mathrm{H}$ pela manhã, seguido de decréscimo no período. Nestas condições, tanto $\mathrm{V}$ como VN não foram significativos a ponto de promover mudanças na quantidade de calor no interior do freestall. Provavelmente, a eficiência desses sistemas esteja relacionada com a taxa de ventilação, a qual deveria ser aumentada no caso do tratamento $\mathrm{V}$, de modo a facilitar a dissipação do calor gerado no microclima interno da instalação, e no tratamento $\mathrm{VN}$ a nebulização deveria ser acionada em intervalos menores, sendo que a linha deveria estar disposta de forma que não fosse susceptível à deriva.

Condicionar o ambiente e controlar as flutuações dos elementos climáticos, de forma a melhorar o desempenho produtivo do animal, depende 
do conhecimento de sua fisiologia, caracterização do ambiente físico e das necessidades comportamentais do bovino, bem como da capacidade destes indivíduos em responder às mudanças realizadas (Costa e Silva, 2003).

\subsubsection{Variáveis fisiológicas}

\subsubsection{Temperatura retal (TR)}

Os valores médios e erros padrão da média verificados para a temperatura retal (TR) durante o período experimental são apresentados na Tabela 9. As equações de regressão ajustadas em função dos horários de avaliação são ilustradas pela Figura 28.

Tabela 9. Valores médios e erros padrão da média de temperatura retal (TR) das vacas em lactação mensuradas das 9 às 17 horas

\begin{tabular}{|c|c|c|c|c|c|c|}
\hline TR & $9 \mathrm{~h}$ & $11 \mathrm{~h}$ & $13 \mathrm{~h}$ & $15 \mathrm{~h}$ & $17 \mathrm{~h}$ & Efeito \\
\hline V0 & $38,1 \pm 0,08 a$ & $37,9 \pm 0,08 b$ & $38,2 \pm 0,08 b$ & $38,4 \pm 0,08 a$ & $38,2 \pm 0,08 a$ & Cúbico $^{1}$ \\
\hline V & $38,2 \pm 0,08 a$ & $38,4 \pm 0,08 a$ & $38,5 \pm 0,08 a$ & $38,5 \pm 0,08 a$ & $38,5 \pm 0,08 b$ & Quadrático $^{2}$ \\
\hline VN & $38,3 \pm 0,08 a$ & $38,4 \pm 0,08 a$ & $38,5 \pm 0,08 a$ & $38,5 \pm 0,08 a$ & $38,6 \pm 0,08 b$ & Linear $^{3}$ \\
\hline
\end{tabular}

A análise dos dados identificou a presença da interação $(P<0,05)$ entre tratamento e hora. Sendo assim, os tratamentos apresentaram comportamentos diferentes sobre a TR, em função dos horários em que foram avaliados. O desdobramento da interação mostrou-se significativo $(\mathrm{P}<0,05)$ apenas para 0 horário das 11, 13 e 17 horas. Em todos esses instantes, os animais que receberam o tratamento V0 apresentaram menores valores de TR em relação aos animais que receberam os tratamentos $\mathrm{V}$ e $\mathrm{VN}$. 
Não era esperado que o tratamento V0 proporcionasse menor valor de $\mathrm{TR}$, entretanto, cabe ressaltar que, no horário das $11 \mathrm{~h}$, os animais mantidos neste lote estavam se dirigindo para a ordenha. Deve-se considerar que as vacas em lactação eram mantidas em sala de espera equipada com sistema de aspersão (chuveirão) durante 30 minutos que antecediam tal prática.

Já o período das $13 \mathrm{~h}$ correspondeu ao retorno dos animais para o freestall, os quais se dirigiam imediatamente para o comedouro, local que também apresentava sistema de aspersão montado em toda extensão da instalação.

Diante disso, possivelmente o resfriamento adicional a que esses animais foram expostos, seja na sala de espera ou na linha de alimentação, pode ter sido responsável pelos menores valores de TR verificados neste tratamento.

Os resultados observados entre os horários de avaliação revelaram efeito cúbico $(P<0,05)$ para $\circ$ tratamento $V 0$, quadrático $(P<0,05)$ para 0 tratamento $V(P<0,05)$ e linear para o tratamento $V N$.

Verificou-se, no tratamento V0, que a TR apresentou valores mais elevados a partir das 13h. Esses resultados estão de acordo com o trabalho realizado por Baccari Junior et al. (1979) que, em condições de termoneutralidade, encontraram que a TR de bovinos holandeses apresentava correlação mais alta $(r=0,96)$ com a hora do dia do que com a temperatura do ar $(r=0,71)$. A partir das 15 horas, a temperatura do ar começou a cair, enquanto a temperatura retal continuou a aumentar, mostrando que durante o dia esta se eleva em função do metabolismo animal que propriamente da temperatura ambiente. 


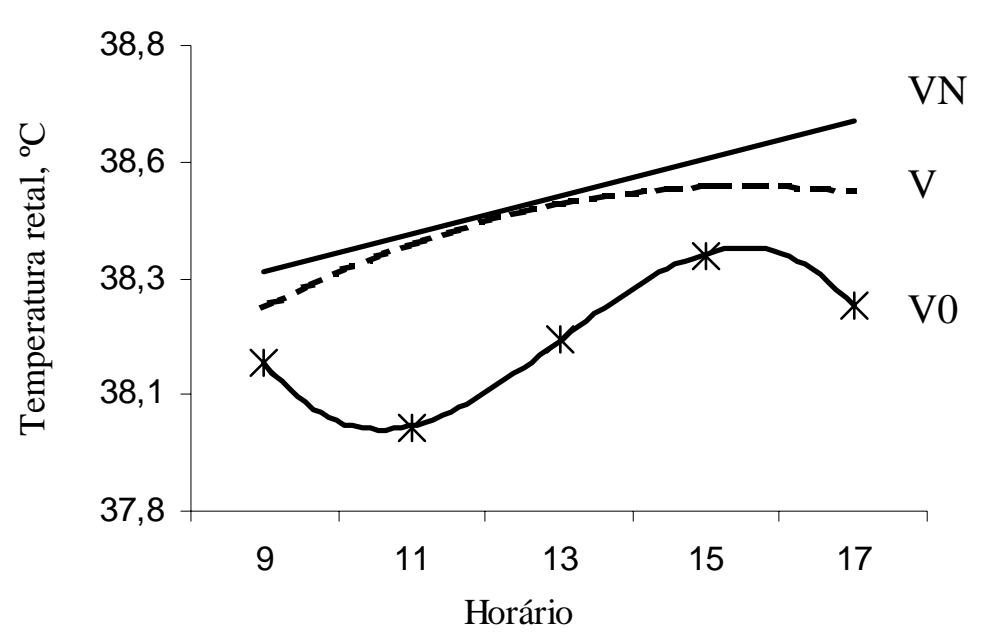

Figura 28 - Equação de regressão ajustada para a TR em função dos horários de avaliação nos tratamentos adotados

De maneira semelhante, Martello (2002) observou na temperatura retal média dos animais uma tendência de elevação durante o decorrer do dia, nos tratamentos estudados, que foram instalação sem climatização, com nebulização ou malha de sombreamento. Os valores numéricos da TR da tarde (13 e 17h) foram superiores aos da manhã em todos os tratamentos.

Verificou-se no tratamento $V$ que o maior valor encontrado para a TR $\left(38,5^{\circ} \mathrm{C}\right)$ foi observado às $16,3 \mathrm{~h}$. Para o tratamento $\mathrm{VN}$, os resultados observados entre os horários de avaliação revelaram efeito linear $(P<0,05)$. Os valores encontrados no presente experimento situaram-se nas faixas de normalidade 38 a 39,5C considerada para a variável em questão (Du Preez, 2000), indicando ausência de estresse térmico.

Os efeitos da ventilação ou ventilação associada à aspersão foram avaliados por Frazzi et al. (1997). Destaca-se, entretanto, que os aspersores foram regulados para não molhar o animal. Desta forma, verificou-se decréscimo na temperatura ambiente máxima entre 2,5 e 3,0ํํ e o aumento na umidade relativa foi de $10-15 \%$. Nas condições em que os experimento foi realizado, as vacas em lactação mantidas no tratamento ventilação associado a 
aspersão apresentaram menor valor de TR. Por outro lado, Arcaro Junior et al. (2001) não observaram diferença na temperatura retal de vacas em lactação mantidas em instalação com aspersão $\left(38,6^{\circ} \mathrm{C}\right)$ ou sem aspersão $\left(38^{\circ} 5^{\circ} \mathrm{C}\right)$.

As alterações na temperatura corporal têm efeitos marcantes na função endógena que levam a distúrbios na fertilidade, crescimento e lactação. A manutenção da temperatura corporal na zona de termoneutralidade é prérequisito para a produtividade máxima das vacas em lactação (McDowell et al., 1976).

\subsubsection{Freqüência respiratória (FR)}

$\mathrm{Na}$ Tabela 10 são apresentados os valores médios verificados para a freqüência respiratória (FR) durante o período experimental. As equações de regressão ajustadas em função dos horários de avaliação são ilustradas pela Figura 29.

A freqüência respiratória não diferiu $(P>0,05)$ entre os tratamentos avaliados. Os resultados observados entre os horários de avaliação revelaram efeito cúbico $(P<0,05)$ para o tratamento V0, quadrático $(P<0,05)$ para 0 tratamento $\mathrm{V}(\mathrm{P}<0,05)$ e linear para o tratamento $\mathrm{VN}$.

Verificou-se no tratamento V0 que a FR apresentou valores mais elevados a partir das 15 horas. O maior valor encontrado para a FR no tratamento $\mathrm{V}\left(59 \mathrm{mov} \mathrm{min}^{-1}\right)$ foi observado às 15 horas. Para o tratamento VN, os resultados observados entre os horários de avaliação revelaram efeito linear $(P<0,05)$. 
Tabela 10. Valores médios e erros padrão da média da freqüência respiratória (FR) das vacas em lactação mensuradas das 9 às $17 \mathrm{~h}$

\begin{tabular}{lcccccl}
\hline FR & $9 \mathrm{~h}$ & $11 \mathrm{~h}$ & $13 \mathrm{~h}$ & $15 \mathrm{~h}$ & $17 \mathrm{~h}$ & Efeito \\
\hline V0 & $56,0 \pm 0,68 \mathrm{a}$ & $56,0 \pm 0,68 \mathrm{a}$ & $56,0 \pm 0,68 \mathrm{a}$ & $64,0 \pm 0,68 \mathrm{a}$ & $60,0 \pm 0,68 \mathrm{a}$ & Cúbico $^{1}$ \\
V & $52,0 \pm 0,68 \mathrm{a}$ & $56,0 \pm 0,68 \mathrm{a}$ & $60,0 \pm 0,68 \mathrm{a}$ & $56,0 \pm 0,68 \mathrm{a}$ & $52,0 \pm 0,68 \mathrm{a}$ & Quadrático $^{2}$ \\
VN & $52,0 \pm 0,68 \mathrm{a}$ & $56,0 \pm 0,68 \mathrm{a}$ & $60,0 \pm 0,68 \mathrm{a}$ & $60,0 \pm 0,68 \mathrm{a}$ & $60,0 \pm 0,68 \mathrm{a}$ & Linear $^{3}$
\end{tabular}

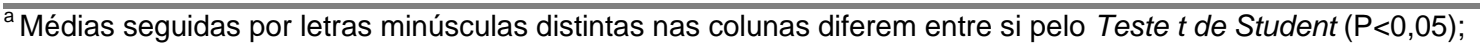

${ }^{1} Y=-x^{3}+9,0 x^{2}-22,0 x+70,4\left(R^{2}=0,78\right) ;$

${ }^{2} Y=-1,7143 x^{2}+10,286 x+43,2\left(R^{2}=0,92\right)$

${ }^{3} Y=2 x+51,6\left(R^{2}=0,78\right)$.

A freqüência respiratória correspondente a 60 movimentos por minuto indica animais com ausência de estresse térmico ou este é mínimo (Hahn e Mader, 1997). Os resultados aqui verificados foram semelhantes aos encontrados por Berman et al. (1985) que relataram freqüência respiratória entre 50 a 60 movimentos por minuto, quando a temperatura ambiente foi superior a $25^{\circ} \mathrm{C}$. Desta forma, os animais analisados sob as condições do presente experimento não se encontravam em estresse térmico.

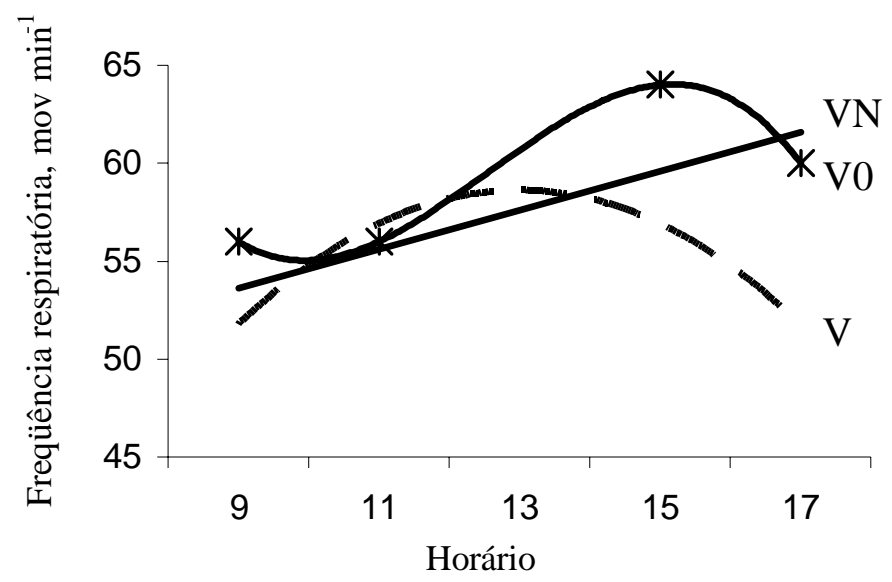

Figura 29 - Equação de regressão ajustada para a FR em função dos horários de avaliação nos tratamentos adotados 
Embora a temperatura retal aumente somente quando o THI se mostra superior a 80, a taxa respiratória apresenta-se alterada com THI igual a 73. Tal fato poderia indicar que o aumento verificado na freqüência respiratória preveniria a elevação da temperatura retal até que o THI alcançasse o valor de 80 (Lemerle e Goodard, 1986).

O primeiro sinal visível de resposta ao estresse térmico é a taquipinéia, embora este seja o terceiro mecanismo na seqüência de adaptação fisiológica, pois a vasodilatação periférica e o aumento da sudorese ocorrem antes (Cunninghan, 1999).

A eficiência do resfriamento evaporativo e seus efeitos sobre as variáveis ambientais e fisiológicas de vacas em lactação foram investigadas por Brouk et al. (2001b). Os tratamentos adotados foram aspersão e aspersão associada à ventilação forçada na linha de alimentação. Ao sistema exclusivo de aspersão na linha da alimentação adicionaram-se, ao longo do freestall, ventiladores a cada 14,6 m; já a outro tratamento, acrescentou-se o sistema de nebulização ao longo do freestall. Este último foi responsável pela menor freqüência respiratória no período da manhã.

No experimento conduzido por Arcaro Junior et al. (2002), os quais avaliaram a eficiência da ventilação ou ventilação associada à aspersão, foi verificado que os animais mantidos no tratamento ventilação (74 movimentos por minuto) ou ventilação associada à aspersão (76 movimentos por minuto) apresentaram menor FR que os submetidos ao grupo controle (96 movimentos por minuto), sendo esses valores superiores aos verificados na presente pesquisa.

Os elementos chave para avaliar a influência do estresse térmico sobre o desempenho e bem-estar de animais confinados são: 1) a magnitude (intensidade e duração) da condição térmica que excede os limites para adaptação e mecanismos compensatórios; 2) a oportunidade para a recuperação noturna. A termorregulação e o comportamento alimentar são as respostas de maior importância em situações de estresse (Hahn, 1993). 
A freqüência respiratória e a temperatura corporal estão relacionadas com a termorregulação, enquanto que a ingestão de matéria seca é o indicativo primário do comportamento alimentar. A freqüência respiratória serve como advertência inicial ao estresse, aumentando marcadamente acima de sua normalidade na tentativa de manter a homeostase por meio da dissipação do excesso do calor corporal. Estudos desenvolvidos apontaram que a FR aumentou 4,3 movimentos por minuto para cada elevação de $1^{\circ} \mathrm{C}$ acima da FR normal de 60 movimentos por minuto.

\subsubsection{Temperatura da superfície do pelame (TP)}

Os valores médios e erros padrão da média verificados para a temperatura do pelame branco (TPB) ou negro (TPN) durante o período experimental são apresentados na Tabela 11.

Tabela 11. Valores médios e erros padrão da média da temperatura do pelame branco (TPB) e negro (TPN) das vacas em lactação mensuradas das 9 às $17 \mathrm{~h}$

\begin{tabular}{|c|c|c|c|c|c|c|}
\hline TPB & $9 \mathrm{~h}$ & $11 \mathrm{~h}$ & $13 \mathrm{~h}$ & $15 \mathrm{~h}$ & $17 \mathrm{~h}$ & Efeito \\
\hline V0 & $37,9 \pm 0,65 a$ & $36,1 \pm 0,65 a$ & $35,5 \pm 0,65 a$ & $34,1 \pm 0,65 a$ & $33,3 \pm 0,65 a$ & Quarto Grau ${ }^{1}$ \\
\hline V & $36,2 \pm 0,65 a$ & $34,2 \pm 0,65 a$ & $35,7 \pm 0,65 a$ & $32,7 \pm 0,65 a$ & $31,9 \pm 0,65 a$ & Quarto Grau ${ }^{1}$ \\
\hline VN & $38,0 \pm 0,65 a$ & $35,1 \pm 0,65 a$ & $35,6 \pm 0,65 a$ & $33,8 \pm 0,65 a$ & $33,7 \pm 0,65 a$ & Quarto Grau ${ }^{1}$ \\
\hline \multicolumn{7}{|l|}{ TPN } \\
\hline V0 & $31,8 \pm 0,42 a$ & $31,1 \pm 0,42 a$ & $33,0 \pm 0,42 a$ & $31,4 \pm 0,42 a$ & $32,2 \pm 0,42 a$ & Quarto Grau² \\
\hline V & $31,7 \pm 0,42 a$ & $31,2 \pm 0,42 a$ & $31,8 \pm 0,42 a$ & $31,4 \pm 0,42 a$ & $31,4 \pm 0,42 a$ & Quarto Grau² \\
\hline VN & $31,8 \pm 0,42 a$ & $31,3 \pm 0,42 a$ & $31,8 \pm 0,42 a$ & $32,2 \pm 0,42 a$ & $32,1 \pm 0,42 a$ & Quarto Grau² \\
\hline
\end{tabular}


Não foi observada diferença $(P>0,05)$ entre os tratamentos para a TPB ou TPN. As equações de regressão ajustadas em função dos horários de avaliação são ilustradas pela Figura 30 . Os resultados observados entre os horários de avaliação mostraram efeito polinomial de quarto grau $(\mathrm{P}<0,05)$ para todos os tratamentos.

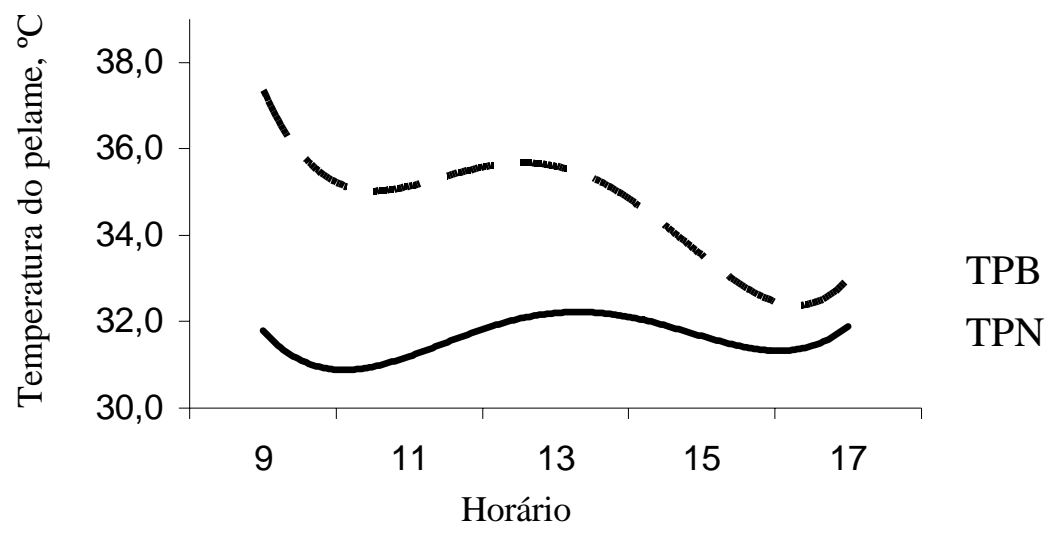

Figura 30 - Equações de regressão ajustadas para a TPB e TPN em função dos horários de avaliação nos tratamentos adotados

A habilidade dos bovinos em resistir aos efeitos negativos do estresse térmico depende da sua adaptação genética e fisiológica ao ambiente. Um dos principais atributos que afetam a resistência desses animais ao calor é a superfície cutânea (Maia, 2002).

O pelame representa a fronteira entre o ambiente climático e o corpo dos animais, podendo, desta forma, influenciar o balanço térmico. $O$ papel termorregulador do pelame pode ser dividido em dois componentes: proteção contra o excesso de absorção da radiação solar e dissipação do calor da superfície do animal (Silva, 2000).

A cor do pelame é uma das mais importantes características envolvidas nos processos de tolerância ao calor. A raça Holandesa é uma das mais 
difundidas para a produção de leite no mundo, entretanto, esses animais com pelagem característica com malhas negras e brancas, podem ser susceptíveis à carga térmica excessiva, uma vez que a malha negra tende a acumular mais energia radiante que a branca (Goodwin et al., 1997).

Os animais com superfície externa pigmentada e escura são mais sujeitos ao estresse pelo calor que os de coloração clara, apresentando maior absorvidade da radiação solar, armazenando, assim, maior quantidade de energia térmica do que os animais que apresentam uma capa com coloração clara. Esta última apresentaria maior refletividade, o que tem levado a maioria dos pesquisadores a aceitar a vantagem adaptativa dos pelames claros nos ambientes tropicais (Silva et al., 2001).

Conforme descrito por Cena e Monteith (1975), o pelame branco apresenta maior penetração da radiação solar, sendo que a transmissão dessa radiação pela capa depende das propriedades estruturais e físicas do pelame (espessura da capa, comprimento, densidade, diâmetro e inclinação dos pêlos). A maior transmissão é proporcionada por pelames brancos, ao passo que os negros, em geral, apresentam transmissão muito baixa ou nula.

Surpreendentemente, no presente experimento a TPN foi inferior à TPB em todos os tratamentos. Provavelmente, tal fato pode estar associado à localização desses animais próximos à linha de aspersão (comedouro) durante os horários em que foram avaliados. Também, deve-se ressaltar que a disposição das malhas brancas e negras na superfície corporal do animal podem ter contribuído de modo que uma ou outra região estivesse mais exposta ao sistema de climatização, permanecendo molhada por mais tempo.

\subsubsection{Ingestão de matéria seca (IMS) e produção de leite (PL)}

Os resultados médios da ingestão de matéria seca (IMS) e produção de leite (PL) dos animais são exibidos na Tabela 12. Os valores médios obtidos para a IMS diária indicaram diferenças $(P<0,05)$ entre os tratamentos. Os 
animais submetidos ao tratamento V0 (20,5 $\left.\mathrm{kg} \mathrm{MS} \mathrm{dia}^{-1}\right)$ e V $\left(21,3 \mathrm{~kg} \mathrm{MS} \mathrm{dia}^{-1}\right)$ apresentaram maior consumo em relação aos mantidos no tratamento VN $(19,3$ $\left.\mathrm{kg} \mathrm{MS} \mathrm{dia}{ }^{-1}\right)$. Os tratamentos V0 e V não diferiram entre si.

Tabela 12. Valores médios diários e erros padrão da média da ingestão de matéria seca $\left(\mathrm{kg} \mathrm{MS} \mathrm{dia}^{-1}\right)$ e produção de leite $\left(\mathrm{kg} \mathrm{dia}^{-1}\right)$ durante o período experimental

Variáveis

V0

VN

\begin{tabular}{llll}
\hline Ingestão média de MS $\left(\mathrm{kg} \mathrm{dia}^{-1}\right)$ & $20,5 \pm 1,39 \mathrm{a}$ & $21,3 \pm 1,30 \mathrm{a}$ & $19,3 \pm 1,92 \mathrm{~b}$
\end{tabular}

Produção de leite $\left(\mathrm{kg} \mathrm{dia}^{-1}\right) \quad 24,1 \pm 1,25 \mathrm{a} \quad 20,2 \pm 1,25 \mathrm{a} \quad 23,7 \pm 1,25 \mathrm{a}$

$\overline{\mathrm{a}, \mathrm{b}}$ Médias seguidas por letras minúsculas distintas nas linhas diferem entre si pelo Teste $t$ de Student $(\mathrm{P}<0,05)$.

Todas as alterações verificadas no organismo animal têm como objetivo reduzir a produção de calor, uma vez que o indivíduo esteja em condições termicamente inadequadas. Desta forma, tende a reduzir a ingestão de alimentos na tentativa de diminuir a taxa metabólica e, conseqüentemente, a produção de calor (Collier et al., 1982).

A ingestão de alimentos das vacas em lactação começa a diminuir quando a temperatura ambiente se situa entre 25 e $26^{\circ} \mathrm{C}$, e a queda é mais acentuada quando esta é superior a $30^{\circ} \mathrm{C}$. A $40^{\circ} \mathrm{C}$ a ingestão da dieta declina em $40 \%$ (NRC, 2001).

Os valores médios da temperatura ambiente verificados nas condições do presente experimento estiveram entre $26,6^{\circ} \mathrm{C}$. Entretanto, a análise dos resultados encontrados para as variáveis termorregulatórias temperatura retal e freqüência respiratória não apresentaram indicativos de estresse térmico em qualquer um dos tratamentos aplicados. Sendo assim, as diferenças relatadas na IMS provavelmente foram influenciadas por outros fatores não controlados, e não necessariamente devido às variáveis climáticas. Ainda mais, era esperado 
que o tratamento $\mathrm{VN}$ refletisse em maior IMS, quando comparado com 0 tratamento V0.

As vacas em lactação submetidas à ventilação associada à aspersão em local sombreado conseguiram reduzir o efeito do estresse calórico na produção diária e apresentaram aumento de 7,8\% no consumo de alimento, 12\% na produção de leite, o qual correspondeu a $2,5 \mathrm{~kg}^{-1 a^{-1}}$, diminuição de $0,2^{\circ} \mathrm{C}$ a 0,5ㄷ da temperatura retal e redução de $29 \%$ na taxa respiratória (Chastain e Turner, 1994).

Quantificar os efeitos diretos do ambiente térmico sobre a produção de leite não é tarefa fácil, uma vez que esta é amplamente afetada por outros fatores, como por exemplo, o manejo nutricional (Fuquay, 1997).

Quando avaliados os resultados médios obtidos para a produção de leite total, não foram observadas diferenças $(P>0,05)$ entre os tratamentos. Os valores médios encontrados foram 21,4; 20,2 e 23,7 $\mathrm{kg} \mathrm{dia}^{-1}$, respectivamente, para os tratamentos $\mathrm{V} 0, \mathrm{~V}$ e $\mathrm{VN}$.

A principal razão para o decréscimo na produção de leite em climas quentes é a redução no consumo de alimentos, sendo esta uma tentativa do animal em minimizar o desbalanço térmico e manter a homeotermia (Yousef e Johnson, 1985). No entanto, o tratamento VN, o qual apresentou menor IMS não teve sua produção de leite afetada.

De maneira semelhante, Fuquay (1997) não observaram diferenças significativas na produção de leite, em vacas submetidas a tratamentos com e sem climatização. Entretanto, os autores relataram que as vacas do grupo controle mostraram menor persistência em lactação. Tal informação mostra-se relevante no tocante à investigação do condicionamento de ambientes para vacas em lactação, uma vez que persistência mais curta reflete de forma negativa na produção de leite por vaca a cada ano.

Uma avaliação geral dos experimentos conduzidos em freestall equipados ou não com sistemas de climatização, em diversas regiões dos EUA, constatou aumento de 4,9 a $12 \%$ nas produções de leite em instalações 
climatizadas. No entanto, ressalta-se que quanto mais fechada a instalação, maior o efeito do sistema (Bucklin e Bray, 1998).

Ingraham (1979) encontrou redução na produção de leite de $0,32 \mathrm{~kg}$ por unidade de aumento no THI. West (2003) encontraram declínio de 0,88 kg por unidade de aumento no THI acima de 72. Nas condições do experimento, o maior valor estimado para o THI foi 75,8 unidades, sendo este ainda inexpressivo para proporcionar decréscimos na PL. Tal fato corrobora os estudos de Martello (2002); Matarazzo et al. (2003) e Perissinotto (2003), sugerindo avaliações adicionais acerca dos limites críticos desses índices para as vacas em lactação mantidas em regiões de climas tropicais.

\subsection{Conclusões}

Conforme os resultados verificados nas condições do presente experimento, pode-se concluir que:

a. A climatização da área de descanso em instalações do tipo freestall não proporcionou melhorias nas propriedades psicrométricas do ar, uma vez que as variáveis meteorológicas e os índices de conforto térmico permaneceram acima da zona de termoneutralidade;

b. As variáveis termorregulátorias temperatura retal, freqüência respiratória e temperatura do pelame não foram alteradas com a aplicação dos tratamentos;

c. Os animais mantidos nos tratamentos com ausência e presença de ventilação apresentaram maior consumo de matéria seca, entretanto, estes não refletiram em maior produção de leite. 


\section{ZOOTECNIA DE PRECISÃO: MONITORAMENTO ELETRÔNICO DAS RESPOSTAS COMPORTAMENTAIS DE VACAS EM LACTAÇÃO ALOJADAS EM FREESTALL CLIMATIZADO}

\section{Resumo}

O trabalho teve como objetivo empregar o monitoramento eletrônico para avaliar as respostas comportamentais de vacas em lactação alojadas em freestall climatizado. Quatro vídeo-câmeras foram instaladas em cada tratamento, nos locais estratégicos do freestall, de modo a capturar, em tempo real, as atividades (ingestão, ruminação e ócio) e o deslocamento dos animais. O experimento teve duração de 28 dias consecutivos do mês de novembro de 2003, no qual as imagens foram gravadas durante sete dias, no intervalo das 9 às 17 horas. Foram utilizadas 15 vacas em lactação, multíparas, com produção média de $20 \mathrm{~kg}$ de leite dia $^{-1}$. Os tratamentos adotados foram: ausência de ventilação (V0), ventilação $(\mathrm{V})$ e ventilação + nebulização $(\mathrm{VN})$ posicionados na área de descanso dos animais. Os dados referentes à temperatura do bulbo seco (TBS), umidade relativa do ar (UR) e temperatura de globo negro (TGN) no interior da instalação e no ambiente externo foram mensurados a cada 15 minutos ao longo das 24 horas. Os animais mantidos no tratamento $\mathrm{V}$ apresentaram maior tempo despendido $(P<0,05)$ com as atividades de ingestão de alimentos (106,8 min) e água (21,7 min), quando comparados com V0 e VN. Verificou-se que o tempo de ruminação dos animais em V0 (164,3 min) foi superior $(P<0,05)$ aos constatados nos tratamentos $V(102,5 \mathrm{~min})$ e $\mathrm{VN}(129,5$ min). Já as vacas do tratamento VN (200,2 min) apresentaram maior tempo em 
ócio ( $\mathrm{P}<0,05)$, quando comparadas com V0 (164,3 $\mathrm{min})$ e $\mathrm{V}(117,0 \mathrm{~min})$. Foram verificadas diferenças $(P<0,05)$ entre os tratamentos com relação ao tempo em pé, sendo que as vacas do tratamento V0 (183,7 $\mathrm{min})$ apresentaram menor permanência nesta posição. Não foram constatas diferenças $(P>0,05)$ entre os tratamentos para o tempo em que as vacas em lactação permaneceram deitadas. Nas condições do presente experimento, a adoção de sistemas de climatização na área de descanso não se mostrou eficiente.

\section{PRECISION ANIMAL SCIENCE: ELECTRONIC MONITORING ON BEHAVIORAL PATTERNS OF DAIRY COWS IN A COOLING FREESTALL}

\section{Summary}

This work aimed to use electronic monitoring for evaluating behavior patterns of lactating cows in a cooling freestall. Four video cameras were strategically installed in each treatment for capturing in real time images of animal displacements and activities, as intake, rumination and resting. The trial was carried out during 28 consecutive days of November 2003, in which images were daily recorded from 9 a.m. to 5 p.m. during 7 days. Fifteen multiparous lactating cows producing $20 \mathrm{~kg}$ of milk per day were used. The tested treatments were: non-fan (F0), fan (F) and fan plus misting (FM) in direction to animal bedding. Dry bulb temperature (DBT), air relative humidity $(\mathrm{RH})$, and black globe temperature (BGT) inside and outside of facility were measured every 15 minutes during 24 hours. In treatment $\mathrm{V}$, animals spent more time eating (106.8 min) and drinking water $(21.7 \mathrm{~min})$ in relation to $\mathrm{VO}$ and $\mathrm{VN}$ treatments. Rumination time of $\mathrm{V} 0$ animals was higher $(164.3 \mathrm{~min})$ than those of $\mathrm{V}(102.5$ $\mathrm{min}$ ) and VN (129.5 min) treatments. Cows of VN treatment spent more resting time $(200.2 \mathrm{~min})$ than those of $\mathrm{V} 0(164.3 \mathrm{~min})$ and $\mathrm{V}(117.0 \mathrm{~min})$ treatments. In relation to time spent standing up, cows of V0 treatment spent the smallest time (183.7 min). There was no difference among lactating cows from the different 
treatments in terms of time spent lying down. Thus, considering this study circumstances, acclimatization system in resting area was not an efficient practice.

\subsection{Introdução}

O comportamento animal é uma característica fenotípica que envolve reações motoras definidas, vocalização e produção de odores, as quais conduzem a ações diárias de sobrevivência e interações sociais, sendo esta, determinadas por fatores ambientais e genéticos (Banks, 1992).

Embora existam poucas referências sobre a extensão das mudanças comportamentais em condições de estresse térmico, fica claro que as alterações dos padrões usuais de ingestão de água e alimentos, postura e movimentação são importantes mecanismos adaptativos para reduzir o efeito do calor (Pires et al., 2000).

A atividade de procura por alimento dos bovinos estabulados é bem característica, representada por dois momentos principais, o início da manhã e final da tarde. O comportamento alimentar é fortemente influenciado pelas interrelações ambientais e sociais; em média, as vacas estabuladas passam cinco horas se alimentando. Embora o confinamento seja um ambiente diferente do natural, o ritmo diurno do padrão alimentar é semelhante àquele do pastejo, mas o tempo total de alimentação é sensivelmente inferior (Fraser e Broom, 1990).

O consumo de água das vacas em lactação é atividade vital para seu desempenho, já que são necessários 4-5 litros de água para cada quilo de leite a ser produzido. Picos no consumo de água são observados nos horários após a ordenha, quando chegam a representar $40-50 \%$ do consumo total diário (Campos, 2000). O aumento na ingestão de água em condições de estresse calórico tem como objetivo repor as perdas sudativas e respiratórias, além de 
resfriamento corporal, por meio do contato da água, mais fria que o corpo, com as mucosas do trato digestivo (Titto 1998).

O tempo despendido com a ruminação em animais estabulados é de aproximadamente oito horas. Os estímulos da ruminação podem permitir o descanso fisiológico e a recuperação física, uma vez que as vacas gastam menos tempo dormindo, quando comparadas com outras espécies como o cão ou os eqüídeos. As vacas preferem, ainda, ruminar deitadas, com o peito junto ao solo; entretanto, em situações de temperaturas elevadas, passam a ruminar mais tempo em pé (Albrigth,1993).

O ócio é a atividade que não inclui nem ruminação nem alimentação, e apresenta duração média de dez horas diárias. Os animais procuram a sombra e reduzem suas atividade nas horas mais quentes do dia, permanecendo deitados, na área de descanso (Blachshaw e Blackshaw, 1994). De acordo com Camargo (1988), os animais em ócio preferiram permanecer em pé nas horas mais quentes do dia, enquanto à noite, mantiveram-se deitados. Tais posturas foram verificadas em condições do Brasil Central.

Dentre os padrões fixos de comportamento, o de deitar é considerado de grande importância para as vacas leiteiras. A privação do descanso pode induzir a frustração que se manifesta por comportamentos estereotipados. Outras conseqüências incluem lesões traumáticas e outros danos físicos, resultando em problemas sanitários e baixo desempenho produtivo (Krohn e Munksgaard, 1993). As vacas passam 10 a 14 horas por dia deitadas, portanto, disponibilizar uma cama limpa e seca é importante, principalmente em condições de freestall (Bickert, 2000).

Diante das alterações comportamentais desencadeadas pelas vacas em lactação, quando em estresse térmico, preservar o bem-estar e garantir condições satisfatórias de conforto são componentes vitais para manter altos níveis de produtividade (Pires et al., 2000).

As modificações ambientais têm sido utilizadas como estratégias para atenuar os efeitos do estresse térmico sobre as vacas em lactação, e essas 
alternativas incluem desde a disponibilidade de sombra até sistemas conjugados em que o resfriamento evaporativo (aspersão ou nebulização) é associado à ventilação forçada (Igono et al. 1985; Gebremedhin e Wu., 2001; Matarazzo et al., 2003b).

Entretanto, pouca investigação tem sido feita a respeito das mudanças comportamentais causadas em função dessas intervenções microclimáticas. Conhecer como o animal reage nessas circunstâncias é fundamental para que se possa planejar o sistema de ventilação e resfriamento de maneira adequada (Frazzi et al., 2002).

Trabalhos recentes relataram que o uso do freestall pode ser um indicador da preferência da vaca, e essa preferência pode ser interpretada como medida do seu conforto (Wagner-Storch et al., 2003). Tem se constatado que a instalação dos sistemas de aspersão ou nebulização na linha de alimentação leva a vaca a permanecer durante longos períodos nesses locais, a fim de se beneficiarem da remoção do calor corporal por meio da evaporação da água na pele. Por outro lado, esses resultados indicaram presença do estresse térmico, considerando que ocorreu aumento no tempo em que os animais ficaram em pé (Calegari et al., 2003). Tais resultados confirmaram os relatos de Shultz (1984), em que o número de animais em ócio ou ruminado em pé aumentou linearmente com a elevação da temperatura ambiente.

Atualmente, as video-câmeras têm sido empregadas como ferramentas para monitorar o tempo despendido em cada local do freestall, bem como as atividades exercidas pelas vacas em lactação. Neste processo, é desnecessário o observador no local, eliminando mais uma fonte potencial de influência sobre a atividade animal que é a presença humana (Haley et al. 2000; Overton et al. 2002).

Dada a possibilidade da adoção desta ferramenta para a investigação dos dados, este trabalho teve como objetivo avaliar as respostas comportamentais de vacas em lactação alojadas em freestall climatizado por meio do monitoramento eletrônico com vídeo-câmeras. 


\subsection{Material e Métodos}

\subsubsection{Local, instalações e manejo}

O experimento foi conduzido com rebanho comercial de gado Holandês, localizado no município de São Pedro, SP, a altitude de $580 \mathrm{~m}$ e coordenadas

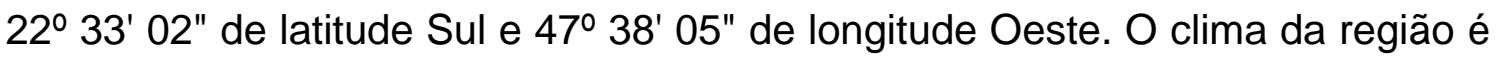
do tipo Cwa da classificação Köppen, ou seja, quente e úmido com estação chuvosa no verão e seco no inverno. A temperatura média anual é de $22^{\circ} \mathrm{C}$, a pluviosidade média anual está próxima de $1200 \mathrm{~mm}$ e os ventos são predominantes do sudeste.

A instalação apresentava as seguintes características construtivas: $80 \mathrm{~m}$ de comprimento e $28 \mathrm{~m}$ de largura, laterais abertas, orientação leste-oeste, corredor central de 3,0 m, pé-direito central de $9 \mathrm{~m}$, telhado de duas águas com cobertura de telha de barro e sistema de lanternim vazado. O piso era de concreto e apresentava ranhuras de $0,5 \mathrm{~cm}$ espaçadas $7,0 \mathrm{~cm}$ entre si. A linha de alimentação tinha a extensão de todo galpão. Os bebedouros eram de alvenaria, localizados estrategicamente nas laterais do galpão, com dimensões de 2,8 $\mathrm{m}$ de comprimento, $0,8 \mathrm{~m}$ de largura e capacidade de $0,8 \mathrm{~m}^{3}$ de água.

Foram utilizados dois galpões ( $\mathrm{A}$ e $\mathrm{B}$ ) para a condução do experimento. Realizou-se inicialmente um monitoramento ambiental (temperatura de bulbo seco, umidade relativa e índice de temperatura e umidade) nas duas instalações para verificar possíveis diferenças no microclima interno. Esta avaliação teve a duração de 27 dias, nos quais os equipamentos de climatização não foram acionados.

O freestall A era dividido em duas seções com 120 baias cada, sendo que foi utilizado para o experimento apenas uma delas. Optou-se por empregar no estudo apenas uma seção, pois essa separação era feita em função da ordem de parição das vacas. Sendo assim, em um lote estavam alojadas as vacas primíparas e no outros as multíparas. Já o freestall B era dividido em 
quatro seções com 60 baias. Neste caso, foram destinadas ao experimento duas seções.

O manejo dos animais durante a fase experimental consistiu em dois horários de alimentação (9 e 15 horas), a qual foi fornecida na forma de dieta completa e de maneira a atender as exigências nutricionais para a manutenção e produção de leite, de acordo com o NRC (2001). A oferta de alimento e sobras foi registrada diariamente e amostradas a cada semana para posterior análise bromatológica. Os animais foram ordenhados e suas produções registradas, diariamente, três vezes ao dia (2, 10 e 18 horas).

\subsubsection{Tratamentos}

O experimento teve a duração de 28 dias consecutivos no mês de novembro de 2003 , dos quais sete foram destinados à adaptação dos animais ao tratamento e manejo empregado. Durante 21 dias, foram coletados dados referentes às variáveis ambientais e produtivas das vacas em lactação. Nos últimos sete dias deste período é que foi efetuada a avaliação dos padrões comportamentais.

Foram utilizadas 15 vacas Holandesas, multíparas, em lactação, com peso médio de $600 \mathrm{~kg}$ e produção média de $20 \mathrm{~kg}$ de leite por dia, distribuídas aleatoriamente nos três tratamentos. Esses animais foram identificados individualmente com colares coloridos, de modo a facilitar seu reconhecimento nas imagens de vídeo.

O freestall foi equipado em toda sua extensão com sistema de aspersão montado à altura de 2,5 m acima da linha de alimentação e constituído por tubo PVC, com espaçamento entre bicos de $1 \mathrm{~m}$. Esse sistema era acionado por uma bomba com motor trifásico, cujo consumo de energia era equivalente a 1,48 kW $\mathrm{h}^{-1}$. A vazão de água na linha de aspersão foi de $30 \mathrm{~L} \mathrm{hora}^{-1}$ e a intermitência foi de $12 \mathrm{~min}$. Os ventiladores foram fixados a altura de 2,5 $\mathrm{m}$ e espaçados a cada 
$11 \mathrm{~m}$. Apresentavam diâmetro de 0,9 m, motor de $1 / 4 \mathrm{CV}$, vazão de $300 \mathrm{~m}^{3} \mathrm{~h}^{-1}$, 495 RPM, com capacidade de produzir movimentação de ar de até $2,5 \mathrm{~m} \mathrm{~s}^{-1}$.

Desta forma, os tratamentos foram aplicados aleatoriamente na área de descanso dos animais (cama) da seguinte maneira:

> Tratamento 1: sem ventilação (V0);

> Tratamento 2: ventilação forçada;

> Tratamento 3: ventilação forçada adicionada de linha de nebulização.

O sistema de nebulização foi montado à altura de $3 \mathrm{~m}$ acima da área de descanso dos animais e era constituído por tubos emborrachados, com espaçamento entre bicos de $1 \mathrm{~m}$. Esse sistema era acionado por uma bomba com motor trifásico cujo consumo de energia era equivalente a $0,74 \mathrm{~kW}$ hora $^{-1}$. $A$ vazão de água na linha de nebulização foi de $3 \mathrm{~L} \mathrm{hora}^{-1}$ e a intermitência foi a mesma do sistema de aspersão (12 min). O SRAE e os ventiladores foram acionados por meio de termostato toda a vez que a temperatura no interior do freestall atingia $25^{\circ} \mathrm{C}$.

\subsubsection{Monitoramento ambiental}

As variáveis registradas no interior das instalações e no ambiente externo foram: temperatura do bulbo seco (TBS), umidade relativa do ar (UR\%) e temperatura do globo negro (TGN). As leituras foram realizadas a cada 15 min ao longo das 24 horas por sensores acoplados ao sistema eletrônico de aquisição de dados $\left(\mathrm{HOBO}{ }^{\circledR} \mathrm{H} 8\right)$. A estação automática foi fixada a altura de 2,5 $\mathrm{m}$ do piso, a fim de protegê-la dos animais. A partir dos valores encontrados para as variáveis climáticas, foram calculados os índices de conforto térmico THI (Thom, 1959) e BGHI (Buffington et al., 1981). 


\subsubsection{Monitoramento eletrônico do comportamento animal}

Dentro da seção do freestall estudada para cada tratamento, foi realizada uma subdivisão, correspondente a $12 \mathrm{~m}$ de comprimento por $12 \mathrm{~m}$ de largura. Este espaço físico dispunha de 14 camas dispostas frente a frente, permitindo que todas as vacas tivessem a mesma oportunidade de escolher o lado desejado para deitar. A restrição da área foi necessária, em função da limitação do alcance das câmeras empregadas.

Quatro vídeo-câmeras coloridas, com lente de 2,45 mm foram alocadas estrategicamente no freestall, à altura de $2,75 \mathrm{~m}$ acima do piso de forma a permitir a visualização completa da área em estudo (Figura 31).
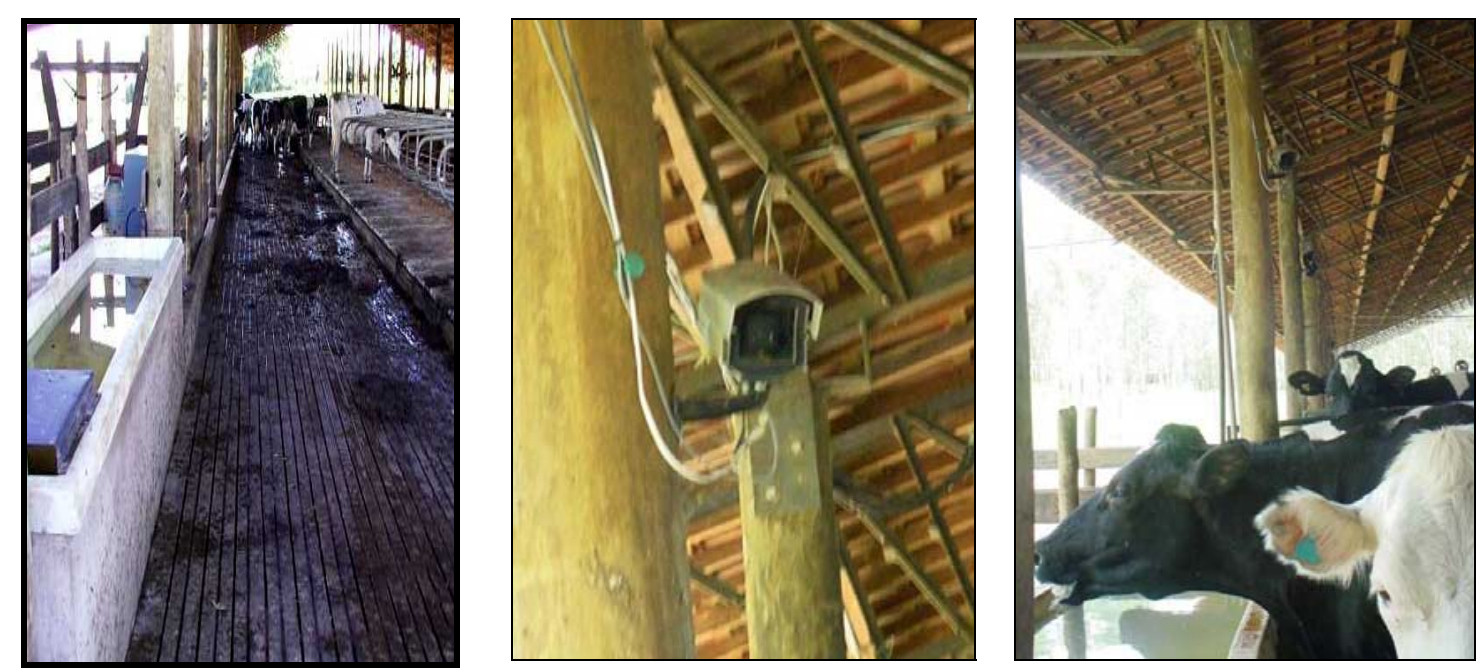

Figura 31 - Detalhe do posicionamento da vídeo-câmera sobre o bebedouro

As câmeras foram acopladas ao microcomputador central que era equipado com placa de captura de imagens, sendo estas gerenciadas em tempo real pelo software Topway $^{\circledR}$ (Figura 32). As imagens foram registradas diariamente, durante sete dias, no intervalo das 9 às 17 horas. 

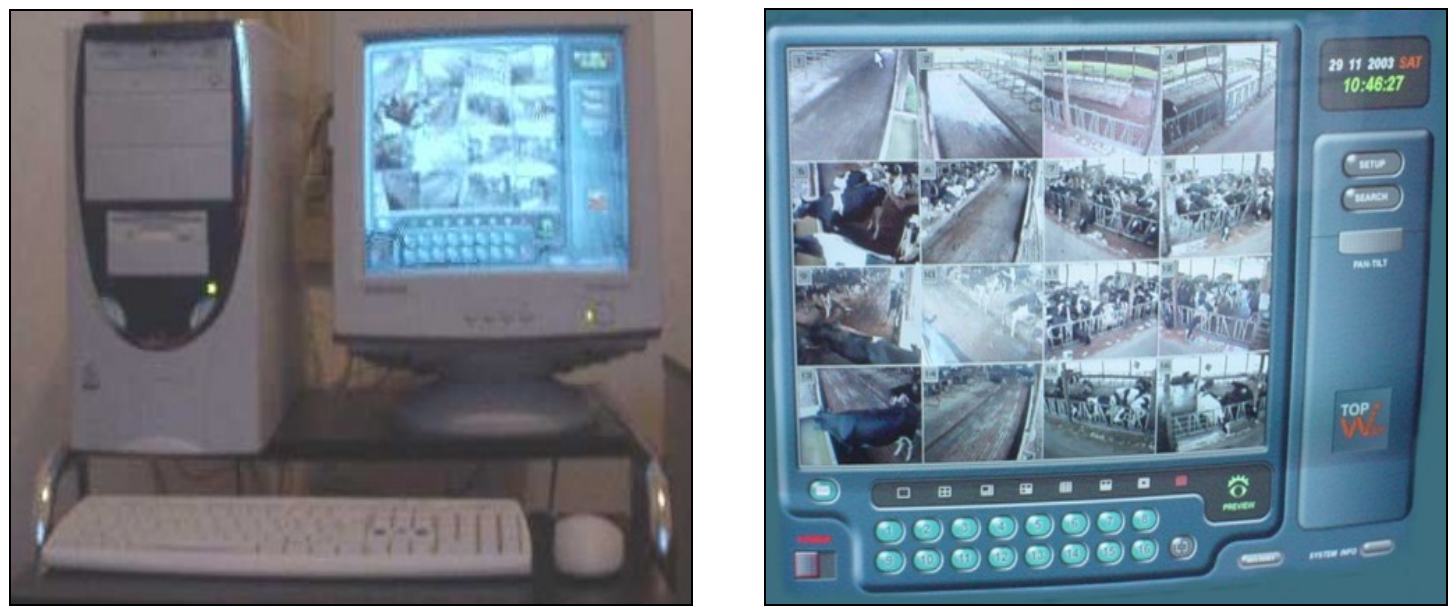

Figura - 32 Detalhe do computador e captura de imagens

Para quantificar os padrões comportamentais, os vídeos foram revistos, e a cada intervalo de dez minutos era anotado o comportamento animal no etograma previamente estabelecido. A partir destes dados, determinou-se o tempo em minutos e em porcentagem em que os animais exerceram cada atividade. Os horários destinados à ordenha dos animais foram desconsiderados da análise.

Os animais foram monitorados quanto a sua localização e atividade dentro da instalação. Os padrões foram caracterizados conforme a Tabela 13.

Tabela 13. Definição dos padrões de comportamentais.

\begin{tabular}{ll}
\hline Atividade & Localização \\
\hline Comendo & Presença na área de alimentação \\
Bebendo & Presença na área do bebedouro \\
Ruminando & Presença na cama próxima à área de alimentação \\
Em ócio & Presença na cama próxima à área do bebedouro \\
Em pé & Presença no corredor próximo á área de alimentação \\
Deitado & Presença no corredor próximo à área do bebedouro \\
\hline
\end{tabular}




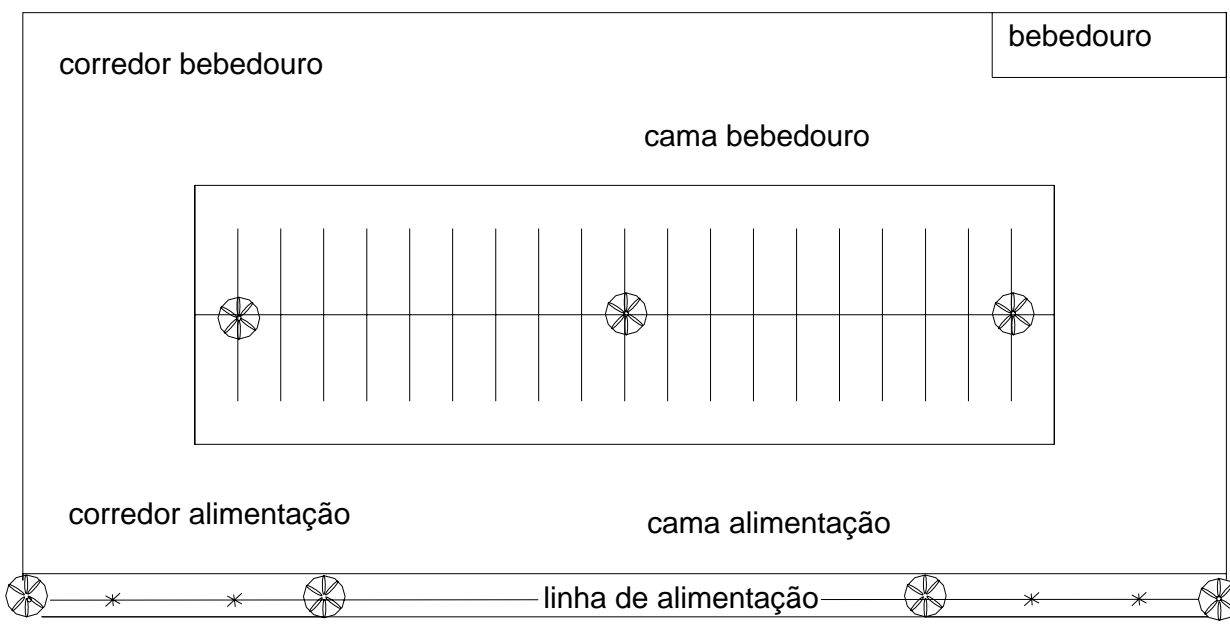

ventilador aspersor

Figura - 33 Representação esquemática dos locais avaliados

\subsubsection{Análise estatística}

O delineamento experimental adotado foi o inteiramente casualizado, utilizando os animais como repetições. Para analisar o efeito dos tratamentos (V0, V e VN) nas variáveis comportamentais (atividades e deslocamento) foram calculados os valores médios das respostas nos sete dias avaliados.

Empregou-se o SAS/LAB para verificar as pressuposições da análise de variância (ANOVA) para cada comportamento. Quando as pressuposições da ANOVA foram satisfeitas (ingestão de alimentos, ruminação (em pé e deitada), ócio (deitada) e postura corporal em pé e deitada) a comparação de médias foi feita pelo Teste de Tukey ao nível de significância de 5\%.

Quando as pressuposições da ANOVA não foram atendidas (tempo despendido com a ingestão de água e a atividade de ócio em pé), os tratamentos foram comparados utilizando-se a macro Kruskall.mac do Minitab, com a aplicação do teste não-paramétrico de Kruskal-Wallis e comparações múltiplas das medianas pelo teste de Dunn (Gibbons, 1976; Noether, 1991). 


\subsection{Resultados e Discussão}

\subsubsection{Tempo despendido em cada atividade}

O período médio diário em que os animais foram monitorados pelas vídeo-câmeras foi de 6,30 horas (376 min), sendo que os horários destinados à ordenha dos animais foram desconsiderados da análise. A Tabela 14 apresenta o tempo, em minutos, em que os animais realizaram as atividades de ingestão de alimento ou água, ruminação e ócio.

Tabela 14. Tempo médio (minutos) em que os animais permaneceram em cada atividade nos tratamentos avaliados

\begin{tabular}{|c|c|c|c|c|}
\hline & & V0 & $\mathrm{V}$ & VN \\
\hline Comendo & & $47,7 \pm 7,1 \mathrm{~b}$ & $106,8 \pm 7,1 \mathrm{a}$ & $59,7 \pm 7,1 b$ \\
\hline Bebendo & & $5,0 \pm 2,0 \mathrm{~B}$ & $21,7 \pm 2,0 \mathrm{~A}$ & $8,3 \pm 2,0 \mathrm{~B}$ \\
\hline Ruminando & & $164,3 \pm 9,0 \mathrm{a}$ & $102,5 \pm 9,0 \mathrm{~b}$ & $129,5 \pm 9,0 \mathrm{~b}$ \\
\hline & em pé & $76,0 \pm 10,8 a$ & $28,4 \pm 10,8 b$ & $59,5 \pm 10,8 \mathrm{ab}$ \\
\hline & deitada & $88,3 \pm 10,4 \mathrm{a}$ & $74,1 \pm 10,4 \mathrm{a}$ & $70,0 \cdot 10,4 a$ \\
\hline Ócio & & $164,3 \pm 7,3 b$ & $117,0 \pm 7,3 \mathrm{~b}$ & $200,2 \pm 7,3$ a \\
\hline & em pé & $55,0 \pm 10,9 \mathrm{AB}$ & $46,3 \pm 10,9 \mathrm{~B}$ & $91,7 \pm 10,9 \mathrm{~A}$ \\
\hline & deitada & $109,3 \pm 13,1 \mathrm{a}$ & $71,5 \pm 13,1 \mathrm{a}$ & $108,5 \pm 13,1 \mathrm{a}$ \\
\hline Em pé & & $183,7 \pm 16,4 b$ & $203,2 \pm 16,4 a$ & $219,2 \pm 16,4 \mathrm{ab}$ \\
\hline Deitada & & $197,6 \pm 18,6 a$ & $145,6 \pm 18,6 a$ & $178,5 \pm 18,6 \mathrm{a}$ \\
\hline
\end{tabular}

Foram verificadas diferenças $(P<0,05)$ entre os tratamentos para a ingestão de alimentos. Observou-se que os animais mantidos no tratamento $\mathrm{V}$ permaneceram 106,8 min se alimentando, os quais corresponderam a $30,6 \%$ do 
tempo total, quando comparados com V0 que ficaram 47,7 min $(12,5 \%$ tempo total) e VN que passaram $59,7 \mathrm{~min}(15,0 \%$ do tempo total). Os tratamentos $\mathrm{V} 0 \mathrm{e}$ VN não diferiram entre si (Figura 34).

Trabalhos realizados por Pires et al. (1998 a) encontraram que as vacas estabuladas permaneceram $20 \%$ do tempo se alimentando, na época do verão. Já Camargo (1988) relatou que para as condições de Brasil Central o tempo de alimentação foi correspondente a $21,7 \%$. Cabe ressaltar que o período de observação comportamental relatado por esses autores foi de 24 horas.

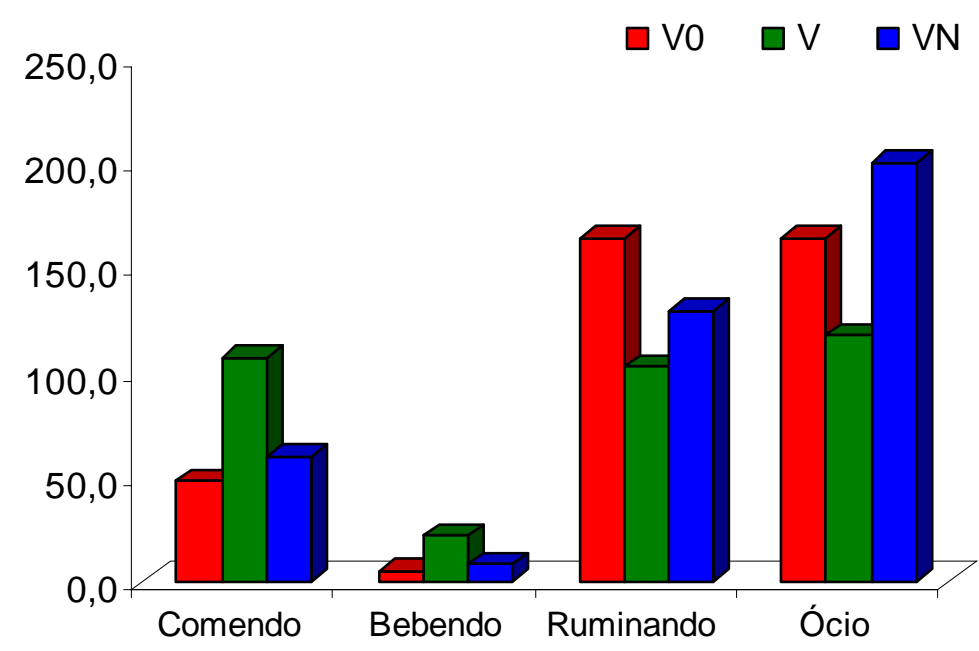

Figura 34 - Tempo (minutos) em que os animais realizaram cada atividade nos tratamentos avaliados

Embora o intervalo de avaliação das atividades das vacas em lactação no presente experimento tenha sido menor (6,30 horas), o valor verificado para o tempo se alimentando no tratamento $\mathrm{V}(30,6 \%)$ foi superior aos supracitados. Tal efeito não era esperado para este tratamento, já que o aumento no tempo de ingestão poderia estar associado à melhoria das condições de conforto térmico no interior da instalação; entretanto, 0 tratamento $V$ foi o que apresentou maior valor para o índice de temperatura e umidade ( $\mathrm{THI}=75)$. 
Mesmo os animais do tratamento $\mathrm{V}$, tendo permanecido por um período maior (108,6 min) se alimentando uma vez, comparados com os demais, quando avaliado o consumo médio de matéria seca, verificou-se que as vacas

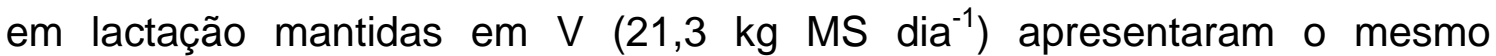
consumo que as submetidas ao V0 (20,5 kg MS dia $\left.{ }^{-1}\right)$. Possivelmente, esses animais permaneceram por um período maior junto ao cocho, local no qual se apresentava o sistema de aspersão, com objetivo de maximizar o resfriamento corporal, e não necessariamente em busca de alimento.

Os resultados deste trabalho estão de acordo com os relatos de Frazzi et al. (1998) observaram aumento no tempo despendido no comedouro nas vacas que receberam resfriamento por aspersão, reduzindo, conseqüentemente, o tempo em ócio e de permanência nas camas.

No sistema freestall, é esperado que as vacas em lactação apresentem comportamento individualizado no que se refere à localização ou mesmo atividade. Com isso, as vacas que apresentam maior necessidade para a ingestão de alimentos (alta produção) ou as vacas que não têm acesso igual ao alimento (vacas subordinadas) podem retornar ao cocho à procura de mais alimento (Osterman e Redbo, 2001).

$A$ ingestão de água apresentou diferenças $(P<0,05)$ entre os tratamentos avaliados. Verificou-se que os animais mantidos no tratamento $\mathrm{V}$ passaram 21,7 min bebendo água, período que correspondeu a $6,2 \%$ do tempo total, quando comparados com V0 que ficaram $5 \mathrm{~min}$ (1,3\% do tempo total) e VN que permaneceram 8,3 min (2,1\% do tempo total). Os tratamentos $\mathrm{V} 0$ e $\mathrm{VN}$ não diferiram entre si.

O consumo de água por vaca em lactação depende de vários fatores: estado fisiológico, produção de leite, peso corporal, raça, consumo de matéria seca, composição da dieta, ambiente, clima e qualidade da água. Durante os meses mais quentes, as vacas sofrem estresse pelo calor e pela elevação da umidade relativa do ar, aumentando o consumo de água, com elevação na excreção de urina e alterando a composição dos dejetos. O hábito no consumo 
de água segue o de consumo de alimento, sendo que o pico de consumo coincide com o pico de consumo de matéria seca, mesmo quando o alimento é oferecido várias vezes por dia. Picos no consumo de água são também observados após as ordenhas, quando podem representar $40 \%$ a $50 \%$ do consumo total diário (Campos, 2000).

Em condições de estresse térmico, os animais aumentam o consumo de água, na tentativa de repor as perdas sudativas e respiratórias, além de possível resfriamento corporal (Titto, 1998). Matarazzo et al. (2003) avaliaram o comportamento de vacas leiteiras em freestall em situações de temoneutralidade e estresse térmico e verificaram que no dia de maior desconforto térmico, os animais permaneceram $21 \%$ do tempo total ingerindo água, enquanto que em condições de conforto, esse tempo foi igual a 10\%.

Embora o tempo despendido na ingestão de água tenha sido maior para os animais do tratamento $\mathrm{V}$, este foi inferior ao verificado por Matarazzo et al. (2003). Pode-se inferir que, nas condições do presente experimento, os animais estavam em ausência de estresse térmico ou esse era brando. As variáveis fisiológicas avaliadas, tais como a temperatura retal e a freqüência respiratória estiveram dentro da faixa de normalidade, desta forma, não eram esperados aumentos significativos na ingestão de água.

A ruminação é uma atividade que permite a regurgitação, mastigação e a passagem do alimento previamente ingerido para o interior do rúmen. Durante a ruminação, deitadas ou em pé, as vacas ficam quietas e relaxadas com sua cabeça baixa e as pálpebras semicerradas (Albright, 1993).

Foram verificadas diferenças entre os tratamentos $(P<0,05)$ para a ruminação. Os animais do tratamento VO permaneceram 164,3 min (43,1\% do tempo total) período significativamente maior, quando comparado com as vacas mantidas em $V$ que passaram 102,5 min $(29,4 \%$ do tempo total) e VN que ficaram 129,5 min (32,6\% do tempo total). Os tratamentos $V$ e VN não diferiram entre si. 
De acordo com Monty Junior e Garbareno (1978) a ruminação é mais intensa à noite. A redução na temperatura do ar, ao longo da tarde, resultou num aumento da freqüência da atividade naquele período, indicando que o calor metabólico produzido por esta atividade é mais tolerável nos momentos em que a temperatura é mais amena. Também Camargo (1988) encontrou maior freqüência de ruminação entre 0 e $5 \mathrm{~h} 30 \mathrm{~min}$, alegando que o período era mais tranqüilo e que as vacas permaneciam mais sossegadas.

Por outro lado, Damasceno et al. (1999) verificaram que reduções significativas na freqüência de ruminação são constatadas nos momentos de maior freqüência de alimentação. Os resultados aqui encontrados são concordantes com os citados pelo referido autor, uma vez que as vacas mantidas no tratamento $\mathrm{V}$ permaneceram menor período na atividade de ruminação ao passo que o tempo despendido com a ingestão de alimentos foi maior.

Quando avaliada a posição dessa atividade, ou seja, se a ruminação, ocorreu em pé ou deitada, também foram constatadas diferenças $(P<0,05)$ entre os tratamentos avaliados (Figura 35 ). Para a ruminação em pé, os animais do tratamento $\mathrm{V}$ passaram $28,4 \mathrm{~min}$ nesta atividade, período significativamente menor, quando comparado com V0 que permaneceram 76,0 min. Já para a ruminação deitada, não foram verificadas diferenças $(P>0,05)$ entre os tratamentos, sendo o tempo de permanência correspondente a 88,3 min, 74,1 min e 70,0 min, respectivamente, para os animais mantidos em $\mathrm{V} 0, \mathrm{~V}$ e VN. Diante desses resultados pode-se inferir que o emprego da climatização na área de descanso não se mostrou eficiente nas condições estudadas. 


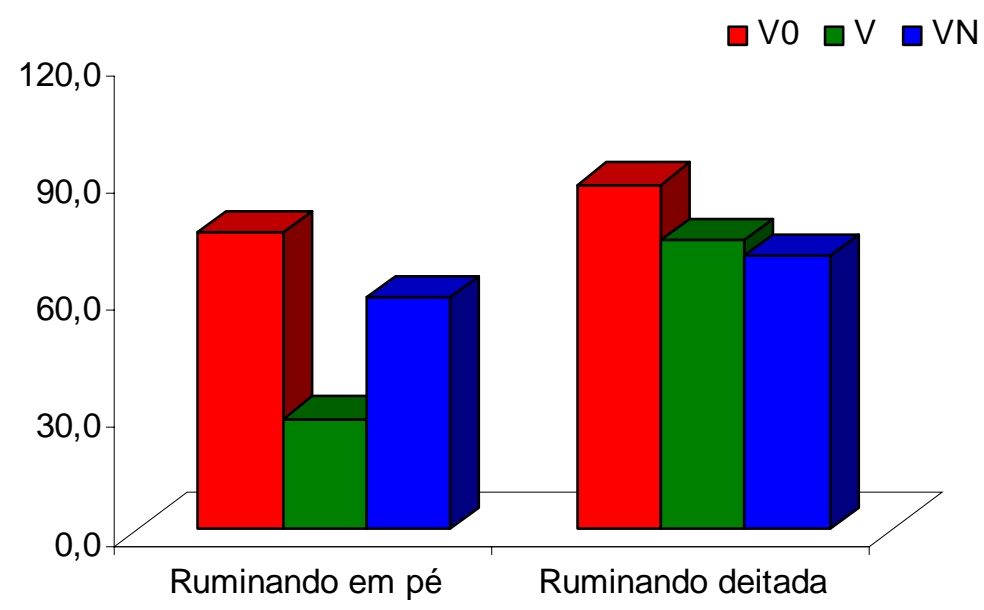

Figura 35 - Tempo (minutos) em que os animais realizaram atividade de ruminação

Geralmente, os bovinos preferem ruminar deitados, embora em condições ambientais desfavoráveis (ventos, chuvas) possam permanecer em pé ou caminhar lentamente. Quando deitados, utilizam a lateralidade esquerda como uma estratégia para otimizar o posicionamento do rúmen e obter, assim, uma ruminação mais eficiente. $O$ tempo total de ruminação pode variar de 4 a 9 horas, sendo dividido em períodos com duração de poucos minutos a uma hora ou mais (Albrigth, 1993).

O ócio é a atividade que não inclui nem ruminação nem alimentação, e apresenta duração média dez horas diárias. Os animais procuram a sombra e reduzem suas atividade nas horas mais quentes do dia, permanecendo deitados, na área de descanso (Blachshaw e Blackshaw, 1994).

Com relação ao tempo em ócio, foram encontradas diferenças entre os tratamentos. Os animais do tratamento VN permaneceram 200,2 min (50,3\% do tempo total) período significativamente maior quando comparado com as vacas mantidas em $V 0$ que ficaram $164,3 \mathrm{~min}(43,1 \%$ do tempo total) e $V$ que passaram 117,0 min (33,8\% do tempo total) e total). Os tratamentos $V$ e V0 não diferiram entre si. Analisando a posição dessa atividade, ou seja, se a vacas 
estavam em ócio em pé ou deitadas, verificaram-se diferenças $(P<0,05)$ entre os tratamentos avaliados (Figura 36).

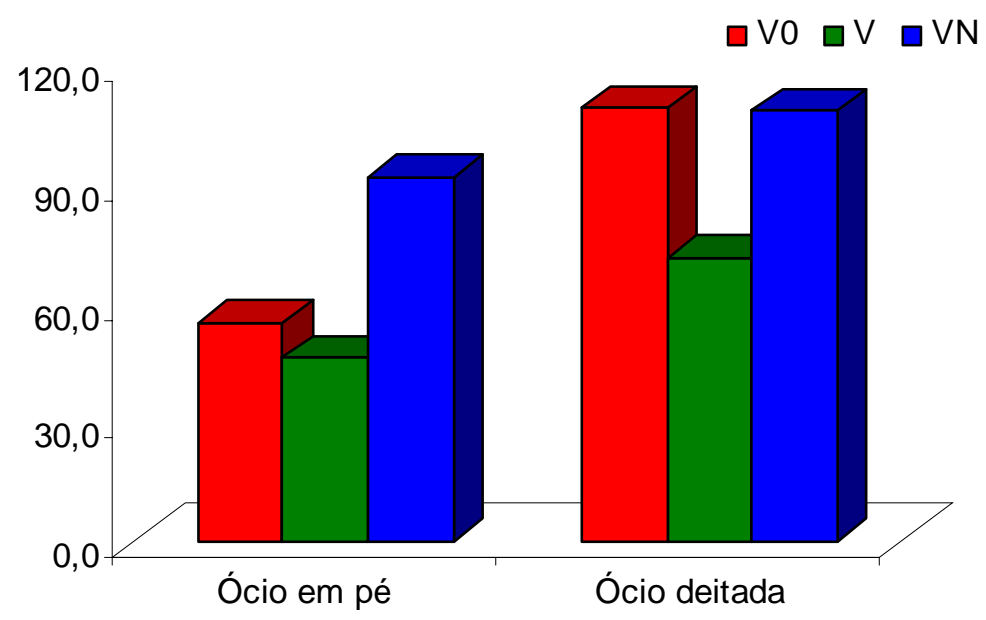

Figura 36 - Tempo (minutos) em que os animais permaneceram em ócio

Os animais do tratamento $V$ passaram 46,3 min no ócio em pé, período este significativamente menor, quando comparado com VN que permaneceram 91,7 min. Por outro lado, não foram verificadas diferenças $(P>0,05)$ entre os tratamentos para o período em que as vacas ficaram em ócio deitadas. $\mathrm{O}$ tempo de permanência dos animais foi 109,3 min, 71,5 min e 108,5 min, respectivamente para os tratamentos $\mathrm{V} 0, \mathrm{~V}$ e VN. Mais uma vez observou-se que a que o emprego da climatização na área de descanso não se mostrou eficiente nas condições estudadas.

O menor tempo em ócio verificado para as vacas mantidas no tratamento $\mathrm{V}$ confirma o comportamento apresentado para os demais padrões, ou seja, as vacas desse tratamento apresentaram maior tempo despendido com a alimentação, conseqüentemente, menores intervalos foram relatados para a ruminação e ócio.

De acordo com Camargo (1988), os animais em ócio preferiram permanecer em pé nas horas mais quentes do dia, enquanto à noite, 
mantiveram-se deitados. Tais posturas foram verificas em condições de Brasil Central.

O comportamento referente ao tempo de permanência em pé apresentou diferenças $(P<0,05)$ entre os tratamentos avaliados (Figura 37$)$. Verificou-se que os animais mantidos no tratamento V passaram 203,2 min em pé, período que correspondeu a $58,2 \%$ do tempo total, sendo este significativamente maior, quando comparado com V0 que ficaram 183,7 min (48,2\% do tempo total).

O comportamento de descanso é de grande importância para as vacas leiteiras, assim, a privação do descanso pode induzir a frustração que se manifesta por comportamentos estereotipados (Krohn e Munksgaard, 1993).

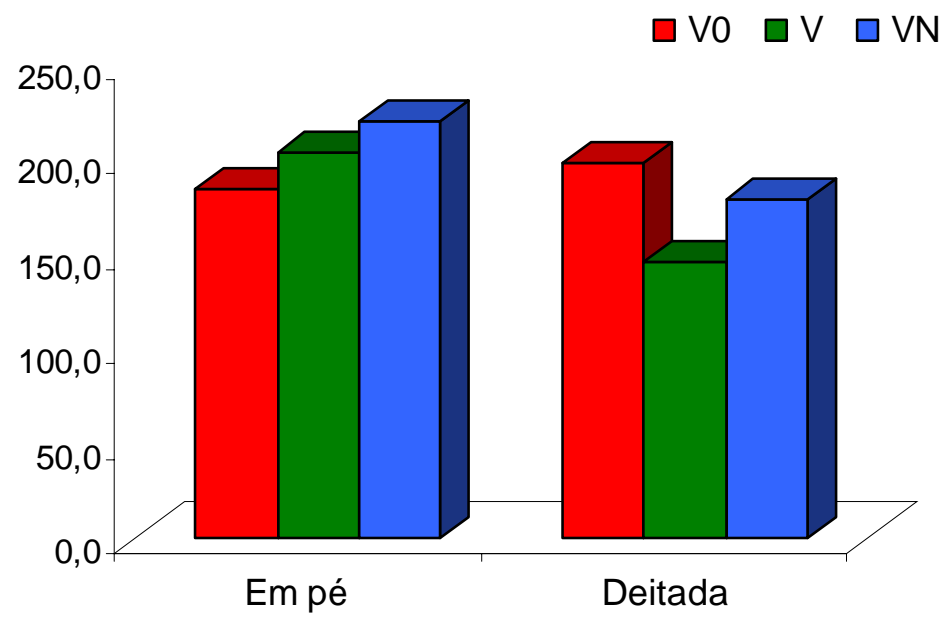

Figura 37 - Tempo (minutos) em que as vacas em lactação permaneceram em pé ou deitadas

O objetivo deste trabalho foi justamente a avaliação do efeito da climatização na área de descanso, entretanto, quando analisados os resultados obtidos para o tempo que os animais permaneceram deitados, não foram constatadas diferenças entre os tratamentos. Sendo assim, os tratamentos empregados não apresentaram a eficiência esperada.

Se as instalações apresentam áreas de descanso confortáveis, é esperado que as vacas permaneçam grande parte de seu tempo deitadas seja 
durante a noite, ou no início da manhã, a menos que, elas estejam "preocupadas" em se alimentar, serem ordenhadas ou ainda em condições de manejo inadequado (Overton et al., 2002).

\subsubsection{Tempo despendido em cada local da instalação}

A Tabela 15 e Figura 38 apresentam o tempo médio, em minutos, que os animais permaneceram na área de alimentação, no bebedouro, nas camas próximas à linha de alimentação, nas camas próximas à área do bebedouro, no corredor próximo à linha de alimentação e no corredor próximo à área do bebedouro.

Tabela 15. Tempo médio (minutos) em que os animais permaneceram em cada local dentro da instalação nos tratamentos avaliados

\begin{tabular}{lccc}
\hline Localização & V0 & $\mathrm{V}$ & $\mathrm{VN}$ \\
\hline Área de alimentação & $60,7 \pm 24,3 \mathrm{~b}$ & $108,3 \pm 15,7 \mathrm{a}$ & $72,5 \pm 17,7 \mathrm{~b}$ \\
Área do bebedouro & $8,3 \pm 4,9 \mathrm{~b}$ & $19,3 \pm 5,2 \mathrm{a}$ & $12,7 \pm 4,2 \mathrm{ab}$ \\
Cama (área de alimentação) & $189,0 \pm 52,2 \mathrm{a}$ & $167,3 \pm 18,0 \mathrm{a}$ & $82,1 \pm 39,8 \mathrm{~b}$ \\
Cama (área do bebedouro) & $51,7 \pm 33,4 \mathrm{AB}$ & $26,7 \pm 12,8 \mathrm{~B}$ & $164,0 \pm 83,2 \mathrm{~A}$ \\
Corredor (área de alimentação) & $53,3 \pm 33,9 \mathrm{~A}$ & $45,0 \pm 23,3 \mathrm{~A}$ & $20,0 \pm 26,3 \mathrm{~A}$ \\
Corredor (área do bebedouro) & $10,0 \pm 5,6 \mathrm{~B}$ & $10,0 \pm 3,9 \mathrm{~B}$ & $35,0 \pm 27,1 \mathrm{~A}$ \\
\hline a,p Médias seguidas por letras minúsculas distintas nas linhas diferem pelo Teste de Tukey (P<0,05) \\
A,B Médianas seguidas por letras maiúsculas distintas nas linhas diferem pelo Teste de Kruskal-Wallis (P<0,05)
\end{tabular}

Os valores obtidos para o tempo de permanência na área de alimentação indicaram diferenças $(P<0,05)$ entre os tratamentos. Os animais submetidos ao tratamento $\mathrm{V}$ passaram mais tempo neste local, sendo equivalente a 108,3 min (28,8\% do tempo total) quando comparados com V0 que ficaram $60,7 \mathrm{~min}$ (16,3\% do tempo total) e VN que permaneceram $72,5 \mathrm{~min}(18,8 \%$ do tempo total). O tempo de permanência dos animais nos tratamentos $\mathrm{V} 0$ e $\mathrm{VN}$ não 
diferiram entre si. Tais resultados corroboram os dados encontrados para o tempo de permanência na atividade ingestão de alimentos.

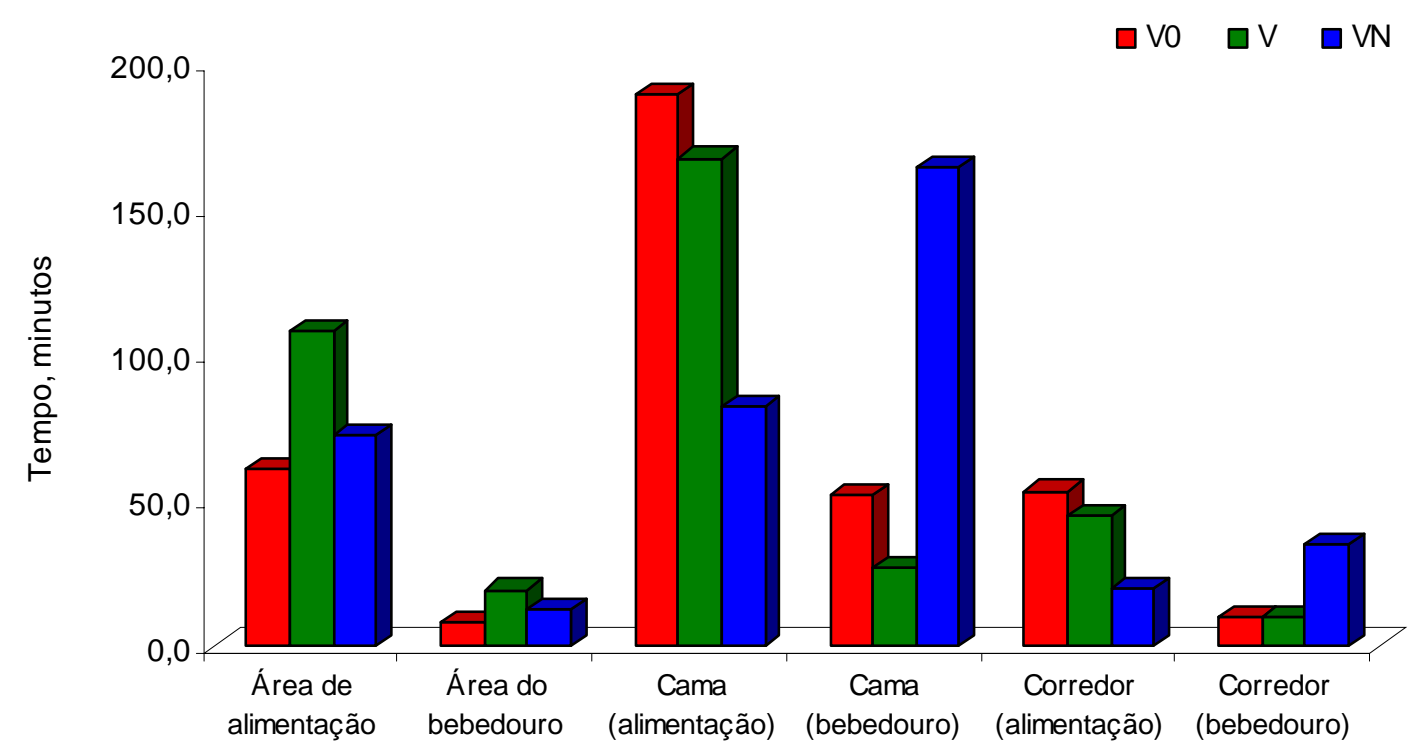

Figura 38 - Tempo (minutos) em que os animais permaneceram nos locais dentro da instalação

Calegari et al. (2003) avaliaram os efeitos da ventilação forçada associada a nebulização em freestall e seus reflexos sobre o comportamento das vacas em lactação. Os autores verificaram que os animais do tratamento com nebulização apresentaram maior tempo despendido em pé, na área de alimentação, sendo esta uma situação indicativa de estresse térmico, já que as vacas procuraram ficar com maior área de superfície corporal exposta, a fim de facilitar as trocas de calor. Sugeriram, ainda, a possibilidade de aliviar esses efeitos indesejáveis, estendendo o sistema de resfriamento evaporativo nas demais instalações, como por exemplo, na sala de ordenha e área de descanso, evitando, assim, a aglomeração na área de alimentação com o intuito de resfriamento. 
Com relação ao tempo de permanência na área do bebedouro, verificaram-se diferenças $(P<0,05)$ entre os tratamentos. Os animais mantidos no tratamento $\mathrm{V}$ permaneceram um período maior neste local, sendo este correspondente a 19,3 min (5,1\% do tempo total) quando comparados com V0 que passaram $8,3 \mathrm{~min}$ (2,2\% do tempo total). Os animais submetidos a VN ficaram $12,7 \mathrm{~min}$ (3,3\% do tempo total), sendo que o tempo de permanência dos animais no tratamento VN não diferiu entre V0 e V. Da mesma forma, tais resultados confirmam os dados encontrados para o tempo de permanência na atividade ingestão de água.

Quando avaliado o tempo em que os animais permaneceram na área de descanso, constataram-se diferenças $(P<0,05)$ entre os tratamentos. Para 0 tempo de permanência na cama próxima à linha de alimentação, os resultados encontrados foram $189,0 \mathrm{~min}(50,7 \%$ do tempo total), $167,3 \mathrm{~min}(44,4 \%$ do tempo total) respectivamente, para os tratamentos $\mathrm{V} 0, \mathrm{~V}$. O tempo despendido pelos animais em VN foi $82,1 \mathrm{~min}(21,3 \%)$, sendo este último, diferente dos demais. Com relação à permanência na cama oposta à linha de alimentação, os valores encontrados foram $51,7 \mathrm{~min}$ (13,9\% do tempo total), $26,7 \mathrm{~min}$ (7,1\% do tempo total) e $164,0 \mathrm{~min}$ (42,5\% do tempo total), respectivamente, para os tratamentos $\mathrm{V} 0, \mathrm{~V}$ e $\mathrm{VN}$, sendo esses dois últimos diferentes entre si.

As vacas tiveram livre acesso aos lados do freestall, sendo assim, todas dispunham da mesma oportunidade de escolher o local desejado para se deitar, uma vez que o espaço delimitado para o estudo apresentava 14 camas dispostas frente a frente.

A maior procura pelas camas próximas à linha de alimentação verificada nos animais submetidos ao tratamento $\mathrm{V} 0 \mathrm{e} \mathrm{V}$ pode estar associada à presença de climatização (aspersão/ventilação) na linha de alimentação. Provavelmente, as vacas sentiram-se atraídas para este lado da instalação, dado ao efeito associativo da aspersão/ventilação no cocho, o qual pode ter promovido alteração no microclima dessa área do freestall, proporcionado, assim, sensação de conforto aos animais. 
Gaworski et al (2003) também constataram um número maior de visitas para as camas próximas à linha de alimentação, sendo que as camas localizadas no centro do freestall foram preferidas em relação às camas distribuídas na periferia. Esses resultados indicaram que as camas afastadas da linha de alimentação ou na periferia são menos desejáveis para as vacas, talvez porque precisem caminhar mais ou por encontrarem obstáculos sociais (vacas dominantes) em seu caminho. Ainda, segundo trabalhos desenvolvidos por Miller e Woodgush (1991), os movimentos dos animais subordinados são prevenidos pela localização das vacas dominantes.

Por outro lado, verificou-se maior procura pelas camas próximas ao bebedouro nos animais mantidos em VN. Cabe ressaltar que neste local, o sistema de nebulização instalado para compor o tratamento encontrava-se, na realidade, no corredor próximo à área do bebedouro e não dirigido à área de descanso, como era esperado. Estes dados confirmaram também a preferência dos animais deste mesmo tratamento a permanecerem por um período maior neste lado do freestall.

Os valores obtidos para o tempo de permanência no corredor junto à área de alimentação não foram diferentes $(P>0,05)$ entre os tratamentos, sendo os valores correspondentes a 53,3 $\mathrm{min}$ (14,3\% do tempo total), $45 \mathrm{~min}(11,9 \%$ do tempo total) e $20 \mathrm{~min}$ (5,2\% do tempo total), respectivamente, para os tratamentos V0, V e VN. Por outro lado, quando avaliados os resultados encontrados para o tempo de permanência no corredor próximo à área do bebedouro, constataram-se diferenças $(P<0,05)$ entre os tratamentos, sendo que os animais mantidos em $\mathrm{V} 0$ e $\mathrm{V}$ ficaram $10 \mathrm{~min}$ (2,7\% do tempo total) neste local, período significativamente menor, quando comparados com $\mathrm{VN}$ que passaram 35 min ( $9,1 \%$ do tempo total).

Além do tratamento VN apresentar o sistema de nebulização deslocado para o corredor, fazendo com que os animais permanecessem mais tempo nesse local, a face lateral do galpão permanecia exposta ao ar livre, sem qualquer tipo de construção ou obstáculos no entorno. Tal fato, provavelmente, 
favoreceu a dissipação de calor dos animais com o meio, estimulando-os a permanecer por mais tempo neste local.

Os estudos comportamentais são fundamentais para a eficiência econômica da produção, uma vez que podem ser empregados como ferramenta auxiliar na solução de problemas que afetam os animais (Pires et al., 1998).

Várias interações devem ser consideradas, tais como o ambiente físico no qual o animal está inserido, sua fisiologia e o manejo adotado para o rebanho. Sendo assim, as análises não podem ser generalizadas uma vez que existem particularidades nos sistemas de produção entre elas a localização regional e o nível tecnológico.

\subsubsection{Conclusões}

Conforme os resultados verificados nas condições do presente experimento, pode-se concluir que:

a. As vacas em lactação apresentaram comportamentos diferenciados para as atividades de ingestão de água e alimentos, ruminação e ócio em função dos tratamentos aplicados;

b. A climatização da área de descanso em instalações do tipo freestall não proporcionou alterações no tempo em que as vacas em lactação permaneceram deitadas. 


\section{CONCLUSÕES GERAIS}

Conforme os resultados verificados nas condições do presente experimento, pode-se concluir que:

a. A intermitência de 16 min resultou em menor consumo de água bem como melhores condições de conforto para as vacas em lactação, podendo ser empregado a fim de evitar desperdícios desnecessários pelo sistema de resfriamento adiabático evaporativo;

b. As intermitências de 14 e 16 minutos proporcionaram menores valores para as variáveis termorregulátorias temperatura retal, freqüência respiratória e temperatura da superfície do pelame;

c. A climatização da área de descanso em instalações do tipo freestall não proporcionou melhorias nas propriedades psicrométricas do ar, uma vez que as variáveis meteorológicas e os índices de conforto térmico permaneceram acima da zona de termoneutralidade;

d. As variáveis termorregulatórias temperatura retal, freqüência respiratória e temperatura do pelame não foram alteradas com a aplicação dos tratamentos; 
e. Os animais mantidos nos tratamentos com ausência e presença de ventilação apresentaram maior consumo de matéria seca, entretanto, estes não refletiram em maior produção de leite;

f. As vacas em lactação apresentaram comportamentos diferenciados para as atividades de ingestão de água e alimentos, ruminação e ócio em função dos tratamentos aplicados;

g. A climatização da área de descanso em instalações do tipo freestall não proporcionou alterações no tempo em que as vacas em lactação permaneceram deitadas. 
ANEXO 
Anexo A. Valores médios da temperatura de bulbo seco (TBS, $\left.{ }^{\circ} \mathrm{C}\right)$, umidade relativa (UR, \%), índice de temperatura e umidade (THI) e entalpia $(\mathrm{H}, \mathrm{KJ} \mathrm{Kg}$ ar seco-1)

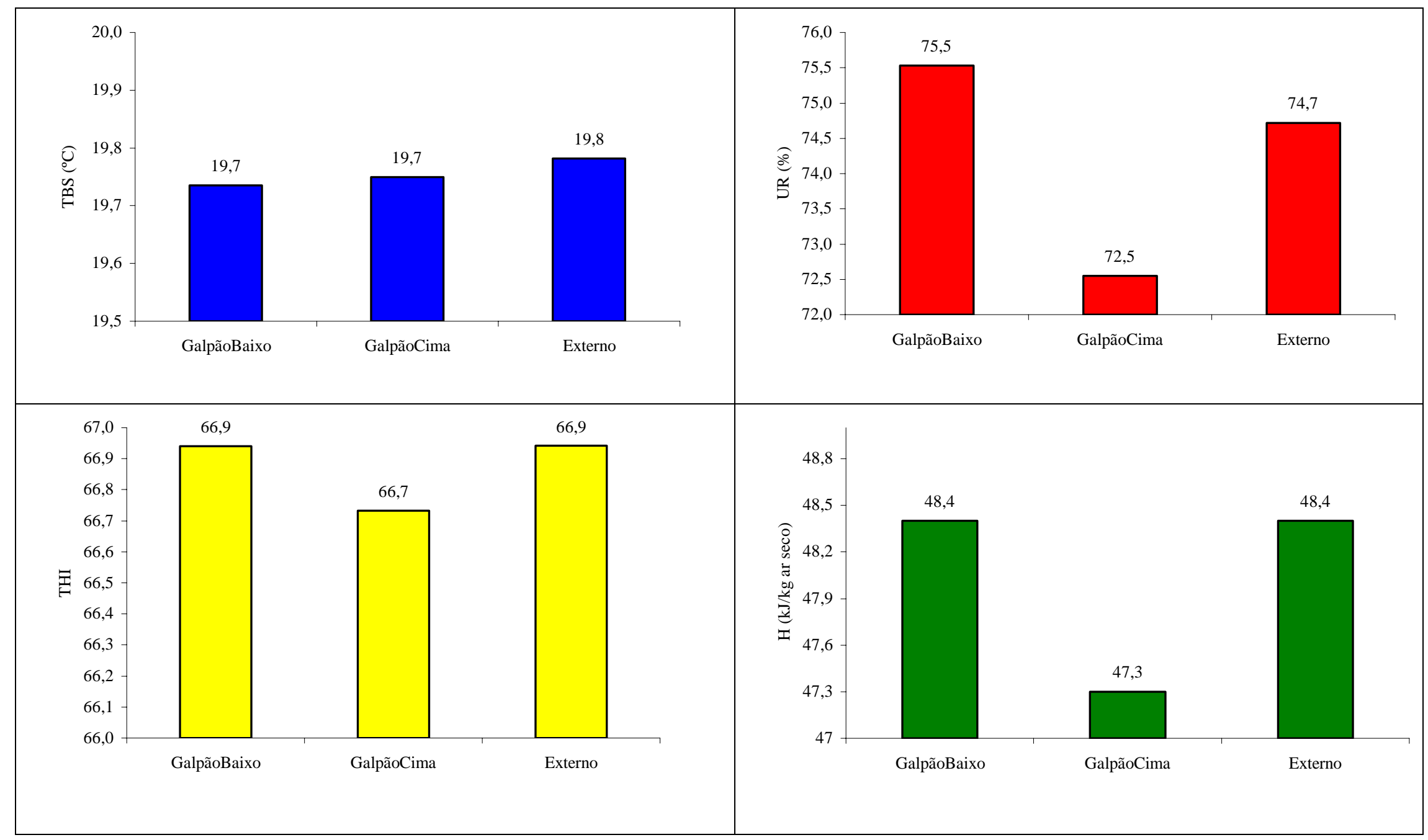




\section{REFERÊNCIAS BIBLIOGRÁFICAS}

AGUIAR, I. A.; TARGA, L. A. Respostas termorreguladoras, armazenamento de calor corporal e produção de leite de vacas holandesas mantidas ao sol e com acesso a sombra natural. Energia na Agricultura. v.14, n. 4, p.9-21. 1996

AKARI, C. T.; NAKAMURA, R. M.; KAM, L. W. G. Diurnal temperature sensitivity of dairy cattle in a naturally cycling environment. Journal of Thermal Biology, v.12, n.1, p.23-26, 1987.

ALBRIGHT, J. Feeding behavior of dairy cattle, Journal of Dairy Science, v.76, p.485498, 1993

ANDERSON, B. E. Regulação da temperatura e fisiologia ambiental. In: DUKES, H. H Fisiologia dos animais domésticos. Rio de Janeiro: Editora Guanabara, 1988. cap.45, p.623-630.

ARCARO JUNIOR, I.; ARCARO, J. R.P.; MATARAZZO, S. V. et al. Produção e composição do leite de vacas holandesas em sala de espera climatizada. (Compact disc). In: CONGRESSO BRASILEIRO DE BIOMETEOROLOGIA, 3. Maringá, 2001. Anais. Maringá: SBBIO, 2001.

ARCARO JUNIOR, I.; ARCARO, J. R.P.; MATARAZZO, S. V. et al. Climatização em sala de espera: variáveis ambientais e fisiológicas de vacas em lactação. In: REUNIÃO DA SOCIEDADE BRASILEIRA DE ZOOTECNIA, 40., Recife, 2002. Anais. Recife: UFRPE, 2002. 
ARMSTRONG, D.V. Heat stress interaction with shade and cooling. Journal of Dairy Science, v.77, p.2044-2050, 1994.

BACCARI JUNIOR, F. Adaptação de sistemas de manejo na produção de leite em climas quentes. In: SIMPÓSIO BRASILEIRO DE AMBIÊNCIA NA PRODUÇÃO DE LEITE, Piracicaba, 1998. Anais. Piracicaba: FEALQ, 1998. p.24-67.

BACCARI JUNIOR, F. Manejo ambiental da vaca leiteira em climas quentes. Londrina:UEL, 2001. 142p

BACCARI JUNIOR, F.; CAMPOS NETO, O.;ROCHA, G. P. Variação fisiológica da temperAturA retal das 8 às 18 horas em bovinos holandeses. Correlação com a temperatura ambiente e hora do dia. In: JORNADA CIENTÍFICA DA ASSOCIAÇÃO DOS DOCENTES DO CAMPUS DE BOTUCATU, 8. Anais, Botucatu: FMVZ. 1979

BACCARI JUNIOR, F.; BLASI, A. C.; MUNIZ, L. M. R. et al. Effect of thermal stress on feed intake and serum triiodothyronine in young buffalo bulls. In: WORLD BUFFALO CONGRESS, 2., New Delhi, 1988. Proceedings. New Delhi:World Society of Buffalo, 1988. p.139-143.

BACCARI JUNIOR, F.; AGUIAR, I. S.; TEODORO, S. M. Hipertemia, taquipinéia e taquicardia em vacas holandesas malhadas de vermelho sob estresse térmico. In: CONGRESSO BRASILEIRO DE BIOMETEOROLOGIA, Jaboticabal, 1995. Anais. Jaboticabal: FUNEP, 1995. p.15-16.

BAÊTA, F. C.; SOUZA, C. F. Ambiência em edificações rurais - conforto animal. Viçosa:Universidade Federal de Viçosa, 1985. 246p.

BANKS, E. Behavioral research to answer question about animal welfare. Journal of Animal Science, v.54, p.434-455, 1982. 
BENJAMIN, M. M. Fluid and eletroctrolytes. Outline of veterinary clinical pathology. Ames: lowa State University Press, 1981. 12p.

BERMAN, A.; FOLMAN, Y. M.; KAIM, M.; et al. Upper critical temperature and forced ventilation effects of high yielding dairy cows in a tropical climate. Journal of Dairy Science, v.67, p. 488-495, 1985.

BIANCA, W. Heat tolerance in cattle its concepts: measurement and dependence on modify factors. International Journal of Biometeorology, v. 5, p.5-30, 1961.

BICKERT, W. G.; HOLMES, B; JANNI, K. et al. Building environment. In: DAIRY FREESTALL HOUSING AND EQUIPMENT, 7, Ames, 2000. Proceedings. Ames: lowa State University, 2003.

BITMAN, J. A.; LEFCOURT, D. L.; STROUD, B. Circadian and ultradian temperature rhythms of lactating dairy cows. Journal of Dairy Science, v.68, p.1014-1023, 1984.

BLACKSHAW, J. K.; BLACKSHAW, A. W. Heat stress in cattle and the effect of shade on production and behavioral: a review. Australia Journal of Experimental Agriculture, v.34, p.285-295. 1994.

BOND, T. E.; KELLY, C. F. The globe thermometer in agriculture research. Agriculture Engineering, v.36, p.251-260, 1955.

BOWLER, P. J. The environmental sciences. New York: W.W Norton and Company, 1993. p. 315.

BROSH, A.; CHOSNIAK, I.; TADMORE, A. et al. Physiochemical conditions in the rumen of Bedouin goats: effects of drinking, foods quality and feeding time. Journal of Agricultural Science, v. 111, p.147-157, 1988. 
BROUK, M.J.; SMITH, J.F.; HARNER III, J.P. Effectiveness of fan and feedline sprinklers in cooling dairy cattle housed in 2 or 4 row freestall buildings. In: INTERNATIONAL LIVESTOCK ENVIRONMET SYMPOSIUM, 6., Louisville, 2001. Proceedings. Louisville: ASAE, 2001a.

BROUK, M.J.; SMITH, J.F.; HARNER III, J.P. Efficiency of modified evaporative cooling in Midwest dairy freestall barn (Compact disc). In: INTERNATIONAL LIVESTOCK ENVIRONMET SYMPOSIUM, 6., Louisville, 2001. Proceedings. Louisville: ASAE, 2001b.

BROUK, M. J.; SMITH, J. F.; HARNER III, J. P. Effecting of utilizing evaporative cooling in tiestall dairy barns equipped with tunnel ventilation on respiration rates and body temperature of lactating dairy cattle. In: INTERNATIONAL DAIRY HOUSING CONFERENCE, 5. Texas, 2003b. Proceedings. Texas: ASAE 2003b. p. 312-319.

BROUK, M. J.; SMITH, J. F.; HARNER III, J. P. Effect sprinkling frequency and air flow on respiration rate, body surface temperature and body temperature of heat stressed dairy cattle. In: INTERNATIONAL DAIRY HOUSING CONFERENCE, 5. Texas, 2003a. Proceedings. Texas: ASAE 2003b. p. 263-268.

BUCKLIN, R.A.; BRAY,D.R. The american experience in dairy management warm and hot climates. In: SIMPÓSIO BRASILEIRO DE AMBIÊNCIA NA PRODUÇÃO DE LEITE, Piracicaba 1998. Anais. Piracicaba: FEALQ, 1998. p.156-174.

BUfFINGTON, D.E.; COLLAZO-AROCHO, A.; CANTON, G. H. et al. Black globehumidity index (BGHI) as comfort equation for dairy cows. Transactions of ASAE, v.24, p.711-714, 1981.

CALEGARI, F.; CALAMARI, L.; FARZZI, E. Effects of ventilation and misting on behavior of dairy cattle in the hot season in south Italy. In: INTERNATIONAL DAIRY HOUSING CONFERENCE, 5. Texas, 2003. Proceedings. Texas: ASAE 2003. p. 303-311. 
CAMARGO, A. C. Comportamento de vacas da raça holandesa em um confinamento do tipo "freestall", no Brasil Central. Piracicaba, 1988. 146p. Dissertação (Mestrado) - Escola Superior de Agricultura Luiz de Queiroz, Universidade de São Paulo.

CAMPOS A. T. A importância da água para o gado de leite. Embrapa Gado de Leite. Disponível em: http://www.sbz.org.br . Acesso em 20 de mar. de 2003.

CAPPA, V.; VAZHAPILLY, P.; MAIANTI, M. G. et al. Effect of environment variations (microclimate) on the performance of dairy cows. Scienza e Tecnica LatieroCasearia, v.40, p.98-115, 1989.

CENA, K.; MONTEITH, J. L. Transfer process in animal coats, I . Radioactive transfer. Proceedings of Research Society of Biometeorology. , v. 88, p. 377-393, 1975.

CHASTAIN, J. P.; TURNER, L. W. Practical results of a model of direct evaporative cooling of dairy cows. In: INTERNATIONAL DAIRY HOUSING CONFERENCE, 3, Orlando, 1994. Proceedings. Orlando: ASAE, 1994. p.337-352.

CIPOLA-NETO, J.; MARQUE, N.; MENNA-BARRETO, L. S. Introdução ao estudo da cronobiologia. São Paulo: EDUSP, 1988. p.142

CLARK, J. A. Environmental aspects of housing for animal production. London: Butterworths, 1981.511p.

COLLIER, R. J.; DOELGER, S. G.; HEAD, H. H. et al. Effects of heat stress during pregnancy on maternal hormone concentrations, calf birth weight and postpartum milk yield of Holstein cow. Journal of Animal Science, v.54, p.309-319, 1982.

COSTA, M. J. R. Aspectos do comportamento da vacas leiteiras em astagens neo tropicais. In: ENCONTRO PAULISTA DE ETOLOGIA, 3. , 1985, Ribeirão Preto. Anais... Ribeirão Preto, 1985. p. 199-217 P.1985 
COSTA E SILVA, E. V. Ambiente e manejo reprodutivo: problemas e soluções. In: ZOOTEC, Uberaba, 2003. Anais. Uberaba:FAZU, 2003. p.75-91.

CUNNINGHAN, J. G. Tratado de fisiologia veterinária. Rio de Janeiro: Guanabara Koogan.1999. 528p.

CURTIS, S. E. Environment management in animal agriculture. Illinois: Animal Environment Services, 1981, $430 \mathrm{p}$.

DAMASCENO, J.C.; BACARI JUNIOR, F.; TARGA, L. A. Respostas comportamentais de vacas holandesas, com acesso a sombra constante ou limitada. Pesquisa Agropecuária Brasileira, v.34, n.4, p.709-715. 1999.

DAVIS, M. S. Effects of water application to feedlot mound during the summer (Compact disc). In: INTERNATIONAL LIVESTOCK ENVIRONMET SYMPOSIUM, 6., Louisville, 2001. Proceedings. Louisville: ASAE, 2001.

DU PREEZ, J.H. Parameters for the determination and evaluation of heat stress in dairy cattle in South Africa. Onderstepoort Journal Veterinary Research, v. 67, 2000, p.263-271.

ESMAY, M.L. Principles of animal environment. West Port: ABI, 1982. 325p.

FLAMENBAUM, I.; WOLFENSON, D.; MANEN, M. et al. Cooling dairy cattle by a combination of sprinkling and forced ventilation and its implementation in the shelter system. Journal of Dairy Science, v.69, p.3140-3147, 1986.

FRASER, A. F.; BROOM, D. M. Farm animal behavior and welfare. $3^{\circ}$ ad. London: Bailliere Tindall, 1990, $437 \mathrm{p}$. 
FRAZZI, E.; CALAMARI, L.; CALEGARI, F.; et al. The aeration, with or without misting: Effects on heat stress in dairy cows. In: INTERNATIONAL LIVESTOCK ENVIRONMET SYMPOSIUM, 5., Minnesota, 1997. Proceedings. St. Joseph: ASAE, 1997. p.907-914.

FRAZZI, E.; CALAMARI, L.; CALEGARI, F. et al. Behavior of dairy cows in response to different barn cooling systems. In: INTERNATIONAL DAIRY HOUSING CONFERENCE, 4., St. Louis, 1998. Proceedings. St. Louis: ASAE, 1998. p.387394.

FRAZZI, E.; CALAMARI, L.; CALEGARI, F. Productive responses of dairy cows to different barn cooling systems. Transactions of ASAE, v.43, n.2, 387-394, 2002.

FUQUAY, J. W. Heat stress and it affects animal production. Livestock Environment, v.2, p.1133-1137, 1997.

FURLAN, R.A. Avaliação da nebulização e abertura de cortinas na redução da temperatura do ar em ambiente protegido. Piracicaba, 2001. 146 p. Tese (Doutorado) - Escola Superior de Agricultura "Luiz de Queiroz", Universidade de São Paulo.

GAWORSKI, M. A.; TUCKER, C. B.; WEARY, D. M. Effects of stall design on dairy cattle behaviour. (Compact disc). In: INTERNATIONAL DAIRY HOUSING CONFERENCE, 5, Fort Worth, 2003. Proceedings. Fort Worth: ASAE, 2003.

GRANT, R. J.; ALBRIGHT, J. L. Feeding behavior and management factors during the transition period in dairy cattle. Journal of Dairy Science, v. 73, p. 2791-2803, 1995.

GEBREMEDHIN, K. G.; WU, B. Sensible and latent heat losses from wet-skin surface and fur layer. American Society of Agricultural Engineering. ASAE Paper 01-4030. p.1-31, 2001. 
GIBBONS, JEAN D. Nonparametric Methods for Quantitative Analysis. New York: Holt, 1976. 254p.

GOODWING, P. J.; GAUGHAN, J. SKELE, P. et al. Coat color and alleviation of heat load in Holstein-Friesian cows. In: INTERNATIONAL LIVESTOCK ENVIRONMET SYMPOSIUM, 5., Minnesota, 1997. Proceedings. St. Joseph: ASAE, 1997. p.923927.

HAFEZ, E.S.E. Adaptacion de los animales domesticos. Barcelona:Labor, 1973. $358 p$.

HAHN, G. L. Compensatory performance in livestock: influence on environmental criteria. In: INTERNATIONAL LIVESTOCK ENVIRONMENT SYMPOSIUM, 2., St. Joseph, 1982. Proceedings. St. Joseph: ASAE, 1982. p.285- 294.

HAHN, G. L. Management and housing of farm animals in hot environment. In: YOUSEF, M. K. Stress physiology in livestock. v.2, 1985. p.151-174.

HAHN, G. L. Bioclimatologia e instalações zootécnicas: aspectos teóricos e aplicados. In: WORKSHOP BRASILEIRO DE BIOCLIMATOLOGIA ANIMAL, 2., Jaboticabal, 1993. Boletim H148b. Jaboticabal: FUNEP, 1993.p.132-146.

HAHN, G. L.; MADER, T. L. Heat waves in relation o thermoregulation, feeding behavior, and mortality of feedlot cattle. In: INTERNATIONAL LIVESTOCK ENVIRONMENT SYMPOSIUM, 5., Minnesota, 1997. Proceedings. St. Joseph: ASAE, 1997. p.125-129

HALEY, D. B.; RUSHEN, J.; PASSILLE, A. M. Behavioral indicators of cow comfort: Activity and resting behaviour of dairy cows in two types of housing. Canadian Journal of Animal Science, v. 80, n.2, p.257-263, 2000.

HARNER, J.P.; SMITH, J.F.; BROOK, M.; et al. Sprinkler systems for cooling dairy cows at a feed line. Kansas State University, 1999. p.1-7. (Paper 2401). 
HEAD, H. H. Management of dairy cattle in tropical and subtropical environments. In: CONGRESSO BRASILEIRO DE BIOMETEOROLOGIA, 1., Jaboticabal, 1995. Anais. Jaboticabal: SBBiomet, 1995. p.26-68.

HEAD, H. H. The strategic use of the physiologic potential of the dairy cows. In: SIMPÓSIO DE LEITE NOS TRÓPICOS: NOVAS ESTRATÉGIAS DE PRODUÇÃO, Botucatu, 1989. Anais. Botucatu: UNESP, 1989. p.38-89.

HILLMAN, P.E.; GEBREMEDHIN, K.G., PARKHRST, A. et al. Evaporative and convective cooling of cows in a hot and humid environment. (Compact disc). In: INTERNATIONAL LIVESTOCK ENVIRONMET SYMPOSIUM, 6., Louisville, 2001. Proceedings. Louisville: ASAE, 2001.

HUBER, J. T. Alimentação de vacas de alta produção sob condições de estresse térmico. In: SIMPÓSIO SOBRE BOVINOCULTURA LEITEIRA. Piracicaba: FEALQ., 1990. p.33-48.

HUHNKE, M. R.; MONTY JUNIOR, D. E. Physiologics responses of preparturient and postparturient Holstein-Friesian cows to summer heat stress in Arizona. American Journal of Veterinary Research, v.37, p.1301-1304, 2001.

IGONO, M.O., STEEVENS, B.J.; SHANKLIN, M.D. et al. Spray cooling effects on milk production, milk and rectal temperature of cows during a moderate temperature summer season. Journal of Dairy Science, v. 68, p. 979-985. 1985.

IGONO, M. O.; JOHNSON, H. D. Physiologic stress index of lactating dairy cows based on diurnal pattern of rectal temperature. Journal of Interdisciplinary Cycle Research., v. 21, p.303-320, 1992.

INGRAHAM, R. H.; STANLEY, R. W.; WAGNER, W.C. Seasonal effects of tropical climates on shaded and nonshaded cows as a measured by rectal temperature, adrenal cortex hormones, thyroid hormone, and milk production. American Journal of Veterinary Research, v.40, p.1792-1792, 1979. 
JOHNSON, H. D. Environmental management of cattle to minimize the stress of climatic change. International Journal Biometeorology, v.24, p.65-78, 1980.

JOHNSON, H. D. Bioclimatology and adaptation of livestock. Amsterdam:Elsevier, 1987. 279p.

JOHNSON, H. D.; RAGSDALE, A. C; BERRY, I. L. et al. Effects of various temperature-humidity combinations on milk production of Holstein cattle. Columbia:Missouri Agricultural Experimental Station, 1962. (Research Bulletin, 791).

JOHNSON, H. D.; RAGSDALE, A. C; BERRY, I. L. et al. Temperature-humidity effects including influence of acclimation in feed and water consumption of Holstein cattle. Columbia:Missouri Agricultural Experimental Station, 1963.(Research Bulletin, 846).

JOHNSON, H. D.; VANJONACK, W. J. Effects of environmental and other stressors on blood hormone patterns in lactating animals. Journal of Dairy Science, v.59, p.1603-1617, 1976.

KADZERE, C. T.; MURPHY, M. R.; SILANIKOVE, N. et al. Heta stress in lactating dairy cows: a review. Livestock Production Science, v.77, p.59-91, 2002.

KLIBER, H. H. Environment physiology with special reference to domestic animals. Influence of temperature, 5 to $95^{\circ} \mathrm{F}$, on evaporative cooling from the respiratory and exterior surfaces in Jersey and Holstein cows. Santa Barbara:Missouri Agricultural Experimental Station, p.1-18. 1950 (Research Bulletin, 46).

KROHN e MUNKSGAARD, L. Behaviour of cows kept in extensive (loose housing/pasture) or intensive (tiestall) environment. Applied Animal Behaviour Science, v.37, p.1-6, 1993. 
LEMERLE, C.; GODDARD, M.E. Assessment of heat stress in dairy cattle in Papua New Guinea. Tropical Animal Health Production, v. 18, p.232-242, 1986

LIN, J. C., MOSS, B. R.; KOON, J. L.; FLOOD, C. A. Comparison of various fan, sprinkler, and mist systems in reducing heat stress in dairy cows. Applied Engineering in Agriculture, v.14, n.2, p.177-182, 1998.

MAIA, A. S. C. Variação genética e ambiental das características morfológicas e das propriedades radiativas efetivas do pelame de bovinos da raça holandesa. Jaboticabal, 2002. 77p. Dissertação (Mestrado) - Faculdade de Ciências Agrárias e Veterinária, Universidade Estadual Paulista.

MARQUES, D. Calor: conhecimentos e cuidados para minimizar seus efeitos sobre os frangos. Amparo: CASP, 1992. 11p.

MARTELLO, L. S. Diferentes recursos de climatização e sua influência na produção de leite, na termorregulação dos animais e no investimento das instalações. Pirassununga, 2002. p.67. Dissertação (Mestrado) - Faculdade de Zootecnia e Engenharia de Alimentos, Universidade de São Paulo.

MARTIN, P.; BATESON, P. Measuring behavior: an introductory guide. Cambridge:University Press, 1993. 222p.

MATARAZZO, S. V.; PERISSINOTTO, M.; SILVA, I. J. O. et al. Water intake and behavior of dairy cows in response to environmental conditions (Compact disc). In: INTERNATIONAL DAIRY HOUSING CONFERENCE, 5., Fort Worth, 2003. Proceedings. Fort Worth: ASAE, 2003a.

MATARAZZO, S. V.; PERISSINOTTO, M.; SILVA, I. J. O. et al. Intermitência de acionamento do sistema de resfriamento evaporativo em freestall e sua influencia no conforto térmico de vacas em lactação. (Compact disc). In: REUNIÃO DA SOCIEDADE BRASILEIRA DE ZOOTECNIA, 40., Santa Maria, 2003. Anais. Santa Maria: UFSM, 2003b. 
McDOWELL, R. E., HOOVEN, N. W.; CAMOENS, Effects of climate on performance of Holstein in first lactation. Journal of Dairy Science, v.59, p.965-973, 1976.

MEANS, S.L.; BUCKLIN, R. A.; NORDSTEDT, R. A. et al. Water application rates for a sprinkler and fan dairy cooling system in hot, humid climates. Applied Engineering in Agriculture, v.8, n.3, p.375-379, 1992.

MILLE,R K.; WOODGUSH, D. G. M. Some effects of housing on the social behavior of dairy cows. Animal Production, v. 53, p. 271-278, 1991.

MILTLÖHNER, F. M.; MORROW-TESCH, S. C.; WILSON, J. W. et al. Shade and water misting effects on behavior, physiology, performance and carcass traits of heat stressed feedlot cattle. Journal of Animal Science, v.78, n.1, p.309-319, 2000.

MOBERG, G. P. A model for assessing the impact of behavioral stress of domestic animals. Journal of Animal Science, v.65, p. 1228-1265, 1987.

MONTY JUNIOR, D. E. GARBARENO, J. L. Behavioral and physiologic response of Holstein-Friesian cows to high environmental temperature $s$ and artificial cooling in Arizona. American Journal of Veterinary Research, v.39, p.877-882, 1978.

MOTA, L. S. Adaptação e interação genótipo-ambiente em vacas leiteiras. Ribeirão Preto, 1997. 69p. Tese (Doutorado) - Faculdade de Medicina de Ribeirão Preto, Universidade de São Paulo.

MOURA, D. J. Ventilação na suinocultura. In: AMBIÊNCIA E QUALIDADE NA PRODUÇÃO DE SUÍNOS., Piracicaba, 1999. Anais. Piracicaba: FEALQ, 1999. p.149-179.

MULLER, C. J. C.; BOTHA, J. A.; SMITH,W. A. Effects of shade on various parameters of Friesian cows in a Mediterranean climate in South Africa. 3. Behavior. South África Journal of Animal Science, v.24, p.61-66, 1994. 
NÄÄS, I.A. Princípio de conforto térmico na produção animal. São Paulo: Ícone, 1989. $183 p$.

NÄÄS, I.A. Tipologia de instalações em clima quente. In: SIMPÓsIO BRASILEIRO DE AMBIÊNCIA NA PRODUÇÃO DE LEITE, Piracicaba, 1998. Anais. Piracicaba: FEALQ, 1998. p.146-155.

NÄÄS, I. A.; MOURA, D. J. LAGANÁ, C. A. A amplitude térmica e seu reflexo na produtividade de frangos de corte. In: CONFERÊNCIA APINCO DE CIÊNCIA E TECNOLOGIA AVÍCOLA, 1., Curitiba, 1995. Anais. Campinas: Facta, 1995. p.203204.

NÄÄS, I. A.; RODRIGUES, E. H. V. Qualidade do ambiente para a produção de suínos na gestação e maternidade. In: AMBIÊNCIA E QUALIDADE NA PRODUÇÃO DE SUÍNOS. , Piracicaba, 1999. Anais. Piracicaba: FEALQ, 1999. p.112-130.

NÄÄS, I. A.; ARCARO JÚNIOR, I. Influencia de ventilação e aspersão em sistemas de sombreamento artificial para vacas em lactação em condições de calor. Revista Brasileira de Engenharia Agrícola e Ambiental. v. 5, n.1, p.139-142, 2001.

NÄÄS, I. A.; SOUZA, S. R. L. Desafios para a produção de leite nos trópicos - conforto térmico. In: ZOOTEC, Uberaba, 2003. Anais. Uberaba:FAZU, 2003. p.64-74.

NIENABER, J. A.; HAHN, G. L.; EIGENBERG, R. A. Quantifying livestock responses for heat stress management: a review. International Journal of Biometeorology, $v$. 42, p.183-188, 1999.

NOETHER, G. E. Introduction to Statistics: The Nonparametric Way. New York: Springer-Verlag, 1991.

NUTRITION RESEARCH COUNCIL. Nutrient requirement of dairy cow. 7.ed. Washington: National academy press, 2001.p.349 
OSTERMAN, S.; REBDO, I. Effects of milk frequency on lying down and getting up behaviour in dairy cows. Applied Animal Behavior Science, v.70, p.167-176, 2001.

OVERTON, M. W.; SISCHO, W.M.; TEMPLE, G. D. Using time-lapse video photography to assess dairy cattle lying behavior in freestall barn. Journal of Dairy Science, v.85, p.2407-2413, 2002.

PERERA, K. S.; GWAZDAUSKAS, F. C.; PEARSON, R. E. et al. Effect of season and stage of lactation on performance of Holstein. Journal of Dairy Science, v.69, p. 28-236, 1986.

PERISSINOTO, M. Avaliação da eficiência produtiva e energética de sistemas de climatização em galpões tipo freestall para confinamento de gado leiteiro. Piracicaba, 2003. p. 122. Dissertação (Mestrado) - Escola Superior de Agricultura Luiz de Queiroz, Universidade de São Paulo.

PINHEIRO, M. G.; ROMA JR, L. C.; LIMA, M. L. P. et al. Produção de leite de vacas da raça Jérsei em ambiente climatizado In: CONGRESSO BRASILEIRO DE BIOMETEOROLOGIA, 3. Maringá, 2001. Anais. Maringá: SBBIO, 2001.

PIRES, M. F. A.; SATURNINO, H. M.; VERNEQUE, A. M. et al. Efeito da estação do ano sobre a temperatura retal e freqüência respiratória da vacas da raça holandesa confinadas em freestall. Arquivo Brasileiro de Medicina Veterinária e Zootecnia, v. 50, n.6, p.747-752, 1998a.

PIRES, M. F. A.; VILELA, D.; VERNEQUE, R. S.; TEODORO, R. L. Reflexos do estresse térmico no comportamento das vacas em lactação. In: SIMPÓSIO BRASILEIRO DE AMBIÊNCIA NA PRODUÇÃO DE LEITE, Piracicaba, 1998 b. Anais. . Piracicaba: FEALQ, 1998 b. p.68-102.

PIRES, M. F. A.; TEODORO, R. L.; CAMPOS, A. T. Efeitos do estresse térmico sobre a produção de bovinos. In: CONGRESSO NORDESTINO DE PRODUÇÃO ANIMAL, 2. Teresina, 2000. Anais. Teresina: SNPA, p.87-104, 2000. 
RODRIGUEZ, L. A.; MCKONNEN, G.; WILCOX, C. J. et al. Effects of relative humidity, maximum and minimum temperature, pregnancy, and stage of lactation on milk production and yield. Journal of Dairy Science, v. 68, p. 973-978, 1985.

ROENFELDT, S. You can't afford to ignore heat stress. Dairy manage, v.35, n.5, p.612, 1998.

ROMA JÚNIOR, L. C.; SILVA, I. J. O.; PINHEIRO, M. G. et al. Avaliação física do sistema de resfriamento adiabático evaporativo (SRAE) em instalações do tipo freestall para bovinos de leite. (Compact disc). In: CONGRESSO BRASILEIRO DE ENGENHARIA AGRícOLA, 23., Foz do Iguaçu, 2001. Anais. Foz do Iguaçu: Conbea, 2001.

SAS INSTITUTE. User'guide: statistics. SAS (Release 6.03). Cary, 1998. 620p.

SCHNEIDER, P. L.; BEEDE, D. K.; WILCOX, C. J. Nycterohemeral patterns of acidbase status, mineral concentration and digestive function of lactating cows in natural or chamber heat stress environments. Journal of Animal Science, v.66, p.112-125, 1988.

SCOTT, I. M.; JOHNSON, H. D.; HAHN, G. L Effect of programmad diurnal temperatures cycles on plasma thyroxine level, body temperature and feed intake of Holstein dairy cows. International Journal Biometeorology, v.1, p.47-62, 1983.

SHARMA, A. K.; RODRIGUEZ, L. A.; MEKONNEN, G. et al. Climatological and genetic effects on milk composition and production. Journal of Dairy Science, v.66, p.119-126, 1983.

SHEARER, J. K.; BEEDE, D. K. Heat stress, part 1: thermorregulation and physiological responses of dairy cattle in hot weather. Agri-Pratice, v. 11, p. 5-17, 1990. 
SHULTZ, T. A. Weather and shade effects on cow corral activities. Journal of Dairy Science, v.67, p.868-873, 1984.

SILANIKOVE, N. Effects of scarcity and hot environment on appetite and digestion in ruminants: a review. Livestock Production Science, v.30, p.175-194, 1992.

SILVA, I.J.O. Climatização das instalações para bovino leiteiro. In: SIMPÓSIO BRASILEIRO DE AMBIÊNCIA NA PRODUÇÃO DE LEITE, Piracicaba, 1998. Anais. Piracicaba: FEALQ, 1998. p.114-145.

SILVA, I.J.O. Vacas produzem mais e melhor em ambientes adequados. Balde Branco, v.35, p.20-27. mar, 1999.

SILVA, R. G.; LA SCALA, N.; POCAY, P. L. B. Transmissão de radiação ultravioleta através do pelame e da epiderme de bovinos. Revista Brasileira de Zootecnia, v.30, n.6, p.1939-1947, 2001.

SILVA, R.G. Introdução à bioclimatologia animal. São Paulo: Nobel, 2000. 286p.

SOTA, R. L. Fisilogia ambiental: mecanismos de respuestas del animal al estress calórico. In: JORNADA DE MANEJO DEL ESTRESS CALÓRICO, 1., La Plata, 1996. Anais. La Plata: EDULP, 1996. p.1-43.

STOOT, G. H. What is animal stress and how it is measured? Journal of Dairy Science, v. 52, p. 150-157, 1981.

STOWELL, R. R.; GOOCH, C. A. BICKERT, W.G. Design parameters for hot-weather ventilation housing: a critical review. (Compact disc). In: INTERNATIONAL DAIRY HOUSING CONFERENCE, 5, Fort Worth, 2003. Proceedings. Fort Worth: ASAE, 2003. 
STRICKLAND, J. T.; BUCKLIN, R. A.; NORDSTEDT, D. K. Sprinkling and fan evaporative cooling for dairy cattle in Florida. American Society of Agricultural Engineering. ASAE Paper 88-4042. 1988, 12p.

THOM, E. C. The discomfort index. Weatherwise, v.12, p.57-59, 1959.

TITTO, E. A.L. Clima: Influência na produção de leite. In: SIMPÓSIO BRASILEIRO DE AMBIÊNCIA NA PRODUÇÃO DE LEITE, Piracicaba, 1998. Anais. Piracicaba: FEALQ, 1998. p.10-23.

TURCO, S. H. N.; ARAUJO, G. G. L.; TEIXEIRA, A. H. C.; et al. Temperatura retal e freqüência respiratória de bovinos da raça sindi sob as condições térmicas do semi-árido brasileiro. In: REUNIÃO DA SOCIEDADE BRASILEIRA DE ZOOTECNIA, 36., Porto Alegre, 1999. Anais. Porto Alegre: UFRGS, 1999.

TURNER, L. W. Fan and high-pressure mist (fog) system performance for cooling lactating dairy cows. In: INTERNATIONAL DAIRY HOUSING CONFERENCE, 4., St.Louis, 1998. Proceedings. St.Louis: ASAE, 1998. p.201-208.

TURNER, L. W. Global position systems (GPS) and grazing behavior in cattle. In: INTERNATIONAL LIVESTOCK ENVIRONMENT SYMPOSIUM, 6., Louisville, 2001. Proceedings. Louisville: ASAE, 2001. p.640-650. 2001

TURNER, L. W.; CHASTAIN, J. P.; HEMKEN, R. W.; GATES, R. S. et al. Reducing heat stress in dairy cows through sprinkler and fan cooling. Applied Engineering in Agriculture, v.8, n.3, p.375-379, 1992.

VASILATOS, R.; WANGSNESS, P.J. Feeding behavior of lactation dairy cow as measured by time-lapse photography. Journal of Dairy Science, v. 63, p. 412416, 1980. 
WAGNER-STORCH, A. M.; PALMER, R. W.; KAMMEL, D. W. Factors affecting stall use for different freestall bases. Journal of Dairy Science, v.86, p.2253-2266, 2003.

WATSON, H. Insulation southern hog building. Columbia: National Hog Farmer, 1971, 105p.

WEST, J. W. Effects of heat-stress on production in dairy cattle. Journal of Dairy Science, v.86, p.2131-2144, 2003.

WHITAKER, J. H. Agricultural building and structure. Henton: Heston publishing, 1979. 306p

WIERSMA, F.; STOTT, C.H. Evaporative cooling. In: HELLICKSON, M. A.; WALKER, J.N. Ventilation of agricultural structures. St. Joseph:ASAE, 1983. p.113-118.

YOUSEF, M. K.; JOHNSON, H. D. Endocrine system and thermal environment. In:YOUSEF, M. K. Stress physiology in livestock. Boca Raton:CRC Press, 1985, v.1, p.133-142. 